MAESTRÍA EN DIRECCIÓN DE EMPRESAS

FACULTAD DE CIENCIAS ECONÓMICAS

UniVERSIDAD NACIONAL DE LA PLATA

Trabajo de tesis para optar al título de Magister

Tema:

\title{
LA COMPETITIVIDAD EMPRESARIAL EN EL SECTOR DE EMPRESAS QUÍMICAS EN LA REGIÓN DE LA PLATA, BERISSO Y ENSENADA
}

AUTOR: ERNESTO FABIÁN BOTANA

DIRECTOR DE TESIS: ANA MARÍA LEGATO

LA PLATA, OCTUBRE DE 2013 


\section{Indice}

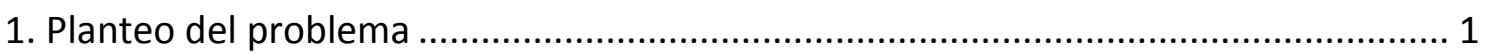

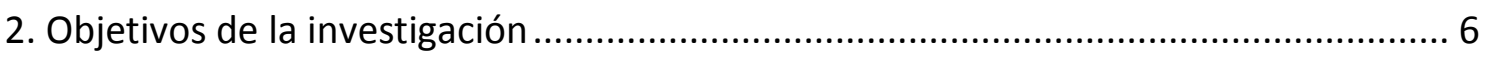

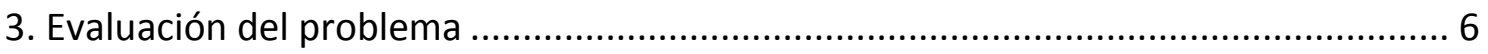

4. Alcance de la investigación............................................................................ 9

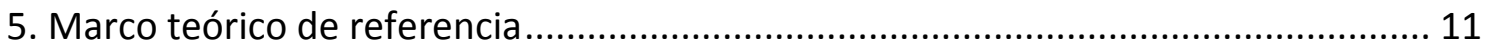

5.1. Antecedentes de la investigación ................................................................................ 11

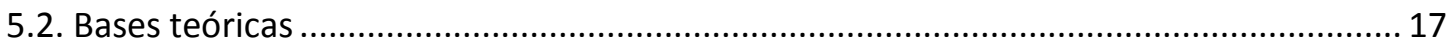

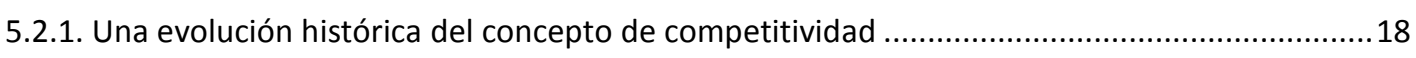

5.2.2. Teorías modernas sobre competitividad: El modelo de la ventaja competitiva de Porter.......31

5.2.3. Teorías modernas sobre competitividad: Enfoques posteriores al modelo de Porter..............50

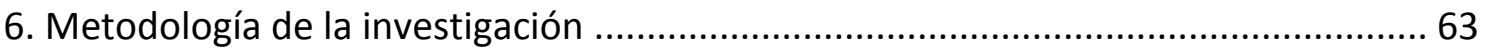

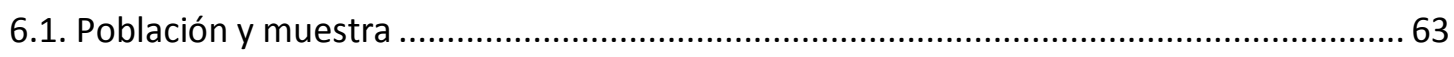

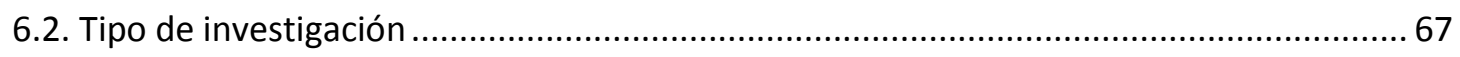

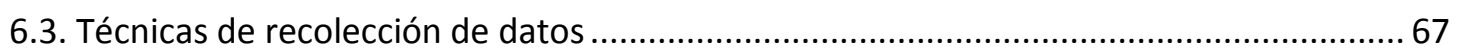

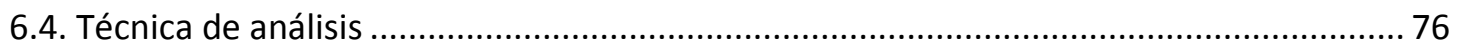

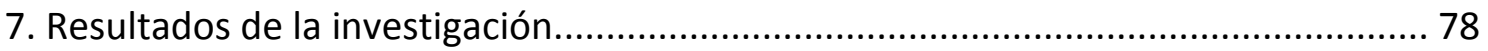

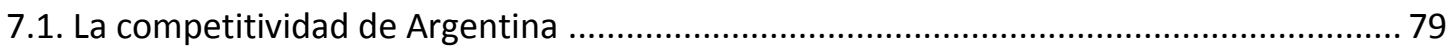

7.2. La competitividad de La Plata, Berisso y Ensenada bajo el supuesto de la región considerada como un país

7.3. La competitividad relativa de los sectores industriales de La Plata, Berisso y Ensenada 85

7.4. La competitividad del sector de empresas químicas en La Plata, Berisso y Ensenada .... 89

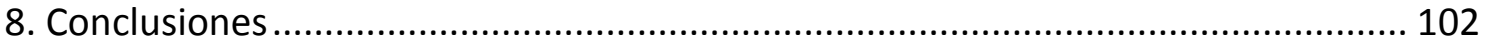

8.1. Consideraciones sobre la medición de la competitividad ............................................ 102

8.2. Consideraciones sobre el potencial de desarrollo competitivo ...................................... 106

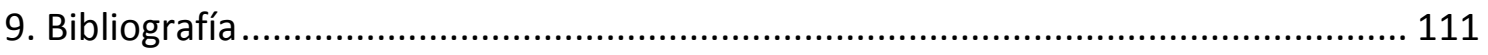




\section{Planteo del PROBLEMA}

El concepto de competitividad se ha hecho muy familiar. Es habitual escuchar hablar de un "tema técnico" como el de competitividad a economistas, empresarios, políticos, periodistas y a muchas otras voces, opinando en los más diversos ámbitos. La competitividad ha dejado de ser un tema de presencia exclusiva en textos sobre macroeconomía, "papers" académicos y libros de ensayo específicos, para ganarse aunque claro que aún muy restringido- un espacio en la agenda y el debate público. La capacidad de ocupar éste espacio suele estar directamente relacionada con la salud de las economías, bien nacionales, bien de bloques regionales. Así, es habitual que cuando una economía comienza a manifestar signos de debilidad y aparece la necesidad de identificar las causas de ello, la "pérdida de competitividad" suele mencionarse más temprano que tarde, con una gran frecuencia y por muy diversos medios. Por otra parte, en cuanto llega el momento de plantear soluciones para reencauzar a esa economía, ahora debilitada, tampoco tardan en aparecer las prescripciones en el sentido de "recuperar competitividad" en forma rápida, "sin demoras, antes de que sea demasiado tarde". Acto seguido, se suele pasar a la fase de análisis sobre las alternativas para ello, las que rara vez escapan a la fórmula de proponer las formas "menos costosas" para implementar el postergado e ineludible "ajuste en el tipo de cambio", eufemismo actual a la acción de devaluar la moneda. Entonces, es fácil percibir como en el debate público todo lo atinente a competitividad rápidamente queda circunscripto al análisis sobre cuándo fue el último ajuste del tipo de cambio, cuánto han cambiado las condiciones macroeconómicas desde ese momento, cuándo y en qué medida será necesario practicar el próximo shock devaluatorio, o si por el contrario se ha actuado con la debida previsión y se han aplicado mecanismos de actualización periódica que permitan evitar pérdidas abruptas del valor de la moneda doméstica.

Lo dicho no sirve más que para considerar una de las dos cuestiones que hacen al planteo del problema en el presente trabajo de tesis: la competitividad poco menos que "está de moda", mucho se habla de ella y mucho se analiza, pero el concepto que habitualmente se tiene es muy restringido: no es mucho más que la consideración de la competitividad como el nivel "adecuado" que debe alcanzar y/o preservar a lo largo 
del tiempo el tipo de cambio para que la economía que se está considerando sea "competitiva", entendiendo por esto su capacidad para que resulte rentable la venta de productos y servicios a mercados del exterior. En otras palabras, se considera la competitividad casi desde el exclusivo punto de vista de plantear si las exportaciones del país resultan caras o baratas en el mundo, en función de la relación entre moneda local y moneda extranjera.

Valgan dos ejemplos para describir esta primera cuestión del planteo del problema: Argentina supo tener su Ley de competitividad ${ }^{1}$ (otros países también las tienen o las han tenido, México y Colombia, entre los latinoamericanos), en épocas del gobierno de la Alianza, cuando Domingo Cavallo fue llamado a su segundo período como Ministro de Economía con la función de idear el escape menos traumático posible a su propia creación: la convertibilidad. La ley -poco menos que impulsada "contra-reloj"- no iba mucho más allá de plantear cambios en los aranceles del comercio exterior para desalentar importaciones y promover la actividad exportadora, proponer una "canasta de monedas" como referencias para el tipo de cambio -ampliando el anclaje exclusivo que el peso tenía sobre el dólar durante la convertibilidad- y promover determinadas industrias y regiones muy afectadas por la recesión económica que a esa altura era ya muy evidente. En síntesis, el proyecto era poco más que el ensayo de una "devaluación encubierta", por la que se intentaba, mediante una serie de artilugios normativos y monetarios, "ganar competitividad" en el tipo de cambio sin tener que tocar el célebre "1 a 1" (la paridad peso-dólar que se había convertido en el gran dogma económico de la época). La ley no tuvo ningún éxito, y lejos de eso naufragó al poco tiempo en lo que sería el prólogo de la gran crisis de 2001 que terminó de la forma más traumática con el gobierno de De la Rua y junto a él con todo el esquema de moneda convertible que signó la economía argentina durante los '90.

En tiempos más cercanos, y como otra muestra de lo "familiar" que se nos ha hecho el concepto de competitividad, al inaugurar su segundo mandato presidencial Cristina

\footnotetext{
${ }^{1}$ La llamada Ley de competitividad nació como un decreto, el № 380/2001, cuyo texto puede consultarse aquí: http://infoleg.mecon.gov.ar/infolegInternet/anexos/65000-69999/66561/norma.htm
} 
Kirchner anunciaba la creación de la Subsecretaría de la Competitividad ${ }^{2}$, área de la estructura del Estado destinada a complementar las políticas de comercio interior y comercio exterior en pos de ganar competitividad en mercados internacionales para los productos argentinos (que al momento de su puesta en marcha terminó recibiendo el nombre de Subsecretaría de Coordinación Económica y Mejora de la Competitividad, dependiente en forma directa del Ministerio de Economía). En este caso el resultado tampoco sería muy feliz. Los muy generales y ambiciosos objetivos iniciales naufragaron rápidamente en un frente externo que comenzaba a mostrar, terminando el 2011, signos de alguna complicación. El Gobierno abandonaría, antes de comenzar, la prosecución de los nobles objetivos de mejora de la competitividad de la economía nacional en favor de la implementación de una serie de medidas de coyuntura, relacionadas, entre otras cosas, con lo que vulgarmente se conocería como el cepo al dólar, con la problemática por las existencias de moneda extranjera en el Banco Central, con la emisión de certificados públicos llamados a funcionar casi como cuasimonedas de denominación foránea (los famosos "cedines") y el casi exclusivo foco de toda política referida al comercio exterior en el control de qué es lo mínimo que puede importarse como para no drenar aún más las menguantes reservas de moneda extranjera. Así, todas las buenas intenciones con las que parecía nacer la nueva área del Gobierno quedarían reducidas, ya antes del alumbramiento, a la simple consideración de si resultaba adecuado o no determinado nivel en el tipo de cambio, y cuál era la mejor manera de evitar una devaluación o de practicar una -llegado el casosin mayores daños colaterales. Una vez más, la consideración de la competitividad se reducía sólo al planteamiento del más restringido asunto sobre cuál debería ser el nivel del tipo de cambio.

Ahora bien, más allá de estos ejemplos lo que se propone es que, sin dejar de reconocer la importancia del valor del tipo de cambio para los niveles de competitividad de un país, se requiere ampliar bastante el foco de atención -sin entrar en el debate sobre si la competitividad exige siempre un "dólar alto" y devaluaciones

\footnotetext{
2 Diario INFOBAE, versión digital, 10 de diciembre de 2011 (puede consultarse en http://www.infobae.com/notas/621462-Crearan-la-Secretaria-de-Comercio-Exterior-y-la-sub-deCompetitividad.html)
} 
periódicas si esa condición se pierde, cuestión que excede por mucho los objetivos del presente trabajo-, en busca de un análisis más profundo sobre los verdaderos determinantes de un buen perfil competitivo para una nación y de la relación sinérgica que se observe entre ellos.

Alcanzando una mirada así, más integral respecto de todas las variables que hacen a la competitividad, se estaría en condiciones de analizar, entre otras cuestiones, la capacidad de una economía para: a) utilizar de la mejor manera posible sus recursos disponibles, además de generar y desarrollar nuevos (por ejemplo, construyendo nueva infraestructura y manteniendo la existente, fomentando en todo momento la formación y especialización de recursos humanos, asegurando niveles mínimos de salud para su población, creando programas de interrelación entre empresas y universidades, etc.); b) satisfacer exigentes condiciones de demanda en determinados productos y servicios, para poder cubrir y desarrollar en forma efectiva mercados internos y de exportación (concentrando el desarrollo en aquellos mercados en los que la economía pueda explotar sus ventajas competitivas); c) generar integraciones entre sectores industriales y entre empresas de un mismo o de distinto sector (creando agrupamientos industriales con crecientes efectos sinérgicos, para superar la simple lógica de agrupamiento geográfico típica, por ejemplo, de los parques industriales); y d) asegurando un ámbito propicio para las inversiones y el desarrollo de la actividad productiva mediante la creación y el mantenimiento de un marco jurídico y normativo con reglas claras y de cierta permanencia a lo largo del tiempo, que permita la implementación de políticas económicas racionales y de largo plazo y de estrategias empresarias que fomenten la competencia y propendan al desarrollo económico general.

Un análisis así resulta mucho más completo y clarificador respecto del nivel de competitividad de una economía que la simple consideración de cuál es y cuál debería ser el nivel del tipo de cambio a corto, a mediano o a largo plazo.

Se llega así a la segunda cuestión que hace al planteo del problema en el presente trabajo, y tiene que ver con la baja consideración que el tema de la competitividad (ya entendido en su concepción "amplia") tiene a nivel de ciudades, provincias o regiones sub-nacionales de un país; o lo que es lo mismo, a la casi exclusiva consideración que 
registra sólo a nivel nación (competitividad de países) o de bloques regionales (competitividad de regiones supra-nacionales).

Una competitividad debidamente medida para una ciudad, una provincia o una región conformada por varias ciudades permitiría contar con buenas herramientas para el diseño de políticas locales, que reflejen en forma más profunda y con mayor detalle las particularidades típicas de ámbitos más específicos a los de toda una nación, e incluso deteniendo el foco en un sector industrial en particular. Un criterio así, más particular, no impone renegar de las visiones más "macro", sino por el contrario complementar y potenciar ambas miradas: la referida a la competitividad de una nación, de rasgos más generales, de lineamientos más gruesos si se quiere, con una mirada muy enfocada típica de las consideraciones más profundas, de ámbitos bien acotados, como los asignados a un sector industrial específico en una provincia, una ciudad o un conjunto de éstas.

Es momento de consignar que en cuanto a la obtención de sus resultados el presente trabajo es parte integrante de una investigación conjunta iniciada en el ámbito de la Maestría en Dirección de Empresas de la Facultad de Ciencias Económicas (UNLP), con el objetivo de medir la competitividad regional de varios sectores industriales, y para el caso particular que comenzamos a tratar, del sector de las empresas químicas.

Entonces, la consideración en forma conjunta de las dos cuestiones que se han planteado (competitividad en sentido amplio, y considerada para regiones) permite validar un debido planteamiento como problema de tesis. ¿En qué forma?: se trata de observar tanto la competitividad desde un enfoque adecuado, integral, abarcador, como de dirigir el lente hacia un sector industrial específico de una determinada región, para conocer su estado actual y su potencial de creación y sostenimiento de ventajas competitivas. Así, se justifica la validez -y el esfuerzo- de iniciar una investigación sobre La competitividad empresarial en el sector de empresas químicas en la región de La Plata, Berisso y Ensenada. 


\section{OBJETIVOS DE LA INVESTIGACIÓN}

Se plantean dos objetivos para el presente trabajo de tesis, fundamentados en el marco teórico que se considerará y en la información aportada por el relevamiento de datos de fuente primaria y secundaria. Ambos son parte de un mismo tronco conceptual, por lo que resultan complementarios. Su consecución permitirá medir el nivel de competitividad y el potencial de desarrollo del sector industrial elegido en el área geográfica objeto del estudio. Así, en términos formales, los objetivos de la investigación son:

- Poder medir, en el ámbito del área comprendida por las ciudades de La Plata, Berisso y Ensenada, el nivel de competitividad del sector industrial formado por las empresas químicas.

- Evaluar el potencial de desarrollo competitivo de este sector, identificando las fuerzas y debilidades que presenta y las oportunidades y amenazas a las que se enfrenta.

\section{EVALUACIÓN DEL PROBLEMA}

El nivel de vida de una nación o de una determinada región depende en buena medida de la capacidad con que allí se cuente para generar valor económico con los recursos existentes. La generación de valor económico, acompañada de políticas adecuadas de salud, educación, empleo y distribución del ingreso aseguran las condiciones para un continuo desarrollo y una siempre creciente mejora en la calidad de vida de la población. Más aún, la generación de valor económico a partir del mejor uso de los recursos disponibles es la que permite contar con los capitales necesarios para la implementación de tales políticas, disparando un círculo virtuoso con una lógica de: generación de valor - incremento del nivel de vida de la población - mayor capacidad de inversión pública y privada - desarrollo y renovación de recursos - mayor generación de valor y vuelta al inicio del ciclo. 
Todo esto hace a la competitividad de la nación o de la región que se esté considerando, e incluido en ello está latente el concepto de productividad de la economía de esa nación o región, medida por el valor de los bienes y servicios producidos por cada unidad de recursos asignados al proceso productivo. En otras palabras, la productividad es el gran determinante del nivel de competitividad, y su magnitud depende de la eficiencia con que sean asignados al proceso generador de bienes y servicios los recursos humanos, los recursos naturales y los recursos de capital existentes, en pos de obtener el mayor valor de producto posible. En términos aritméticos, dado determinado stock de recursos, a mayor nivel de producto, mayor productividad; o en forma similar, a menor asignación de recursos para igual producto, mayor productividad.

El nivel de vida de una nación o de una región depende entonces de cuán competitiva sea su economía, y el nivel de competitividad está determinado por la productividad. La alta productividad es la que permite que en una nación o en una región puedan sostenerse a lo largo del tiempo altos niveles de salarios y una atractiva rentabilidad para el capital invertido, que junto a la implementación y el sostenimiento, a lo largo del tiempo, de las ya mencionadas políticas de empleo, salud, educación y distribución del ingreso, impulsan la calidad de vida de la población, renovando, como se dijo, una y otra vez el círculo virtuoso.

Entonces, al hablar de competitividad la meta primera de una nación o de una región no debe ser la captura de nuevos mercados o la amplitud de los existentes, ya que el efectivo cumplimiento de objetivos de ese tipo vendrá por añadidura del desencadenamiento del círculo virtuoso generado por el incremento de la productividad. Una economía enfocada en incrementar su productividad siempre terminará siendo competitiva, en cuyo caso serán objetivos accesibles los de tener fuerte presencia en los mercados de los productos y servicios donde registre ventaja competitiva. En este esquema, por ejemplo, no importará si las empresas son nacionales o de capital extranjero, como tampoco tendrá trascendencia por si mismo el papel que se reserve el Estado como regulador de la economía o incluso participando como productor, siempre y cuando, y en todo momento, estos actores 
económicos se encuentren alineados en torno a la línea madre de incrementar la productividad de toda la economía.

El entorno competitivo en el que se incrementa la productividad, en el que se genera cada vez más valor agregado, y en el que así se impulsa el desarrollo de todo el entramado socio-económico no está determinado exclusivamente por el accionar de las empresas siguiendo cada una de ellas sus distintas estrategias de crecimiento. Por el contrario, está dado por la condición sistémica de las interrelaciones entre los distintos actores económicos: empresas, Estado, agrupamientos industriales, instituciones educativas, gremios empresarios y de trabajadores, organizaciones no gubernamentales, etc.; todos los cuales, interrelacionados, determinan un específico perfil competitivo de la economía nacional o regional en que estén inmersos.

Así planteado el escenario de un buen perfil competitivo que sostenga el crecimiento y desarrollo de un país o una región, las empresas competirán sin restringirse a demandar entornos protegidos que reduzcan el riesgo empresario, mediante, por ejemplo, la presión por crear aranceles o limitaciones a la inversión extranjera, o bien constituir barreras artificiales de entrada a sus sectores industriales. El Estado, por su parte, asegurará un marco jurídico con estabilidad, con reglas de juego claras y legítimas, e impulsará las políticas públicas que favorezcan el desarrollo económico en general y el de los sectores con ventaja competitiva en particular. Por su parte, los sectores industriales actuarán en forma integrada, generando asociaciones y esquemas de colaboración (no precisamente reñidos con la competencia entre empresas) que impulsen, con su sinergia, el desarrollo de todo el sector. Las instituciones educativas, persiguiendo sus objetivos específicos, asegurarán tanto la educación elemental (ciclos primarios y secundarios) de toda la población como el desarrollo y la capacitación permanente sobre quienes logre insertar en los niveles universitarios, fomentando adicionalmente la integración sistema educativo-sistema productivo con políticas específicas (por ejemplo, para la colaboración universidadempresas). En cuanto a las agremiaciones empresarias y de trabajadores, cumplirán con su rol básico de defensa de sus intereses gremiales, pero bajo el convencimiento respecto de la necesidad de no perder de vista los intereses generales que hacen al crecimiento de los sectores industriales en los que desarrollan su función. Por último, 
las organizaciones no gubernamentales cumplirán con las exigencias del objeto al que deban su existencia también con el convencimiento de estar formando parte de un entramado sistémico al que están llamadas para hacer su aporte, sea controlando, sea apoyando actividades específicas, sea proponiendo alternativas para distintas estrategias de desarrollo, etc.

Un escenario competitivo como el descripto bien puede parecer utópico, pero plantea un óptimo que permite una consideración más amplia de la competitividad, no centrada exclusivamente en la empresa sino en un enfoque más global, más macro, en el que los determinantes de la ventaja competitiva están dados por todos los elementos del escenario competitivo y por la relación sistémica que ellos guardan entre sí. Bajo este enfoque más amplio, la ventaja competitiva ya no será sólo patrimonio de las empresas, sino más bien del sistema que conforma el escenario competitivo en el que están inmersas. La creación de ventaja competitiva deja entonces de ser producto exclusivo de las empresas para serlo de la relación sistémica de los componentes del escenario, cuestión que pasamos a llamar ventaja competitiva de la nación o de la región que estemos considerando.

Bajando a tierra estos conceptos, es fácil entender lo crítico que resulta entonces poder medir el nivel de competitividad de un nación o de una región sub-nacional; medida que, una vez obtenida, permitirá analizar el potencial de desarrollo de esa nación o esa región en función de la capacidad que tengan para crear y sostener en el tiempo ventajas competitivas.

\section{AlCANCE DE LA INVESTIGACIÓN}

Los resultados puntuales en que se sustenta este estudio sobre empresas químicas son parte de los obtenidos en el proyecto de investigación La competitividad empresarial y su impacto regional. Este proyecto ha sido instrumentado en el ámbito de la Maestría en Dirección de Empresas de la Facultad de Ciencias Económicas de la Universidad 
Nacional de La Plata, y cuenta con la debida acreditación del Programa de Incentivos de la Secretaría de Ciencia y Técnica de esta casa de estudios.

La investigación tuvo como área geográfica bajo estudio a la región comprendida por las ciudades de La Plata, Berisso y Ensenada, y se realizó con datos relevados durante el segundo semestre del año 2011.

Sobre la región objeto de estudio, a muy grandes rasgos, puede enunciarse que:

- Cuenta con un población de 700.276 habitantes $^{3}$ (La Plata: 649.613, Berisso: 30.688 y Ensenada: 19.975), distribuidos en un área geográfica de $1.179 \mathrm{Km}^{2}$.

- El valor bruto de la producción regional se atribuye $a^{4}$ :

- Sector primario: $3 \%$

○ Sector secundario (industrias): $36 \%$

○ Sector secundario (construcción, electricidad, gas y agua): 7\%

- Sector terciario (comercio mayorista): $12 \%$

- Sector terciario (comercio minorista): $21 \%$

- Sector terciario (servicios): $21 \%$

- La región cuenta con dos parque industriales en La Plata (Parque industrial I y Parque industrial II), un polígono industrial en Berisso y un agrupamiento industrial en Ensenada. Dentro de Ensenada, y por su gran trascendencia sobre el sector industrial objeto del presente estudio, es oportuno mencionar la existencia del Polo Petroquímico.

- Respecto de la formación y capacitación de recursos humanos, la región cuenta con oferta para todos los niveles educativos, a través de la

\footnotetext{
${ }^{3}$ Datos según Censo 2010 (más información en www.censo2010.indec.gov.ar)

${ }^{4}$ Los datos de éste item y de los siguientes fueron extraídos del Informe sobre caracterización productiva regional en La Plata, Berisso y Ensenada, año 2010. (Para consultar el informe:

www.econo.unlp.edu.ar/uploads/docs/caracterizacion productiva regional 2010 la plata berisso ensenada.pd f)
} 
actividad de más de mil establecimientos consagrados a esta función ( 842 para La Plata, 118 para Berisso y 72 para Ensenada).

- La región está bien provista por los servicios básicos de agua corriente, gas y electricidad; y cuenta con una amplia red de infraestructura en transporte terrestre, ferroviario y portuario. Sobre éste último medio, es de destacar la magnitud del Puerto La Plata, que incluye en su ámbito al Astillero Río Santiago.

Volviendo a las consideraciones sobre la investigación, y como apretada síntesis, puede decirse que el trabajo contó con un tronco común para evaluar la competitividad empresarial y su impacto en la región de todos los sectores industriales, para luego subdividirse en distintas ramas y poder hacer foco en el análisis de la competitividad de cada sector. Fue así como se tomaron, para el análisis en detalle, a los sectores de Productos alimenticios, bebidas y tabaco; Textiles y cuero; Industria de la madera; Imprentas y editoriales; Sustancias químicas; Productos minerales no metálicos; Industrias metálicas básicas y Productos metálicos, maquinarias y equipos. Respecto de la consideración del presente trabajo de tesis, el mismo se ha concentrado en los resultados obtenidos en la investigación para el sector de Sustancias químicas.

\section{MARCO TEÓRICO DE REFERENCIA}

\subsection{ANTECEDENTES DE LA INVESTIGACIÓN}

El proyecto de investigación La competitividad empresarial y su impacto regional tiene dos grandes referencias como antecedentes. Se trata de dos trabajos de investigación de periodicidad anual y de gran prestigio internacional: uno es el Reporte de Competitividad Global del Foro Económico Mundial ${ }^{5}$ (The Global Competitiveness

\footnotetext{
${ }^{5}$ Ref.: $\underline{\text { www.weforum.org/reports }}$
} 
Report del WEF), con sede en Davos, Suiza, y el otro el Libro Anual de la Competitividad Mundial del Institute for Management Development ${ }^{6}$ (World Competitiveness Yearbook del IMD), que es una de las escuelas de negocios más prestigiosas del mundo afincada en Ginebra, también en Suiza.

Estos dos estudios son la gran referencia mundial en el análisis y cuantificación de los factores que determinan la competitividad de las naciones. Ambas instituciones suizas supieron en su momento publicar sus informes en cooperación, pero desde el año 1996 lo han venido haciendo en forma separada, al comenzar a trabajar el WEF en forma casi directa con Michael Porter, de la Harvard Businnes School, autor que, como luego se verá, se ha convertido en el gran hito referencial de la competitividad de los países desde la publicación, en 1990, de su obra La ventaja competitiva de las naciones naciones ${ }^{7}$. Ambos estudios utilizan como fuentes datos estadísticos y percepciones de directivos de las más variadas empresas, que relevan mediante la realización de encuestas de opinión.

Los dos estudios utilizan factores de competitividad similares para analizar y jerarquizar las economías de los países que incluyen en sus informes de competitividad. Por parte del WEF, clasifica sus datos en doce pilares que define como determinantes de la competitividad: Instituciones, infraestructura, estabilidad, salud y educación primaria, educación superior y formación profesional, eficiencia del mercado de productos, eficiencia del mercado de trabajo, sofisticación del mercado financiero, disponibilidad tecnológica, tamaño del mercado, sofisticación del ambiente de negocios e innovación.

\footnotetext{
${ }^{6}$ Ref.: www.imd.org/wcc

7 La ventaja competitiva de las naciones. Michael E. Porter. Javier Vergara Editor (1991). Con este libro Porter completa su trilogía sobre competitividad iniciada con Estrategia competitiva. Técnicas para el análisis de los sectores industriales y de la competencia y luego continuada con Ventaja competitiva. Creación y sostenimiento de un desempaño superior.
} 
Figura 1: Los pilares de la competitividad en el informe WEF

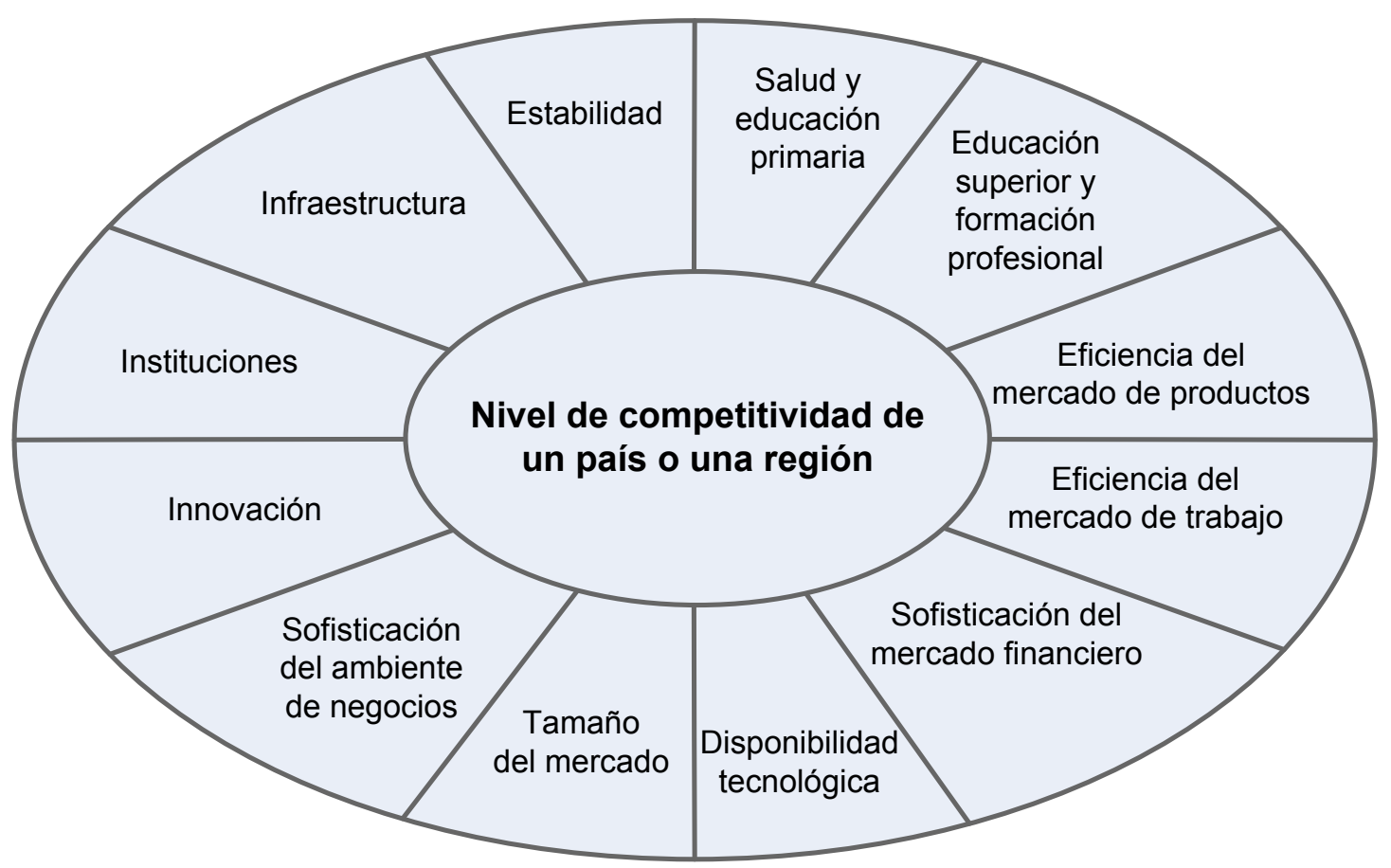

Fuente: Elaboración propia

El IMD, en cambio, apela a un esquema de factores y "subfactores", con cuatro principales factores que a su vez están determinados por cinco subfactores cada uno. Los factores principales, con la mención de sus subfactores entre paréntesis son: actuación económica (economía doméstica, comercio internacional, inversión extranjera, nivel de empleo, nivel de precios), eficiencia del Gobierno (situación de finanzas públicas, política fiscal, modelo institucional, modelo empresarial, niveles y estado de la educación), eficiencia empresarial (niveles de productividad, mercado laboral, mercados financieros, prácticas de gestión, impacto del fenómeno de globalización) e infraestructura (infraestructura básica, infraestructura tecnológica, infraestructura científica, salud y medio ambiente, sistema de valores). 
Figura 2: Los factores y sub-factores de la competitividad en el informe IMD

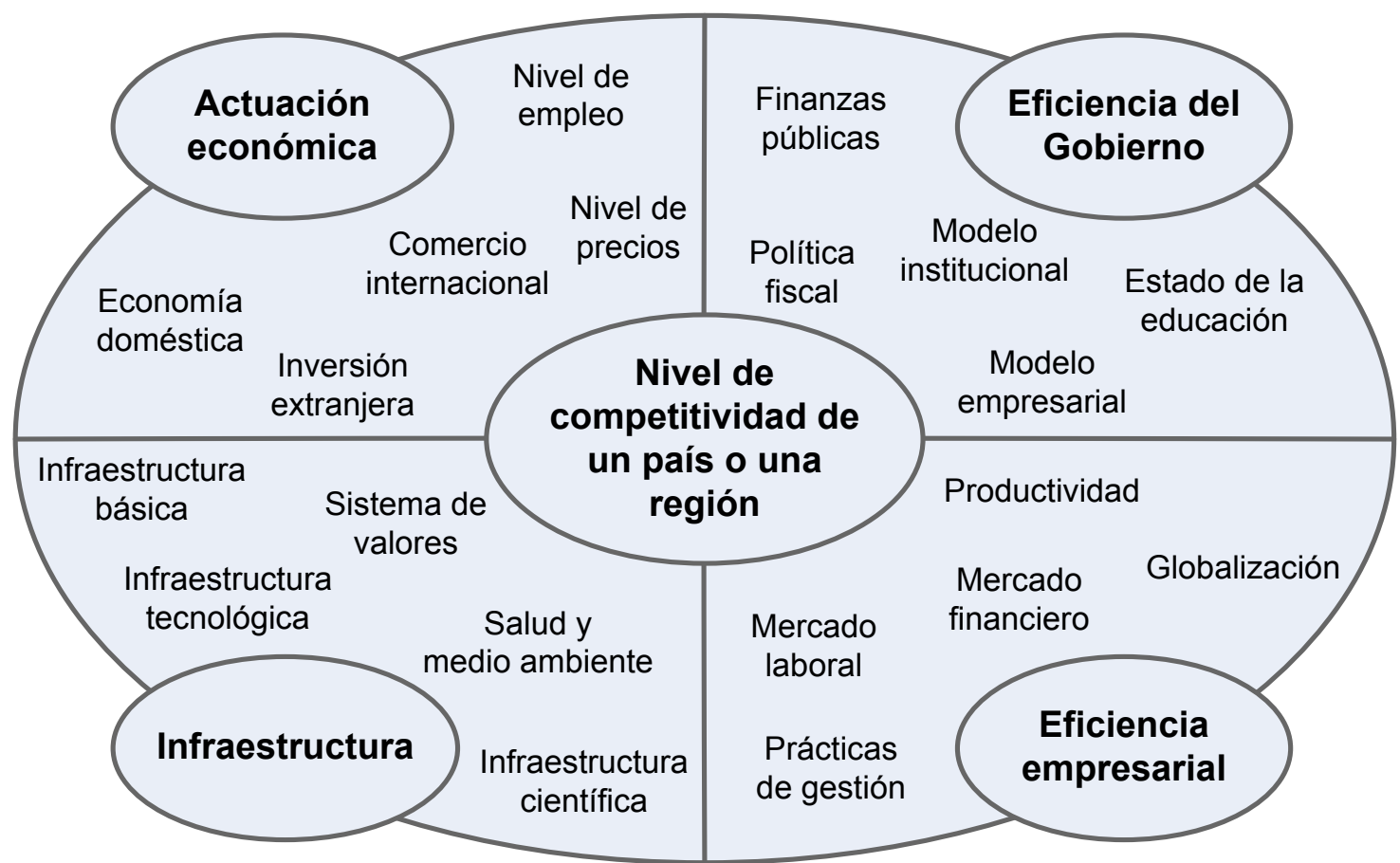

Fuente: Elaboración propia

\subsubsection{El REPORTE DE COMPETITIVIDAD Global DEL WEF}

El Reporte de Competitividad Global es parte de una serie de informes que el WEF publica desde el año 1979. Ya en 1996 inician un trabajo conjunto con Harvard University que habilita la incorporación de Michael Porter como colaborador de privilegio en los grandes lineamientos de la elaboración de los informes. Este acuerdo les permitió la utilización de todo el cuerpo teórico relacionado con lo que se conoce como el diamante de la competitividad de Porter, referencia ineludible en todo lo que tiene que ver con la competitividad de las naciones ya desde ese año 1996 (el concepto de diamante competitivo cobró rápidamente relevancia mundial desde la ya mencionada publicación, en 1990, de La ventaja competitiva de las naciones).

La elaboración de los informes bajo el modelo de diamante competitivo (que se describirá con algún detalle más adelante) ha generado beneficios para ambas partes. Para el WEF, la posibilidad de utilizar en la elaboración de sus reportes un modelo sólido de fama mundial, testeado por el propio Porter en el trabajo previo a la 
publicación de su obra. Por su parte, la colaboración con el WEF le ha permitido a Porter poner a prueba sus teorías en muchos países (vale mencionar que el análisis del reporte alcanza a más de ciento cincuenta naciones) durante muchos años, experiencia que ha servido para ajustar detalles del modelo en forma ininterrumpida, a partir del hecho de que año a año se dispone de la "retroalimentación" necesaria en la forma de los datos generados en cada uno de los países.

El Reporte de Competitividad Global se basa en el análisis particular de distintas variables que determinan la competitividad de un país, a las que agrupa en grandes apartados que se conocen como "pilares" de la competitividad (pilar Instituciones, pilar Infraestructura, Estabilidad macroeconómica, Salud y educación, etc.). El producto obtenido son índices que miden la competitividad y son comparables entre países, sea en un período puntual o a lo largo de una serie histórica. Es así como desde el reporte se genera un índice de competitividad "general" de cada país, que luego puede desagregarse para medir la competitividad en cada "pilar competitivo" y, en el extremo, en cada una de las variables que determinan la competitividad.

Si bien se está mencionando que el proyecto La competitividad empresarial y su impacto regional tiene dos grandes antecedentes en los informes del WEF y del IMD, en realidad, la referencia directa está dada sobre los reportes del WEF, ya que se ha utilizado la metodología con que se elaboran estos últimos para obtener los resultados correspondientes a aquél.

Vale aclarar también que para la comparación con los resultados obtenidos en la investigación realizada para el presente trabajo de tesis se ha tomado la versión Business Competitiveness Index del reporte del WEF (BCl, por las siglas en inglés de lo que en español sería el Indice de Competitividad de los Negocios). La versión $\mathrm{BCl}$ es algo más acotada que la versión "general" sobre la competitividad de un país, por hacer un foco más particular sobre las variables que hacen al desempeño de las empresas, las que son analizadas con mayor profundidad, y no tanto sobre las variables más "macro" del contexto económico y social. En otras palabras, la versión $\mathrm{BCl}$ toma algunas variables menos que la versión "general" del reporte del WEF, pero mucho más enfocadas en lo que hace a la competitividad propia de las empresas en determinados sectores, algo que resulta más representativo de cara a comparar los 
resultados con los obtenidos sobre el sector de empresas químicas en la región de La Plata, Berisso y Ensenada.

De este modo, la comparabilidad entre los resultados de uno u otro trabajo queda asegurada (como se describirá más adelante en el apartado sobre metodología de la investigación) por la consideración de idénticas variables al momento de medir la competitividad. Prueba de esto es que para el relevamiento de datos de fuente primaria en el proyecto La competitividad empresarial y su impacto regional se utilizó exactamente la misma encuesta de opinión que la utilizada por el WEF en todo el mundo para su medición del $\mathrm{BCl}$.

\subsubsection{EL LIBRO ANUAL DE LA COMPETITIVIDAD MUNDIAL DEL IMD}

Respecto del segundo antecedente de la presente investigación, el Libro Anual de la Competitividad Mundial, se trata de un informe también referido a la competitividad global de los distintos países, pero considerando una menor cantidad de éstos, porque a diferencia de los informes del WEF que comprenden más de ciento cincuenta naciones, el IMD analiza poco más de cincuenta.

Las diferencias se extienden también a las teorías aplicadas en la investigación, ya que, como se dijo, mientras el WEF utiliza el diamante competitivo de Porter, el IMD hace uso de su propio modelo de las cuatro fuerzas fundamentales. En este caso, el modelo del IMD propone que la competitividad de una nación es generada por los efectos de cuatro fuerzas fundamentales que, todas ellas "traccionando" e influenciándose en forma recíproca, dan forma a un contexto competitivo determinado y dinámico en el tiempo. Cada una de las cuatro fuerzas supone la consideración de dos extremos o dos puntos opuestos de un continuo; las fuerzas son: atracción versus agresividad, proximidad versus globalidad, activos versus procesos y toma de riesgo individual versus cohesión social.

Como sintética mención, la fuerza relacionada con lo atractivo-agresivo tendrá que ver con las políticas implementadas en un país para crear condiciones favorables a la inversión y el desarrollo de negocios (atractivo) o la búsqueda proactiva, agresiva para 
asegurar tales condiciones (agresivo). En cuanto a proximidad-globalidad, se refiere a la mayor tendencia por concentrar la competitividad en sectores y procesos productivos domésticos (proximidad) o en la búsqueda de sinergias y economías de escala de alcance global (globalidad). En cuanto a activos-procesos, analiza la forma en que un país sustenta su ventaja respecto de otros, si lo hace más concentrado en el "stock" de recursos disponibles (activos) o en la generación de fortalezas a partir de recursos muy escasos (procesos). Por último, para la fuerza toma de riesgo individualcohesión social, el análisis se centra en cuan habitual es en la economía encontrar agentes económicos muy propensos a asumir riesgos y estar dispuestos a competir entre sí (toma de riesgo individual) o a la defensa de valores mas relacionados con la cooperación entre agentes para asegurar un entorno de no tan elevado riesgo (cohesión social).

\subsection{BASES TEÓRICAS}

\subsubsection{UNA EVOLUCIÓN HISTÓRICA DEL CONCEPTO DE COMPETITIVIDAD}

Indagando en la historia de la economía ${ }^{8}$ pueden encontrarse referencias a la competitividad ya desde la época del mercantilismo, e incluso si se pretende encontrar rastros sobre conceptos que no sean idénticos pero sí muy emparentados con la capacidad competitiva de una economía bien se puede ir mucho más atrás en el tiempo. Ahora bien, por una prudente necesidad de síntesis surge la exigencia de acotar, en un trabajo como el presente, las referencias a la evolución histórica del concepto de competitividad, a fin de utilizarlas sólo a modo de introducción de lo que son hoy los marcos teóricos dominantes en la materia. Se presentarán entonces, en las próximas páginas, breves referencias a obras y autores que de una u otra manera se encuentran asociados al concepto de competitividad.

\footnotetext{
8 Para un más profundo estudio de las corrientes económicas a lo largo de la historia puede consultarse la muy amena Historia de la Economía, de John Kenneth Galbraith (editorial Ariel, Buenos Aires, 1994).
} 
Es oportuno mencionar que como guía para armar esta muy breve evolución histórica del concepto de competitividad se consultó el trabajo de Stéphane Garelli sobre Los fundamentos de la competitividad de las naciones, que fuera parte del Libro anual de la competitividad mundial 2006 del IMD ${ }^{9}$

\section{Adam SMith. La Ventaja absoluta en el COMERCIO INTERNACIONAL}

En 1776 aparece una de las obras que con el tiempo se convertirían en referencia ineludible en la historia de la economía: Una investigación sobre la naturaleza y causas de la riqueza de las naciones ${ }^{10}$. Su autor, el célebre Adam Smith, propone allí algunos de los fundamentos de lo que hoy se conoce como economía clásica. Uno de estos es el concepto de ventaja absoluta en el comercio entre naciones. Las ideas de Smith suponen un importante avance respecto de lo que se pensaba durante el mercantilismo sobre el comercio internacional, al dejar de plantearse a éste como un juego de "suma cero" en el que si alguna nación ganaba era a costa de otra que perdía, en sentido inverso, la misma proporción. A cambio de esto, se plantea al comercio internacional como una actividad de "suma suma", en la que dos o más naciones intervinientes ganan comerciando entre sí y no necesariamente a expensas de las otras. En concreto, según Smith las naciones que comerciaran entre sí pueden beneficiarse del comercio internacional especializando la producción en los bienes para los que pueden asumir el menor costo de producción en términos absolutos; es decir, para aquellos bienes sobre los que detentan ventaja absoluta. El comercio internacional se origina entonces al vender esos países esos bienes y comprar a otras naciones aquellos para los que afrontan mayores costos de producción. Se dice que sobre estos últimos bienes el país comprador tendrá así "desventaja absoluta".

En pocas palabras, según las ideas de Smith, la ventaja absoluta en la producción de un bien asegura la existencia de comercio internacional: mientras las naciones

\footnotetext{
${ }^{9}$ Fuente aparecida en Un índice regional de competitividad para un país. Jorge Benzaquen y otros. Revista Cepal Nº2 (página 71). Diciembre de 2010.

${ }^{10}$ Una investigación sobre la naturaleza y causas de la riqueza de las naciones. Adam Smith. Alianza Editorial (1994).
} 
especializan su producción en aquellos bienes sobre los que detentan ventaja absoluta, a fin de ser más eficientes y obtener más producto de sus recursos productivos, completan sus necesidades de otros bienes adquiriéndoselos a otras naciones en el mercado internacional, naciones que, por su parte, venden en ese mercado internacional por detentar ventaja absoluta sobre la producción especializada de esos otros bienes.

La extensión de este concepto a todo el conjunto de naciones es lo que explica, a partir de Smith, la concepción del comercio internacional como una actividad en la que "todos ganan", a partir de que las distintas naciones producirán sólo los bienes que maximicen el rendimiento de sus recursos productivos y comprarán el resto a los mismos países a los que les venden sus bienes exportables. En síntesis, según la idea de Smith, todos los países especializan su producción, todos maximizan la utilización de sus recursos productivos, y todos disfrutan de una oferta completa de bienes gracias a que comercian entre sí en el mercado internacional.

El punto débil de las ideas de Smith se encontraría luego al preguntarse qué pasa cuando las naciones en realidad no detentan ventaja absoluta en la producción de ningún bien, cuestión que en principio inhabilitaría la posibilidad de existencia de comercio internacional (ninguna nación con ventaja absoluta ni por tanto con producción especializada, lo que elimina las condiciones de existencia de comercio internacional). La respuesta a esta cuestión vendría de la mano de David Ricardo y su evolución hacia el concepto de ventaja comparativa.

\section{DAVID Ricardo. LA Ventaja EN EL COMERCIO ENTRE NACIONES}

Según el planteamiento de Adam Smith, no existirá comercio internacional si una nación alcanza ventaja absoluta en más de un bien, porque en ese caso esa nación no tendrá ningún estímulo para comerciar con otros bienes que por sí misma puede producir al menor costo posible. Pero David Ricardo fue un paso más allá de esto, ampliando la idea de ventaja absoluta para proponer que existirá comercio internacional aunque una nación tenga ventaja absoluta en más de un bien, o desde otra óptica, aunque otra nación no tenga ventaja absoluta en ninguno de los bienes 
que produce. A esta teoría la llamó de la ventaja comparativa, y plantea, simplemente, que una nación debe especializarse en la producción de los bienes en los que más ventaja tiene, sin necesidad de que esa ventaja sea en términos "absolutos"; esto es, sin necesidad de que esa ventaja sea por ser el productor de más bajo costo posible. Aunque una nación tenga ventaja absoluta en la producción de todos los bienes, igualmente le será conveniente comerciar con otras naciones, vendiéndoles sólo lo que mejor y a menor costo produce y comprándoles a ellas el resto, no dejando entonces de comerciar como en principio sugiere la idea de ventaja absoluta.

Por la necesidad de síntesis, puede plantearse la diferencia entre uno y otro concepto mediante la utilización de un ejemplo: Supongamos que existe un abogado y un pintor. El abogado es el mejor abogado (el que "produce sus servicios" en forma más eficiente, a menor costo) y el pintor es el mejor pintor. En este caso, cada uno detenta en su profesión ventaja absoluta, y por tanto es lógico que comercien entre sí, llamando el abogado al pintor cuando debe pintar su casa y contratando el pintor al abogado cuando debe defender sus derechos. Hasta allí, todo el comercio entre ellos está de acuerdo con la idea de la ventaja absoluta. Ahora bien, si consideramos la idea de ventaja comparativa, seguirá habiendo comercio entre el abogado y el pintor aunque el primero no sólo sea el mejor abogado sino ahora también el mejor pintor, ya que siempre le resultará conveniente asignar sus recursos (sus horas como profesional) a la actividad que mejor hace (la abogacía), aunque como pintor sea mejor que el propio pintor de profesión. En éste otro supuesto, el abogado seguirá contratando al pintor para librarse de la pintura de su casa y poder asignar sus horas a la actividad sobre la que tiene ventaja comparativa, sobre la que es más productivo, la de abogado. Visto entonces desde la óptica de la ventaja comparativa, el sólo hecho de que exista diferencial de ventajas asegura entonces la existencia de comercio, sin necesidad de que se cumpla con las premisas de la ventaja absoluta.

David Ricardo expuso estas ideas en su obra más conocida: Principios de Economía Política y Tributación, que terminó de escribir en $1817^{11}$. Con el tiempo, la idea de ventaja comparativa se convertiría en uno de los más fuertes antecedentes de las

\footnotetext{
${ }^{11}$ Principios de economía política y tributación. David Ricardo. Fondo de Cultura Económica (2010).
} 
actuales teorías sobre ventaja competitiva, explicando algunas de las condiciones por las que existe comercio internacional entre naciones ${ }^{12}$.

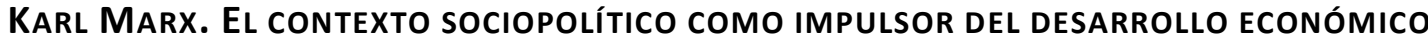

Puede resultar extraña la inclusión de Marx en una breve reseña de marcos teóricos históricos relacionados con la competitividad, pero no tanto si consideramos sus contribuciones a una teoría integral contemplativa no sólo de los factores económicos sino también de los sociales y políticos como determinantes del desarrollo de una sociedad.

Hoy se sabe que el entorno socioeconómico y el sistema político existente en una nación explica en buena medida el nivel de competitividad que ella pueda haber alcanzado, a partir de considerar que existen, claramente, entornos que favorecen -y otros que no lo hacen- el desarrollo de determinados perfiles competitivos. El tronco teórico de la economía marxista fue el primero en destacar especialmente el efecto del contexto sociopolítico para el desarrollo económico, superando y complementando de ese modo a los enfoques más clásicos de Smith y Ricardo, casi exclusivamente concentrados en los aspectos económicos. La crítica de Marx al capitalismo -expresada fundamentalmente en su obra El Capital, Crítica de la Economía Política, concluida en $1867^{13}$ - incluye el estado de ese contexto como una de las causas que, según su predicciones, agotarían el sistema de producción y acumulación capitalista. El ideal marxista contemplaba un cambio en lo social y en lo político como condición previa para un "salto de calidad", superador del capitalismo, de todo el sistema económico mundial.

Las predicciones de Marx fracasaron en cuanto a que aún no se ha presenciado el agotamiento del capitalismo y su reemplazo por un sistema mejor, pero toda su base teórica es útil aún para considerar cómo todo un contexto social, un sistema político y

\footnotetext{
12 Para un análisis profundo de la evolución posterior del concepto de ventaja comparativa puede consultarse el muy difundido Modelo de Heckscher-Ohlin sobre cómo funcionan los flujos del comercio internacional.

${ }^{13}$ El Capital. Crítica de la Economía Política. Karl Marx. Siglo XXI Editores (1975).
} 
unas puntuales condiciones económicas determinan el grado de desarrollo de una nación y la calidad de vida de su población, conceptos todos que resultan familiares en las modernas teorías sobre generación y sostenimiento en el tiempo de capacidad competitiva por parte de una nación.

\section{Max Weber. Valores y CReencias como determinantes del desempeño económico}

La mención de Max Weber debe ser de menor entidad, porque al pensar en una evolución histórica del concepto de competitividad y desarrollo económico no es tan directa su contribución. Pero es válida su inclusión si se analiza que logró ampliar aún más el enfoque respecto de cuáles son las condiciones que deben darse para un buen desempeño de la economía, al considerar, además de las económicas y políticas, a las cuestiones morales y hasta las creencias religiosas como determinantes del mismo. Cuando Weber escribió, ya estaban muy firmes las ideas de que el desarrollo de la economía de una nación no era explicado exclusivamente desde la consideración de sus condiciones económicas, pero él fue bastante más allá al estudiar cómo influían en esto y en el comportamiento individual de los actores económicos también las esferas de la moral y la religión. Sus hipótesis cotejando los desiguales niveles de desarrollo en sociedades bajo las influencias del protestantismo y del catolicismo (tal como hiciera en La ética protestante y el espíritu del capitalismo, de $1905^{14}$ ) no se muestran reñidas a lo que hoy podría ser cualquier análisis profundo en las teorías modernas sobre las causas determinantes de la competitividad de las naciones.

\section{John Maynard Keynes. El rol del Estado}

John Maynard Keynes fue una figura central en el período de entreguerras. Se le atribuye, con pocas disidencias, ser el mentor de las ideas que forjaron las políticas instrumentadas para la recuperación de la economía mundial durante la gran crisis mundial de los años '30 del siglo pasado (ideas reunidas en su ya célebre Teoría

\footnotetext{
${ }^{14}$ La ética protestante y el espiritu del capitalismo. Max Weber. Editorial Reus (2009).
} 
general del empleo, el interés y el dinero, de $1936^{15}$ ). Con el tiempo, Keynes se ha convertido en referencia ineludible toda vez que se pretende analizar cuál debe ser el rol del Estado en la economía. Las bases teóricas de las políticas que lograron que el mundo emergiera de la gran crisis de esos años atribuyen un rol preponderante al Estado como agente económico, trazando los grandes lineamientos de recuperación y desarrollo y siendo uno de los pilares del sostenimiento de la demanda agregada. Precisamente, el concepto de demanda agregada cobrará celebridad a partir de Keynes como el gran punto de enfoque para mantener economías en buen nivel de actividad y lejos de los siempre indeseados ciclos depresivos.

Traer a Keynes a esta muy breve mención respecto de la evolución del concepto de competitividad resulta oportuno precisamente por eso: se puede coincidir que es Keynes el gran punto de referencia al interpretar y analizar con detalle el rol del Estado como determinante del desempeño económico, de la capacidad de una nación para insertarse en el contexto internacional (el Keynesianismo fue asimismo la base de la gran proliferación del comercio internacional en el largo período de prosperidad de la segunda posguerra) y de las formas en que pueden generarse ventajas económicas en un contexto mundial globalizado.

Como pronto veremos, no es incorrecto reclamarle a Michael Porter una gran deuda de gratitud hacia Keynes, ya que en la esfera atribuible al rol del Estado (Porter lo llama Gobierno) dentro de su teoría de la ventaja competitiva de las naciones puede percibirse parte de los grandes lineamientos teóricos del gran economista inglés, sobre todo en el papel del Estado como regulador, como gestor de políticas públicas y como actor de relevancia en el escenario económico.

\footnotetext{
${ }^{15}$ Teoría general de la ocupación, el interés y el dinero. John Maynard Keynes. Fonde de Cultura Económica (1992).
} 
JoSEPH SHUMPETER. El EMPRENDEDOR COMO FIGURA DEL DESARROLLO COMPETITIVO

Joseph Shumpeter propuso (en su obra Capitalismo, Socialismo y Democracia ${ }^{16}$, de 1942) el concepto de destrucción creativa, para hacer referencia a las fuerzas económicas y a los agentes económicos que, "destruyendo" reglas y quehaceres tradicionales, reinventan en forma permanente las formas de producir y comercializar bienes, manteniendo de este modo siempre "vivo" todo el tejido económico y social. En esta lógica, destacó la figura del emprendedor como impulsor del progreso técnico y gerencial, atribuyéndole un rol trascendental en el proceso de desarrollo de una economía. Una figura que, asumiendo riesgos, no da por sentado nada y siempre se encuentra en permanente estado de atención para descubrir dónde pueden diseñarse e instrumentarse mejores prácticas de diseño y desarrollo de productos y procesos productivos. Shumpeter creía que sin la figura del emprendedor las economías tenían destino inevitable de estancamiento y atraso económico. Veía al emprendedor como el gran agente de cambio, como aquél que, en situaciones de incertidumbre, mejor interpretaba los avances tecnológicos para aplicarlos en concreto al sistema económico-productivo, mejorándolo.

Su mención como parte de una evolución histórica del concepto de competitividad se justifica en la trascendencia que la innovación y las prácticas innovadoras han sabido ganarse como factor determinante de la creación y sostenimiento en el tiempo de ventajas competitivas, tato sea si se habla de empresas como de naciones. Las modernas teorías sobre competitividad toman todas a la innovación y a la figura del empresariado innovador como uno de los factores de competitividad, algo que Shumpeter, con buena visión de futuro, ya supo hacer en la década de los años cuarenta del siglo pasado. La irrupción de este economista austríaco significó en su momento cierto malestar en la teoría económica, muchas veces afecta a los postulados que firmes en el tiempo buscan situaciones de equilibrio, y lejos de cualquier línea argumental que proponga la "destrucción creativa" del ordenamiento establecido. Por el contrario, Shumpeter llegó para plantear firmemente la necesidad de buscar los "desequilibrios" que habilitaran las vías para soluciones innovadoras,

\footnotetext{
${ }^{16}$ Capitalismo, Socialismo y Democracia. Joseph A. Schumpeter. Ediciones Folio (1996).
} 
única forma, según él, de asegurar los necesarios saltos de calidad que requiere la permanente búsqueda del desarrollo económico.

De la exaltación del espíritu innovador que hizo Shumpeter no puede renegar hoy en día ninguna teoría sobre ventaja competitiva que se precie de tal.

\section{Peter Drucker. Una gestión Racional de empresas como factor de competitividad}

Las tres décadas doradas para el capitalismo, durante la segunda posguerra mundial, de muy alto crecimiento económico, vieron la difusión en todo el mundo de las técnicas de gestión típicas de la gran empresa norteamericana. El período se inició con la reconstrucción de Europa después de la guerra y culminó con la primera gran crisis energética por la elevación de los precios del petróleo en los primeros años de la década del setenta. En ese lapso, y en parte de la mano de lo que se conoció como el Plan Marshall, cobró vida en todo el mundo $-\mathrm{y}$ fundamentalmente en la parte del mundo dominada por occidente- el puntual fenómeno de la gran empresa con sede en Estados Unidos que se expande con filiales en muchos países hasta convertirse en gigantesca multinacional (en sectores como productos de consumo, petróleo, automotrices, alimentos elaborados, laboratorios medicinales, etc.). Como consecuencia lógica de este proceso, se registró la rápida difusión mundial de las técnicas de management que las empresas norteamericanas utilizaban en su país de origen y que trasladaban sin grandes cambios a aquellos en donde abrían sus filiales. En ese marco, Drucker se convirtió rápidamente en un teórico de gran influencia, colaborando en mucho con la internacionalización del management norteamericano. En sus obras -todas muy accesibles, despojadas de tecnisismos-, se encarga de destacar la importancia de una gestión racional de las empresas, con todas sus áreas perfectamente alineadas en la implementación de una estrategia común de escala global en busca del desempeño efectivo que les asegure el ser competitivas, desarrollarse y crear valor para sus accionistas.

Así, como su objeto de estudio fue la gran empresa multinacional, de enorme influencia en las economías donde operaba, sus ideas no tardaron en formar parte de las consideraciones que se creían necesarias para fomentar también la competitividad 
de los propios países, en una lógica inductiva de pensar que lo que es bueno para el desempeño de las empresas, al ser éstas gigantes y al ser consideradas en conjunto, es bueno para el desarrollo de toda una economía nacional.

En los enfoques más actuales sobre competitividad pueden encontrarse aún señas claras de lo propuesto en su momento por Drucker. Como muestra, puede mencionarse el papel trascendente que reservaba a la figura del emprendedor (era un confeso admirador de Shumpeter), o la propuesta de gestionar en forma deliberada y racional la innovación. Además, el análisis de detalle que proponía sobre los factores demográficos relacionados con la educación elemental y la formación de recursos humanos, o sobre la figura del "manager" y su continua necesidad de capacitarse a lo largo de toda su vida laboral. También supo prestar debida atención a la necesaria relación entre sistema educativo y sectores productivos, y a la necesidad de comprender las diferencias culturales existentes en el mundo como paso previo para entender las demandas en distintos mercados mundiales.

\section{Michael Porter. nuevas teorías sobre la ventaja competitiva de las naciones}

En 1990 aparece La ventaja competitiva de las naciones ${ }^{17}$, obra con la que Michael Porter logra completar su trilogía sobre competitividad iniciada una década antes con Estrategia Competitiva ${ }^{18}$ y luego continuada con Ventaja Competitiva ${ }^{19}$. A diferencia de estas dos, muy enfocadas en la competitividad a nivel de empresas, La ventaja competitiva de las naciones suponía una ampliación del enfoque hacia el análisis

\footnotetext{
${ }^{17}$ Porter. Op. cit.

${ }^{18}$ Estrategia competitiva. Técnicas para el análisis de los sectores industriales y de la competencia. Michael Porter. CECSA (1981). El gran aporte de Estrategia competitiva, hace ya treinta años, fue el planteamiento de un modelo de análisis para evaluar escenarios competitivos en sectores industriales, proponiendo el concepto de las cinco fuerzas competitivas y sus interrelaciones.

${ }^{19}$ Ventaja competitiva. Creación y sostenimiento de un desempaño superior. Michael Porter. CECSA (1986). En cierta forma Ventaja competitiva complementa a Estrategia competitiva. Fue una obra publicada cinco años después y su gran aporte consistió en proponer el concepto de Cadena de valor agregado, con la descripción de actividades principales generadoras de valor y actividades de apoyo a la línea principal de la cadena.
} 
pormenorizado de la creación y sostenimiento de ventaja competitiva pero ahora a nivel naciones.

No es momento ahora para explayarse sobre la obra de Porter, ya que su teoría será la esencia de lo que se analice en el marco teórico del presente trabajo, en la próxima sección. Pero puede adelantarse, en esta muy resumida evolución histórica, que su gran contribución fue la de proponer el ya célebre modelo del diamante competitivo, constituido por la relación sistémica de las variables que hacen a los recursos productivos, las condiciones de la demanda de bienes y servicios, el contexto competitivo de las empresas de un sector y el tipo de vínculo con los sectores relacionados y de apoyo, complementadas todas éstas por las condiciones del azar y el papel del gobierno.

El gran logro de Porter fue el de saber "compilar" las teorías y conceptos existentes en relación con la competitividad de las naciones para enriquecer sus muy probados modelos previos referidos a la empresa, obteniendo un nuevo modelo enriquecido, superador, con un enfoque ampliado a la competitividad de las economías nacionales.

Desde la irrupción de la obra de Porter, su modelo de diamante competitivo ha sido la referencia ineludible para todo debate, análisis o planteamiento crítico de la ventaja competitiva de las naciones. Desde hace veinte años, le sobran a Porter admiradores, continuadores y críticos, situación que le ha asegurando hasta el día de hoy la plena vigencia como referente mundial si de competitividad se trata.

\section{Paul Krugman. Una crítica al Concepto de COMPetitividad}

En plena vigencia del modelo de Porter y con la competitividad como una temática estrella en el debate económico, aparece a mediados de los noventa el Premio Nobel Paul Krugman con una ácida crítica a lo que él supone una desmedida sobrestimación del concepto mismo de competitividad como impulsor del desarrollo de una economía. En su muy difundido artículo La competitividad: una peligrosa obsesión (aparecido en 1997 como uno de los ensayos de su libro El internacionalismo moderno. La economía 
internacional y las mentiras de la competitividad ${ }^{20}$ ), Krugman destaca lo peligroso que puede llegar a resultar el enfoque de políticas públicas sobre comercio exterior basadas en la premisa de que las naciones compiten entre sí en un contexto competitivo internacional, como si de empresas de un sector industrial compitiendo entre ellas se tratase. Krugman destaca en el ensayo que no sólo no es correcto trasladar teorías sobre competitividad a nivel de empresas hacia el nivel "macro" de economías nacionales, sino que, para algunas economías, es hasta irrelevante otorgar excesiva importancia a muchas de las cuestiones atinentes al comercio internacional, por tener esas economías en gran medida fundamentado su crecimiento en el desarrollo de sus mercados internos.

Amparado en un profundo análisis de datos estadísticos, y tomando como objeto de estudio a la economía estadounidense, Krugman se despacha sin contemplaciones hacia quienes considera poco menos que paladines de la competitividad, a quienes no duda en acusar del abuso en la utilización del concepto como medio para explicar fácilmente políticas erróneas en materia comercial o hasta la deshonesta justificación para no implementar medidas necesarias pero que puedan resultar desagradables para la población o el electorado.

Esta breve mención de Krugman sirve para tomar en cuenta que al hablar de competitividad no todas las voces están del "mismo lado de la biblioteca", y que existen algunas, y con buenas credenciales, que saben cómo usar sólidos argumentos para cuestionar la relevancia del concepto de competitividad.

\section{ACEMOgLU y Robinson. LA CALIDAD INSTITUCIONAL COMO CLAVE DEL DESARROLLO}

En una obra de reciente aparición sobre los orígenes de la prosperidad y la pobreza en el mundo, Daron Acemoglu y James Robinson ${ }^{21}$ ponen la lupa sobre la calidad de las

\footnotetext{
${ }^{20}$ El internacionalismo moderno. La economía internacional y las mentiras de la competitividad. Paul Krugman. Editorial Crítica (2004).

${ }^{21}$ Por qué fracasan los países. Los orígenes del poder, la prosperidad y la pobreza. Daron Acemoglu y James Robinson. Editorial Ariel (2013).
} 
instituciones de los distintos países alrededor del mundo, en la actualidad y a lo largo de la historia, proponiendo que se trata de un factor determinante al momento de explicar el porqué algunas regiones han prosperado enormemente y otras no han podido escapar jamás a un destino de postergación y pobreza. Pero lejos de confiar en un destino escrito, estos autores sostienen que la capacidad de los países para desarrollarse económicamente y ser actores de relevancia en el contexto internacional, asegurando así una mejora continua en los niveles de vida de sus poblaciones, depende casi exclusivamente de la forma en que hayan sabido construir a lo largo de toda su historia una red de instituciones sólidas, seguras, de carácter permanente y que otorguen incentivos para el crecimiento e igualdad de oportunidades a todos sus habitantes. Por el contrario, los países atrasados y con bajas perspectivas de desarrollo económico parecieran estar presos de los efectos perjudiciales de unas instituciones de muy baja calidad, dedicadas sólo a extraer recursos del sistema económico en beneficio de pequeñas elites del poder, sin ninguna lógica de desarrollo o de reposición de los mismos.

Por lo tanto, según Acemoglu y Robinson, la evolución a lo largo de la historia y la calidad actual de sus instituciones es lo que determina que un país esté en condiciones de asegurar los debidos incentivos a todo su entramado económico y social, para fomentar así el desarrollo económico y el permanente crecimiento en los niveles de vida de su población y en la productividad con que son utilizados todos los recursos. $\mathrm{O}$ lo que es lo mismo, para fomentar su competitividad.

La mención de esta obra en el final de este repaso histórico sobre el concepto de competitividad tiene que ver en que su gran foco de análisis, las instituciones, resulta ser uno de los pilares más relevantes sobre los que cualquier teoría moderna mide hoy en día niveles de competitividad de una nación. 


\subsubsection{TEORÍAS MODERNAS SOBRE COMPETITIVIDAD: EL MODELO DE LA VENTAJA} COMPETITIVA DE LAS NACIONES

Como se mencionó pocos párrafos atrás, un hito importante en la evolución del concepto de competitividad fue la aparición de la obra de Porter La ventaja competitiva de las naciones, que supuso un aporte trascendental y aún en plena vigencia para entender cómo es que compiten las naciones y cuál es la forma que tienen para crear y sostener en el tiempo ventaja competitiva. Porter tuvo la capacidad de plantear una teoría integral desde un enfoque sistémico y explicar así cuáles son los elementos determinantes de la ventaja competitiva de una nación y cómo es que esos elementos se relacionan en forma dinámica entre sí. Siguiendo lo propuesto por Porter es que de hace más de veinte años se puede analizar tanto el perfil global de una país en el escenario competitivo mundial como indagar en cada una de las variables que determinan su desempeño competitivo.

El aspecto saliente de su teoría es el concepto de diamante competitivo, por medio del cual se identifican claramente los determinantes que por su condición y por su interrelación mutua hacen a la competitividad de una nación. A un muy breve abordaje de ello se destinan los próximos apartados.

\section{LOS DETERMINANTES DE LA VENTAJA COMPETITIVA NACIONAL}

Al momento de presentar los determinantes de la ventaja competitiva nacional Porter comienza preguntándose “¿Por qué alcanza una nación el éxito global en un sector económico en particular?", para él mismo responderse que "la respuesta se encuentra en cuatro atributos genéricos de una nación que conforman el entorno en que han de competir las empresas locales y que fomenta o entorpece la creación de ventaja competitiva" ${ }^{\prime 2}$. Por los cuatro atributos entiende lo que llamamos los determinantes de la ventaja competitiva, que define así:

\footnotetext{
22 Porter. Op. cit., página 110.
} 
1. “Condiciones de los factores. la posición de la nación en lo que concierne a mano de obra especializada o infraestructura necesaria para competir en un sector dado.

2. Condiciones de la demanda. La naturaleza de la demanda interior de los productos o servicios del sector.

3. Sectores relacionados y de apoyo. La presencia o ausencia en la nación de sectores proveedores y sectores afines que sean internacionalmente competitivos.

4. Estrategia, estructura y rivalidad de la empresa. Las condiciones vigentes en la nación respecto a cómo se crean, organizan y gestionan las compañías, así como la naturaleza de la rivalidad doméstica."

Según Porter, una nación crea y sostiene ventaja competitiva en uno o más sectores cuando logra alcanzar una combinación favorable de los cuatro determinantes, lo que no implica que deba ser "excelente" en todos ellos, pero sí que pueda interpretar cuál es la más efectiva forma de combinarlos para extraer de su conjunto el máximo potencial posible. Por el contrario, no considera que pueda sustentarse una ventaja competitiva basada en sólo uno o dos de los determinantes, tipo de ventaja esta última muy precaria, relacionada con sectores y naciones muy dependientes de recursos naturales o de tecnologías o técnicas poco avanzadas.

La consideración e interrelación de los cuatro determinantes suele presentarse gráficamente de este modo: 


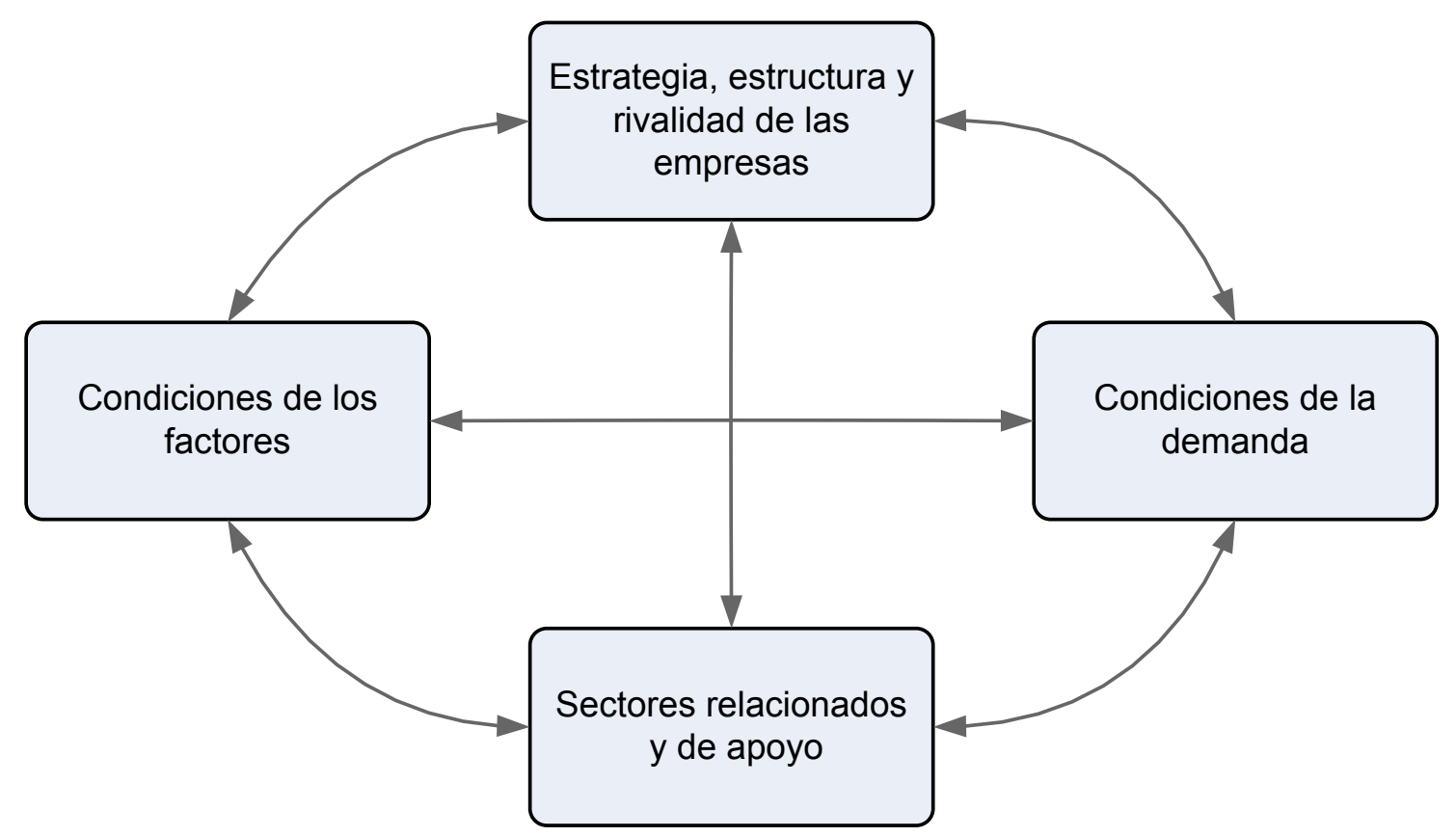

Fuente: Porter

Porter luego considera dos variables adicionales a los cuatro determinantes: el papel de la casualidad, entendiendo por esto la ingerencia en los distintos escenarios competitivos de los eventos imprevistos, trascendentes pero imposibles de predecir, y el rol desempeñado por el Gobierno, como actor de importancia en sus funciones de regular, controlar y gestionar las políticas del Estado. Los cuatro determinantes y las dos variables adicionales, consideradas en conjunto, relacionándose entre sí en forma sistémica, conforman lo que se conoce como el diamante de la ventaja competitiva nacional.

Entonces, consideremos primero, cada uno por separado, a los determinantes y a las variables adicionales, para luego concluir la breve mención a la teoría de Porter con la consideración de todo ello funcionando en conjunto dentro de la dinámica del diamante de la competitividad. 


\section{LAS CONDICIONES DE LOS FACTORES}

El primero de los determinantes de la ventaja competitiva de una nación es la condición de sus factores de producción, entendiendo por esto a cuál es el stock de sus recursos productivos y, casi más importante, cuál es su capacidad para mantenerlos, perfeccionarlos y/o generar nuevos. Se entiende que una nación será competitiva cuando pueda priorizar la asignación de sus recursos, siempre escasos, en aquellos destinos que impliquen la mayor productividad posible por el uso de los mismos.

Hasta allí nada nuevo, nada que no esté contemplado ya en los tradicionales enfoques de ventaja absoluta y ventaja comparativa. Pero Porter va más allá en el análisis al describir qué tipo de factores son los de mayor calidad y los que mayor probabilidad tienen de ser fuente de ventaja competitiva. Así es como propone que factores de calidad no serán los heredados sino los generados por la propia economía, que no serán los que ya existen sin la intervención de un proceso previo de generación de valor sino aquellos que requieren una permanente innovación para su creación, mantenimiento y mejora continua. El de los recursos naturales es el típico ejemplo de un recurso de baja calidad. El de disponibilidad de recursos humanos de elevada formación uno bien representativo de los de alta.

Porter llega a proponer que la abundancia de factores puede incluso degradar más que mejorar la ventaja competitiva de una nación, ya que determinadas desventajas en factores productivos disparan en la economía mecanismos de innovación y mejora para suplir las carencias, que siempre están relacionados con externalidades positivas para el conjunto de los sectores económicos.

La teoría de Porter resulta un gran avance al momento de considerar qué se entiende por factores de producción, abandonando la repetida consideración de factores tierra, mano de obra y capital de las teorías tradicionales para proponer una serie de categorías genéricas donde agrupar factores ahora entendidos en un amplio sentido del término. Así, agrupa factores bajo categorías relacionadas con recursos humanos (no sólo la tradicional mano de obra sino también las personas que basan su productividad en la aplicación de conocimientos científicos, técnicos, etc.), recursos físicos (desde los tradicionales tierra, agua y minerales hasta la consideración de 
factores climáticos y posiciones geopolíticas), recursos de conocimiento (básicamente, el stock de "know-how" que tenga una nación y la capacidad para regenerarlo y crear nuevo en forma permanente), recursos de capital (no sólo el stock de capital existente en la economía sino la flexibilidad, capacidad de crédito y posicionamiento de la nación en el contexto financiero internacional) e infraestructura (entendiendo por tal desde el conjunto de recursos "duros" como los sistemas de transporte, redes de comunicación, asistencia sanitaria, etc., hasta "blandos" como instituciones culturales o incluso el atractivo de determinada nación como un buen lugar para vivir y trabajar).

Otra consideración relevante en Porter es la de la jerarquía de los factores, pudiendo ser ellos, por una parte, básicos o avanzados, y por otra, generalizados o específicos. Los factores básicos son los heredados por una nación, los que existen por sí mismos. También es factor básico la mano de obra no especializada y la infraestructura elemental. Por el contrario, los factores avanzados son los que para su disponibilidad requieren prolongados procesos de innovación y fuertes inversiones, como la infraestructura digital, el personal altamente capacitado, las instituciones académicas y los centros de investigación. Porter propone que una ventaja competitiva de orden superior, más sólida, más estable y más difícil de igualar es la que se construye sobre factores avanzados, porque dotan a una nación de una especificidad única en el tipo de factores que dispone y aplica en sus procesos productivos, distinguiéndose de esa manera de aquellas naciones que sólo hacen uso de su factores básicos, heredados, sin mayor desarrollo.

Por otra parte, en la otra distinción por jerarquías, los factores generalizados son los que están al servicio del conjunto de los sectores de la economía, sin distinción específica por sus características o sus aplicaciones (ej.: red de carreteras, red de comunicaciones); en cambio, los factores específicos comprenden aquellos que son destinados a su asignación altamente especializada en sectores y procesos productivos muy puntuales (disponibilidad de recursos humanos con conocimientos muy avanzados y especializados, laboratorios de investigación sobre ramas muy concretas de las ciencias, etc.). Complementando lo anterior, una ventaja de orden superior se logrará entonces sustentando la economía no sólo en factores avanzados sino ahora también en los muy específicos. 
Por último, Porter también propone una categorización de factores según sean heredados o creados. Como se adelantó, los heredados son aquellos de los que la nación dispone sin haber hecho nada para ello, como sus recursos naturales o su situación geográfica; mientras que, por el contrario, los creados son producto de procesos y mecanismos específicos para crearlos, que siembre requieren innovación, altos niveles de inversión y políticas de claro objetivos mantenidas a lo largo del tiempo. En forma similar para este caso, la ventaja competitiva de orden superior será la cimentada bajo el uso de factores creados, siempre más difíciles de ser copiados o igualados.

\section{LAS CONDICIONES DE LA DEMANDA}

Al hablar de condiciones de la demanda como uno de los determinantes de la ventaja competitiva, Porter en realidad se refiere a demanda "interior". La demanda interior es la que en primer término, con sus exigencias, crea las condiciones para que determinado sector logre ventaja competitiva en los mercados globales. La lógica de este proceso sería: una demanda interna de determinado sector productivo, al ser muy exigente en sus hábitos de consumo, genera empresas preparadas, entrenadas y muy entendidas en la forma de satisfacer tal nivel de demanda. Con el tiempo, esto crea una serie de conocimientos, prácticas y capacidades por parte de las empresas como para, internacionalizando ese "know-how", trasladar el dominio en el mercado interno hacia los mercados del exterior. Las cualidades de la demanda interna son entonces uno de los pilares sobre los que se construye ventaja competitiva.

Según Porter, tres atributos genéricos de la demanda interior son especialmente significativos, en sus palabras: "la composición de la demanda interior (o naturaleza de las necesidades del comprador), la magnitud y pautas de crecimiento de la demanda interior, y los mecanismos mediante los cuales se transmiten a los mercados extranjeros las preferencias domésticas de una nación." ${ }^{23}$

\footnotetext{
${ }^{23}$ Porter. Op.cit., página 129.
} 
Sobre la composición de la demanda interior, puede decirse que será un factor impulsor de ventaja competitiva cuanto más específicamente segmentada se encuentre, con segmentos de mercado de características y exigencias únicas y fácilmente reconocibles, compuestos por consumidores muy entendidos y exigentes en sus demandas, conocedores al detalle de todos los atributos que debe proveer una oferta de calidad. Será trascendente también el que las necesidades y deseos de los compradores domésticos sean precursoras respecto de las correspondientes a los mercados de otros países, algo así como que la demanda doméstica "lidere" el nivel de exigencias respecto de los mercados del exterior.

Respecto de la magnitud y pautas de crecimiento de la demanda interior, resulta importante destacar en principio el tamaño de esa demanda, en el sentido de que cuanto más grande sea el mercado interno más posibilidad dará de aprovechar economías de escala no sólo en los procesos productivos, sino sobre todo en las fases de investigación y desarrollo de nuevos productos y en las inversiones necesarias en capacidad industrial e infraestructura. Luego, será importante también que la demanda esté constituida por un gran número de consumidores, para de esa manera asegurar una gran diversidad y desarrollo de nuevas exigencias, las que por el contrario podrían "congelarse" en caso de que ese número sea escaso, con un altamente probable retraso en el desarrollo de nuevas exigencias. Además, la demanda interior será fuente de ventaja competitiva cuánto más rápidamente se sature, impulsando de esa manera a las empresas del sector a conseguir una visión global que les permita salir a competir por los mercados del exterior en pos de remover el limitante de crecimiento del mercado doméstico.

Por último, el tercer atributo de la demanda interior para ser fuente de ventaja competitiva estará dado por las condiciones en que ella pueda ser internacionalizada por parte de las empresas domésticas. Esto será posible si las empresas logran que las condiciones de los mercados internos "traccionen" la demanda hacia los mercados del exterior, en un proceso que dependerá de cuán móviles internacionalmente o cuán internacionalizados estén algunos de los consumidores domésticos más importantes, 0 qué grado de influencia puedan tener estos sobre sus "pares" del exterior, a quienes 
así puedan trasladarles las características o exigencias propias del mercado interno y que son muy conocidas por las empresas.

\section{LAS SECTORES RELACIONADOS Y DE APOYO}

Este tercer determinante propuesto como impulsor de ventaja competitiva está referido a la presencia, dentro de un país, de sectores proveedores o auxiliares del sector competitivo que se esté considerando y que cuenten ya con ventaja competitiva propia. Esto es, si un sector llamado a crear ventaja competitiva se encuentra relacionado con sectores conexos y auxiliares que ya la poseen, la propia lógica de la relación funciona muy bien como impulsor de la ventaja, del sector original y de sus sectores conexos.

En palabras de Porter, "la presencia en una nación de sectores proveedores internacionalmente competitivos crea ventaja, de diferentes maneras, en los sectores que van tras los proveedores en la cadena producción-consumo. La primera de estas maneras es por la vía del acceso eficaz, pronto, rápido a los insumos más rentables con relación a su coste", aunque también "más significativa que el acceso a la maquinaria u otros insumos es la ventaja que los proveedores establecidos en el propio país pueden aportar en lo concerniente a una coordinación continuada". ${ }^{24}$

Es habitual que, al momento de decidir competir en mercados del exterior, las empresas utilicen como base la red de proveedores, también nacionales, que ya cuenten con un perfil de desempeño superior también en el escenario internacional. Con ello trasladan al exterior sin mayores dificultades todas las prácticas y metodologías que les son bien conocidas en la economía doméstica. De igual modo, es habitual que el desarrollo competitivo de un sector a nivel internacional se dé en simultáneo con el desarrollo de sus sectores conexos y auxiliares, en un proceso mediante el cual el sector que lidera la creación de ventaja competitiva internacional tracciona en el mismo sentido a toda lo que es su red de proveedores y sectores de apoyo.

\footnotetext{
${ }^{24}$ Porter. Op.cit., página 150.
} 
Con el paso del tiempo y un buen desempeño competitivo a nivel doméstico, las empresas tejen toda una red de relaciones comerciales que, si el círculo es virtuoso, autorrefuerza la potencia competitiva de los sectores industriales directos y relacionados. Esta lógica va creando las condiciones para generar agrupamientos industriales que pueden trasladarse a los mercados del exterior, sustentando la creación y sostenimiento de ventaja competitiva por parte de los sectores que dieran origen al agrupamiento. Nuevamente en palabras de Porter, "la presencia en una nación de sectores competitivos que guardan conexión unos con otros lleva frecuentemente al nacimiento de nuevos sectores competitivos. Sectores conexos son aquellos en los que las empresas pueden coordinar y compartir actividades de la cadena de valor cuando compiten, a aquellos que comprenden productos que son complementarios. Compartir actividades es algo que puede acontecer en el desarrollo de tecnologías y en la fabricación, distribución, comercialización o servicio de productos".$^{25}$

\section{ESTRATEGIA, ESTRUCTURA Y RIVALIDAD DE LAS EMPRESAS}

El cuarto determinante de la ventaja competitiva en un sector está dado por el contexto de la economía doméstica en que actúan las empresas y en la naturaleza que presenta el grado de rivalidad competitiva entre empresas. Las fuerzas del escenario competitivo determinan la capacidad que pueda tener un sector para desarrollar ventaja competitiva, moldeando las pautas bajo las cuales las empresas deben operar.

Según Porter, "las circunstancias nacionales afectan mucho a la forma en que las empresas van a gestionarse y a competir. Aunque no hay nación donde exista uniformidad entre todas sus empresas, el contacto nacional crea unas tendencias suficientemente fuertes para ser inmediatamente apreciables a los ojos de cualquier observador". ${ }^{26}$ Además, "las naciones tenderán a alcanzar el éxito en sectores en que

\footnotetext{
${ }^{25}$ Porter. Op. cit., página 154.

${ }^{26}$ Porter. Op. cit., página 157.
} 
las prácticas directivas y las formas de organización propiciadas por el entorno nacional sean adecuadas para las fuentes de ventaja competitiva de los sectores". 27

Las estrategias que formulen las empresas incidirán en gran medida en la configuración que tome el contexto competitivo doméstico, de allí que será necesario indagar en cuáles son los objetivos empresarios que fundamentan a aquellas. Prematuros objetivos de expansión de mercados habilitan rápidamente las vías para un desarrollo competitivo internacional de determinados sectores, lo que genera el impulso necesario que necesita cualquier sector para crear ventaja competitiva en mercados globales. Esto no podrá ser posible si el entorno competitivo a nivel nación está dominado por objetivos poco ambiciosos de desarrollo interno.

La teoría de Porter hace mucho hincapié en los fundamentos culturales y en las costumbres de una nación como determinante de cómo compiten sus empresas, de cómo plantean sus estrategias y de cómo se estructuran, llegando a enfocarse marcadamente en las metas y objetivos hasta de los propios empleados, en el "orgullo" por competir en forma permanente a fin de "ganarle al vecino", y en la predisposición que exista en general dentro de un país para valorar el trabajo comprometido, la conducta emprendedora y el esfuerzo personal.

La otra esfera que destaca la teoría como determinante de ventaja competitiva es la del grado de rivalidad registrado en el escenario donde compiten las empresas de un sector en particular. Porter destaca que en sus estudios a hallado siempre una alta correlación entre una enérgica rivalidad doméstica entre empresas y la capacidad del sector que ellas componen para crear y sostener ventaja competitiva internacional. "La rivalidad doméstica, como cualquier rivalidad, crea presiones sobre las empresas para que mejoren e innoven. Los rivales locales se hostigan entre sí para reducir los costes, mejorar la calidad y el servicio y crear nuevos productos y procesos. Aunque es posible que las empresas no mantengan las ventajas durante largos espacios de tiempo, la

\footnotetext{
${ }^{27}$ Porter. Op. cit., página 158.
} 
presión activa de los rivales estimula la innovación tanto por miedo a quedar rezagado como por el aliciente de ponerse en cabeza". ${ }^{28}$

Cuando un entorno doméstico presenta altos niveles de rivalidad esto impulsa a las empresas a salir más temprano que tarde a la conquista de mercados del exterior, nuevo entorno adonde las empresas trasladan su disposición a competir y sus niveles de rivalidad. "Curtidas por la rivalidad doméstica, las empresas domésticas de mayor fortaleza están preparadas para alcanzar el éxito en el extranjero. Es raro que una empresa pueda enfrentarse a difíciles rivales extranjeros si no se ha enfrentado previamente a una competencia significativa en el mercado interior" ${ }^{29}$

\section{EL PAPEL DE LA CASUALIDAD}

Más allá de los cuatro determinantes genéricos de la ventaja competitiva, Porter completa la consideración de los elementos de su diamante con el rol de influencia que le otorga a los acontecimientos casuales y a la actuación del Gobierno. A ninguno de los dos presenta como un quinto determinante genérico, pero sí como factores de elevada influencia sobre la condición de cada uno de los cuatro impulsores principales de la ventaja competitiva.

Respecto de los acontecimientos casuales, considera que "son incidentes que tienen poco que ver con las circunstancias de una nación y que frecuentemente están, en gran parte, fuera de control y de la capacidad de influir tanto de las empresas como del Gobierno. Los acontecimientos casuales son importantes porque crean discontinuidades que propician algunos cambios en la posición competitiva. Pueden anular las ventajas de los competidores previamente consolidados y crear el potencial para que las empresas de una nueva nación puedan ocupar sus puestos para conseguir una ventaja competitiva en respuesta a nuevas y diferentes condiciones". ${ }^{30}$

\footnotetext{
${ }^{28}$ Porter. Op. cit., página 171.

${ }^{29}$ Porter. Op. cit., página 172.

${ }^{30}$ Porter. Op. cit., página 178.
} 
El enfoque se preocupa por resaltar el papel que juegan los acontecimientos casuales, aquellos que marcan determinados puntos de inflexión en un escenario competitivo y que son imposibles de ser considerados previamente por un proceso de predicción o planificación estratégica. Pero en ninguna medida llega a considerar que, por sí solos y aunque sean de gran magnitud, estos acontecimientos pueden identificar con su sola aparición una posibilidad de crear una nueva ventaja competitiva, y mucho menos aún generarla y sostenerla en el tiempo sin participación alguna de los cuatro determinantes genéricos.

\section{EL ROL DEL Gobierno}

En igual medida, Porter atribuye al rol del Gobierno sólo el papel de facilitador o retardador de la construcción de ventaja competitiva. Asombrosamente, no le otorga la condición de "determinante" de tal ventaja, sino la función de "ayuda" en la construcción de la misma. Con la instrumentación de sus políticas y con el desempeño de sus funciones elementales, el Gobierno puede facilitar o impulsar la ventaja competitiva, pero en sí mismo no representa un factor determinante de ella, papel que siempre se reserva para las empresas, sus sectores relacionados, las condiciones de la demanda y las condiciones de los factores (los cuatro determinantes genéricos ya descriptos).

Según Porter, el Gobierno, al igual que la casualidad, está llamado a desempeñar un papel, si no secundario, al menos no central, de facilitador o inhibidor de todo el proceso de creación de ventaja. En sus palabras: "Es tentador hacer del Gobierno el quinto determinante. Y sin embargo, tal cosa no sería ni correcta ni la forma más útil de comprender el papel del Gobierno en la competencia internacional. El auténtico papel del Gobierno en la ventaja competitiva nacional es del de influir en los cuatro determinantes". ${ }^{31}$ Y también: "El Gobierno ejerce una importante influencia sobre la ventaja competitiva nacional, aunque su papel es inevitablemente parcial. La política gubernamental fracasará si sigue siendo la única fuente de ventaja competitiva

\footnotetext{
${ }^{31}$ Porter. Op. cit., página 181.
} 
nacional. Las políticas que llegan a tener éxitos lo consiguen en aquellos sectores donde están presentes ( $y$ reforzados por la acción gubernamental) los determinantes fundamentales de la ventaja nacional". ${ }^{32}$

\section{LA DINÁMICA DE LA VENTAJA COMPETITIVA NACIONAL}

Luego de presentados los determinantes genéricos de la ventaja competitiva y los dos factores adicionales que influyen sobre ellos, la contribución de Porter se concentra en lo que realmente es el núcleo de su teoría: la relación sistémica de todos esos elementos en lo que da en llamar el diamante de la competitividad nacional. Por diamante Porter entiende la relación e influencia que todos los determinantes tienen entre sí, influidos a su vez por el papel desempeñado por los hechos imprevistos y por el Gobierno. En este marco, y dada la naturaleza de cada nación, existirán pautas para la creación de factores en donde cada uno de ellos guarda determinada forma para crear, enriquecer o, por el contrario, devaluar a los demás.

Porter propone, obviamente que sin agotar las distintas posibilidades que puedan existir según las características de la nación, una enunciación sobre cómo cada determinante recibe el aporte de las condiciones existentes en los tres restantes. Sumadas las influencias de la casualidad y del Gobierno, todo configura determinada situación y determinada dinámica en el tiempo de todo el diamante. El comportamiento del diamante de cada nación es lo que determina la capacidad de crear y mantener ventaja competitiva. En palabras del autor, "en los sectores nacionales de más éxito no suele ser fácil saber por dónde empezar para explicarse la ventaja competitiva: la interacción y autorreforzamiento de los determinantes es tan compleja que puede difuminar causa y efecto. El entorno nacional se hace más favorable para competir con el transcurso del tiempo, a medida que el diamante se reestructura. El sistema está igualmente en constante movimiento. El sector nacional

\footnotetext{
32 Porter. Op. cit., página 183 (cursivas del propio autor).
} 
evoluciona continuamente como reflejo de las cambiantes circunstancias o entra en declive". ${ }^{33}$

La teoría hace especial hincapié en que para detentar una ventaja competitiva de orden superior no es necesario contar con un rendimiento superlativo en cada uno de los determinantes de dicha ventaja, sino que se requiere el "funcionamiento acorde" de todo el diamante dado por una configuración particular del mismo. Bajo esa lógica, un país puede tener desventaja relativa respecto de la condición de un determinante y no obstante ser esto más que compensado por el aporte de los restantes y la relación sistémica de todos ellos dentro del diamante.

Gráficamente, el funcionamiento del diamante suele representarse así:

Figura 4 - El diamante de la competitividad nacional

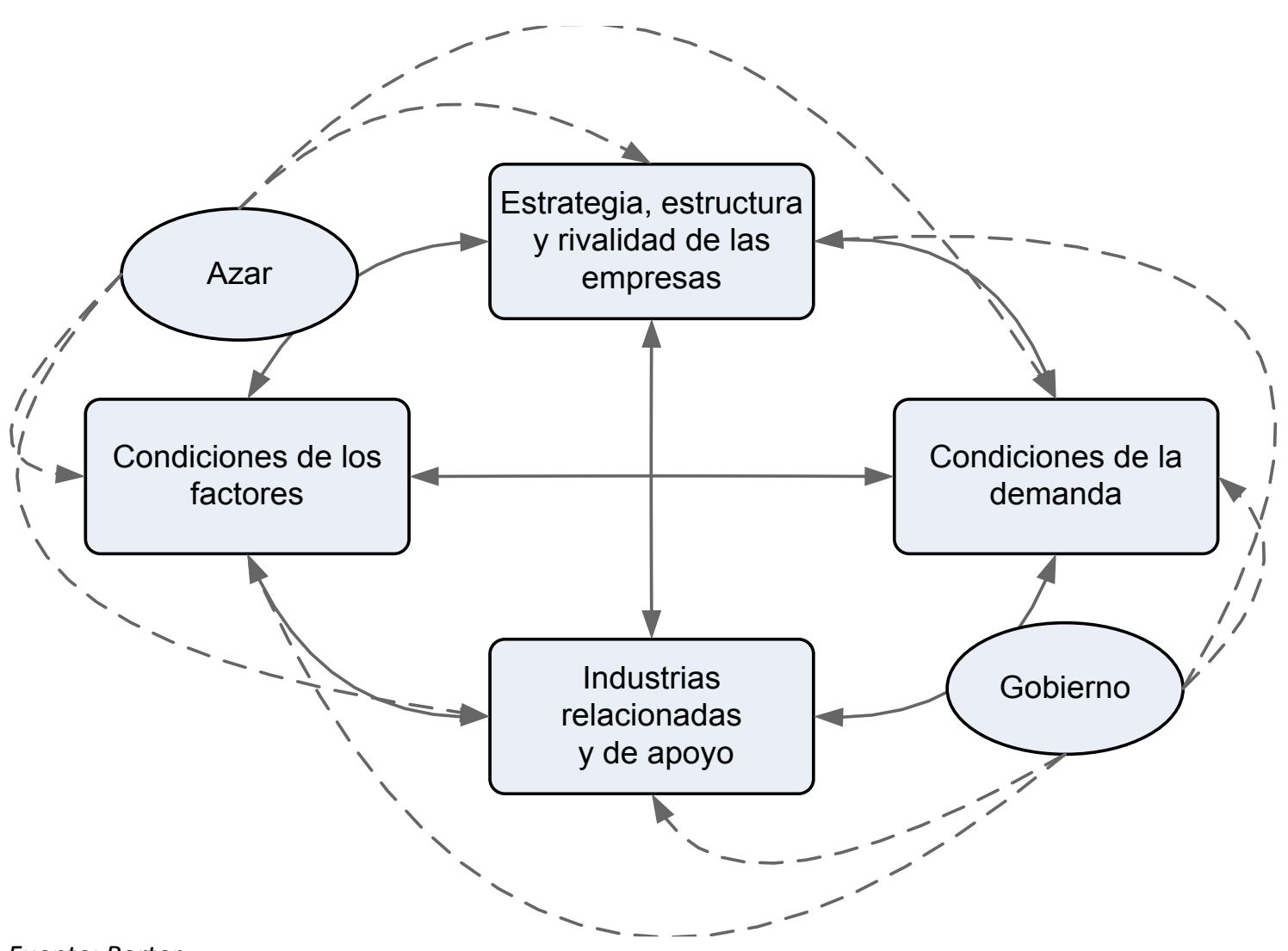

Fuente: Porter

\footnotetext{
${ }^{33}$ Porter. Op. cit., página 202.
} 
El gráfico intenta representar las relaciones sistémicas entre los cuatro determinantes, con la influencia ejercida por los dos factores adicionales, y las interrelaciones e influencias mutuas entre todos los elementos, en un carácter dinámico que genera determinado comportamiento para todo el diamante y permite crear y mantener ventaja competitiva. De igual forma, el diamante trabajaría en sentido inverso cuando las condiciones de los elementos y las interrelaciones que mantienen entre sí sean disfuncionales para la creación de ventaja competitiva. En este otro caso, la propia lógica de funcionamiento de diamante no impulsaría sino que degradaría la ventaja competitiva que pueda haberse construido. En síntesis, cuando el círculo es virtuoso, el diamante impulsa la creación y sostenimiento de ventaja competitiva. Por el contrario, cuando es vicioso, acelera la erosión de la ventaja y la pérdida de competitividad.

\section{AgRUPAMIENTO DE SECTORES COMPETITIVOS Y CONCENTRACIÓN GEOGRÁFICA}

Cuestión relevante en la propuesta de Porter es el análisis que hace de los agrupamientos sectoriales y de las causas que explican el porqué estos suelen concentrarse en determinadas regiones geográficas, siempre muy acotadas. Según sus palabras: "la naturaleza sistémica del diamante propicia el agrupamiento de los sectores competitivos de una nación. Normalmente, los sectores de más éxito de una nación suelen estar vinculados mediante relaciones verticales (comprador/proveedor) u horizontales (clientes, tecnologías y/o canales comunes)" ${ }^{34}$

Los agrupamientos sectoriales, cuando son virtuosos, no hacen más que reforzar las virtudes de los diamantes. Los agrupamientos se convierten así en fuertes impulsores para la creación de ventaja competitiva por varias razones; entre ellas, por los flujos de información que se generan entre sus participantes respecto de necesidades técnicas y transferencias de tecnología, por el perfeccionamiento en la instrumentación de procesos productivos comunes a toda una industria, por el desarrollo de cualidades para competir derivadas de una alto grado de rivalidad entre empresas, por la capacidad de un agrupamiento de armar defensas en pos de intereses comunes, por la

\footnotetext{
${ }^{34}$ Porter. Op. cit., página 207.
} 
atracción de recursos desde otros sectores menos atractivos o por los vínculos comunitarios que se tejen desde un agrupamiento entre personas e intereses de una misma región. Todas estas cuestiones generan efectos sinérgicos que contribuyen sin duda a la ventaja competitiva de una nación.

Por su propia naturaleza, un agrupamiento de sectores tiene todas las condiciones para potenciar las relaciones sistémicas que se dan dentro del diamante, extrayendo el mayor valor posible de cada determinante de la ventaja competitiva. En igual sentido, un buen agrupamiento permite un mejor y más oportuno aprovechamiento de las oportunidades generadas por los hechos imprevistos favorables, y una mayor capacidad para reducir las amenazas de los desfavorables. En igual sentido, también genera un más sólido poder de negociación para influir sobre distintas acciones y políticas del Gobierno.

Porter destaca que en su estudio pudo comprobar que los agrupamientos industriales suelen establecerse en regiones geográficas muy limitadas, que concentran a todo un grupo de empresas y sectores industriales y de servicios relacionados en torno a un núcleo territorial común. Esta disposición facilita la formación de una red de relaciones que supone ser el principal sustento del funcionamiento del diamante. En palabras del autor, "la concentración geográfica de las empresas en sectores que han alcanzado el éxito internacional se produce frecuentemente debido a la influencia de cada uno de los determinantes del diamante y a su mutuo reforzamiento, que se ven potenciados por la estrecha proximidad geográfica dentro de una nación". ${ }^{35}$

\section{DEgRADACIÓN DE LA VENTAJA COMPETITIVA Y PERDIDA DE COMPETITIVIDAD}

Como no todo es creación y sostenimiento de ventaja competitiva, Porter identifica puntuales causas generadoras de un proceso regresivo de pérdida de competitividad. Esto ocurre cuando determinadas circunstancias generan que el diamante comience a funcionar "en sentido inverso", diluyendo su potencialidad para generar ventaja tanto por la desactivación de su condición sistémica virtuosa como por la desintegración de

\footnotetext{
${ }^{35}$ Porter. Op. cit., página 215.
} 
los agrupamientos. Según Porter, las causas de pérdida de ventaja competitiva suponen una cuestión necesaria de ser controlada en forma permanente, a fin de evitar que sea muy tarde para corregir algo cuando se comience a percibir el inicio de un círculo vicioso sobre el funcionamiento del diamante.

Las causas de pérdida de competitividad identificadas por Porter son:

- Deterioro en la condición de los factores. Proceso por el cuál el sector económico deja de tener la condición de generar y enriquecer sus factores de producción, por determinadas razones: pérdida de capacidad de innovación, reducida inversión en creación de factores, disminución en la calidad de los mismos, incrementos de costos, etc.

- Disparidad entre las necesidades locales y la demanda mundial. Aquí el proceso degenerativo se dispara cuando comienza a crearse una brecha entre las exigencias y/o características de los consumidores locales (la demanda doméstica) y los de otras naciones (demanda internacional). Esto revierte el proceso virtuoso por el cuál la demanda interna debe traccionar a la internacional en pos de crear ventaja competitiva.

- Los consumidores locales dejan de ser exigentes. Una razón hasta complementaria de la anterior, ya que ahora la demanda interna no sólo se disocia de la internacional sino que comienza a perder impulso, transformándose en una fuerza que pierde la capacidad de generar los procesos de innovación en la oferta que siempre ayudan a impulsar la ventaja competitiva.

- El cambio tecnológico lleva a apremiantes desventajas en factores especializados o a la necesidad de nuevos sectores de apoyo de los que se carece. Se trata en este caso de un proceso degenerativo a raíz de las consecuencias sufridas por cambios profundos en las tecnologías base de los procesos productivos, que pueden llegar a desposicionar a los sectores económicos creándoles necesidades urgentes de dominar nuevas tecnologías y de desechar parte de las que hasta ese momento dominaban, con la exigencia adicional de tener que crear nuevas redes de sectores 
conexos y de apoyo. Tal esfuerzo, demasiado exigente, puede provocar sin más la pérdida total de ventaja competitiva por parte de los sectores afectados.

- Determinados objetivos de rentabilidad afectan el ritmo de inversiones necesarias para mantener ventajas competitivas. En este caso se trata de una readecuación de objetivos, primando los que implican rápidos retornos sobre inversiones en desmedro de objetivos estratégicos con retornos de lenta maduración, pero necesarios para crear los cimientos de una ventaja competitiva sólida. Una rápida readecuación de objetivos en este sentido puede generar una igualmente veloz e inevitable pérdida de competitividad.

- Pérdida de flexibilidad para adaptarse a entornos cambiantes. Una razón que afecta a todo el diamante, referida a la incapacidad que pueden llegar a mostrar las empresas del sector competitivo para acomodarse a nuevas condiciones surgidas en sus escenarios inmediatos o generales. El resultado de un proceso así: una sostenida pérdida a lo largo del tiempo de la capacidad para generar ventaja competitiva.

- Descenso en la rivalidad doméstica de las empresas. Siendo la rivalidad entre empresas de un mismo sector uno de los impulsores más potentes de la ventaja competitiva del mismo, esta se degradará por cualquier cuestión que reduzca tal grado de rivalidad. Al disminuir la rivalidad entre empresas el sector económico pierde el acicate para los procesos de innovación y mejora continua, degradando la condición de todo el diamante competitivo. Las causas de disminución en el grado de rivalidad pueden ser varias, entre ellas, la dominación del sector por parte de uno o dos actores, las prácticas colusivas que atentan contra la competencia, las estrategias empresarias de fusiones y adquisiciones, la instrumentación de políticas de Estado proteccionistas respecto de sectores ineficientes o el éxito económico sostenido de todo un sector que "adormece" las capacidad de innovación y mejora. 


\section{Consideración final sobre la contribución de Porter}

Para concluir el marco teórico del presente trabajo de tesis, se presentará en el siguiente apartado una breve muestra de algunos de los autores que han hablado de competitividad en los últimos veinte años. Muchos de ellos han tomado a la obra de Porter como punto de partida, o bien para criticarla, o bien para enriquecer algunos de sus conceptos. Durante este lapso de tiempo es plena la vigencia que ha mantenido la contribución de Porter al concepto de competitividad de una nación, prueba de ello es que La ventaja competitiva de las naciones sigue siendo hoy en día una obra de ineludible referencia para toda consulta o estudio sobre el tema. Entonces, y ya para cerrar su tratamiento, se enunciarán a continuación algunos de los conceptos fuertes que nos ha dejado:

- Con La ventaja competitiva de las naciones Porter cierra su trilogía fundamental iniciada con la publicación previa de Estrategia competitiva y Ventaja competitiva, logrando amalgamar en un mismo cuerpo teórico todo lo referente a la competitividad empresaria y a la competitividad de una nación y de sus sectores industriales.

- El esquema de los cuatro determinantes de la ventaja competitiva de una nación supone una herramienta poderosa para poder indagar en los fundamentos de la ventaja competitiva de una nación.

- El esquema se completa con la consideración de dos factores adicionales que influyen sobre los cuatro determinantes. Estos son, el rol de la casualidad y el papel que le incumbe al Gobierno.

- Sobre la casualidad, es muy acertada la consideración por la trascendencia que determinados hechos imprevistos, que escapan a cualquier escenario de planeamiento, pueden tener como puntos disruptivos que provocan cambios profundos en la naturaleza de un sector económico. Respecto del Gobierno, si bien Porter no deja de considerarlo, es cierto que parece no otorgarle el papel realmente trascendente que tiene como gestor de políticas económicas e industriales de indudable trascendencia para la ventaja competitiva. 
- Considerando en conjunto todos los elementos (los cuatro determinantes y los dos factores de influencia), aparece el concepto de diamante de la competitividad, por el que se alcanza un grado de análisis superior al permitir relevar el proceso mediante el cuál una nación logra construir y mantener en el tiempo determinada ventaja competitiva.

- En sentido inverso, la consideración de los determinantes, los factores influyentes y el funcionamiento del diamante permite explicar también porqué algunos países no logran sobresalir en el contexto competitivo internacional, ya sea por no poder crear ventaja competitiva alguna o bien porqué, luego de poseerla, no la han podido mantener.

- Porter otorga especial consideración a los agrupamientos industriales como fundamento de una ventaja competitiva nacional. Su descripción de cómo se forma y potencia un agrupamiento entre empresas de un sector y sus sectores proveedores, conexos y de apoyo ha sido gran referencia todo este tiempo y la base de muchas investigaciones posteriores.

- Paralelo a ello, la idea de alta concentración geográfica de los agrupamientos permite análisis detallados que son útiles para explicar la potencialidad de determinadas regiones dentro de una nación, de cara a la generación de ventajas competitivas en sectores industriales específicos.

- Por último, es bueno destacar la numerosa evidencia empírica en la obra de Porter, de utilidad para analizar en forma comparativa la historia y el desempeño competitivo de naciones con distintos grados de desarrollo.

\subsubsection{TEORÍAS MODERNAS SOBRE COMPETITIVIDAD: ENFOQUES POSTERIORES AL MODELO DE PORTER}

Luego de presentar una evolución histórica del concepto de competitividad y detenerse con cierto detalle en el análisis del modelo de Porter, es momento de cerrar 
el marco teórico de referencia del presente trabajo de tesis presentando alguno de los enfoques que en estos últimos veinte años han contribuido a un entendimiento más profundo de la temática. Sin intención de agotar la mención a estos enfoques, sólo se traerá a cuenta las propuestas sobre Los desafíos de la competitividad de Benjamín Coriat, El doble diamante generalizado de Moon, Rugman y Verbeke, Los nueve factores de la competitividad de Cho y La competitividad sistémica del Instituto Alemán del Desarrollo.

\section{Relevancia del rol del Gobierno en Benjamin Coriat}

Al momento de analizar la ventaja competitiva nacional Benjamín Coriat ${ }^{36}$ le atribuye un papel superlativo al rol que desempeña el Gobierno, lejos de la consideración como factor de mero "acompañamiento" de los cuatro determinantes que Porter le atribuye en su esquema de diamante.

En su concepción de la competitividad, Coriat distingue entre ventajas estáticas y ventajas dinámicas. Las primeras, más emparentadas con las ventajas comparativas de la teoría clásica (recordar lo visto para Ricardo); mientras que las segundas, más cerca de la moderna postura de Porter. Para Coriat, las ventajas realmente relevantes para la competitividad de un país son las dinámicas, que son las que se obtienen luego de un proceso deliberado de agregación de valor económico sobre los recursos productivos de que dispone una nación. En la construcción de estas ventajas dinámicas participa todo el conjunto de la economía con cada una de sus partes o con cada uno de los actores económicos haciendo su aporte de agregación de valor en una actitud proactiva de construcción, lejos de la pasividad que podría verse en las economías que sustentan su crecimiento en la utilización de ventajas estáticas, sobre recursos heredados, sin mayor agregación de valor.

En este marco es en el que Coriat define la trascendencia que en la construcción de las ventajas dinámicas tiene la política industrial, a cargo, indudablemente, del Estado.

\footnotetext{
36 BENJAMÍn CORIAT. Los desafíos de la competitividad. Asociación Trabajo y Sociedad, Oficina de Publicaciones del CBC, Universidad de Buenos Aires (1997).
} 
Para él, es el Estado y no las empresas el que diseña, instrumenta e impulsa la política industrial, obviamente que no en un contexto aislado, sino en un entramado en el que deben participar todos los actores, pero para el que debe reservarse, se insiste, un papel central a cargo del Estado. En palabras del autor, "a partir del momento en que las verdaderas ventajas competitivas de largo plazo son aquellas que han sido socialmente construidas, hace falta una política industrial". Y este es el punto a resaltar: según Coriat, para hacer posible la creación y sostenimiento de ventaja competitiva (obviamente que siempre se habla de ventajas "dinámicas") es imprescindible la existencia de una política industrial determinada en ese sentido y que resulte efectiva, la que por su parte sólo es posible si están dadas las condiciones macroeconómicas y estructurales mínimas necesarias para ello. Con esta lógica, se revierte en parte la ponderación de cada elemento del diamante competitivo, ya que pasa a ser central la consideración del Gobierno como actor de relevancia y ya no sólo como "asistente" o "facilitador" de los cuatro determinantes según el esquema de Porter.

Siempre según Coriat, las condiciones macroeconómicas y estructurales mínimas estarán determinadas por cómo sea el escenario competitivo respecto de elementos como las reglas fiscales y los gastos presupuestarios, la protección aduanera, las tasas de cambio y de interés, y las políticas referidas al trabajo, los salarios, la educación y la distribución del ingreso. Estas condiciones delimitan la capacidad de un Gobierno para instrumentar determinada política industrial que favorezca la creación de ventaja competitiva, a partir de dos grandes orientaciones: a) la de crear un entorno favorable para las empresas, lo que tiene que ver con los bienes colectivos, las infraestructuras, la educación, la investigación, los procesos de innovación, etc.; y b) la de modificar de manera deliberada las asignaciones que espontáneamente haría el mercado sobre los recursos generadores de riqueza y de ventaja competitiva.

Además, para la instrumentación de la política industrial desde las dos orientaciones, Coriat expone tres tipos posibles de "actitudes" que puede seguir un Gobierno, complementarias ellas y referidas a la necesidad de acompañar a las empresas creando escenarios adecuados para que canalicen sus iniciativas, impulsar a las empresas emergentes o con falencias puntuales para que puedan reorientar $y$ 
concentrar sus esfuerzos, y anticipar cambios en la estructuración de escenarios futuros, moldeando el diseño de los mismos con las herramientas que suponen ser las políticas de Estado.

En conclusión, propuestas como la de Coriat no están reñidas con la de Porter, pero sí revierten enteramente la ponderación que entre los factores del diamante se le otorga al papel del Gobierno.

Figura 5. La generación de ventaja competitiva en Coriat

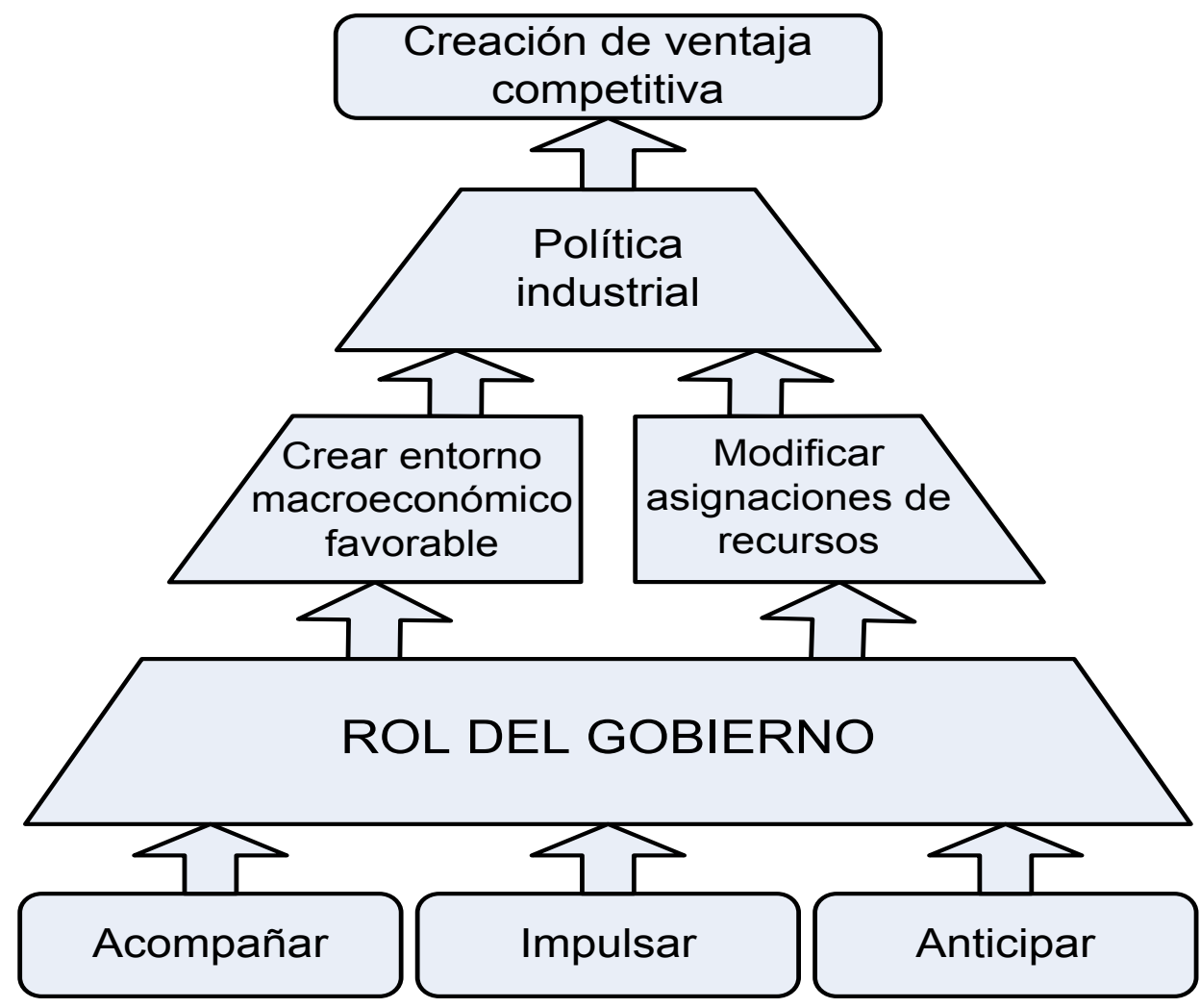

Fuente: Elaboración propia

\section{El doble diamante generalizado de Moon, Rugman y Verbeke}

Ante los primeros planteamientos al modelo de Porter sobre cierta limitación para explicar los determinantes de la ventaja competitiva cuando de economías pequeñas se tratara (partiendo del supuesto que el modelo estaba basado en evidencia empírica sólo de economías grandes, desarrolladas), aparece el enfoque de Moon, Rugman y 
Verbeke ${ }^{37}$, conocido como El modelo de doble diamante generalizado. En principio, el nuevo enfoque no implica un aporte muy innovador sobre el modelo de Porter, pero bien puede considerarse que lo complementa, al plantear la lógica sistémica del diamante desde una perspectiva combinada "local-global". Si el modelo de Porter supone que la ventaja competitiva hecha raíces primero en el mercado local y luego logra, por la propia lógica del diamante, expandirse al mundo; en el enfoque de doble diamante el apoyo de la ventaja competitiva se plantea desde un inicio por el funcionamiento del diamante tanto en el escenario local como global.

Entonces, mientras que en Porter un sector competitivo siempre explica su rendimiento primero desde su base local para luego expandirse al mundo, en Moon, Rugman y Verbeke el mismo sector se plantea desde el vamos un rendimiento superior fundamentando su ventaja en un ámbito local e internacional al mismo tiempo. Este cambio de enfoque ayudaría así a entender porqué pueden ser competitivos sectores industriales en países de economías pequeñas y no muy desarrolladas, en donde no disponen desde el inicio de una oferta local adecuada de factores, o la demanda doméstica es muy pequeña, o al existir pocas empresas en el sector no se alcanzan a plantear grados de rivalidad de cierta magnitud. En el esquema de Porter, estas últimas cuestiones que son determinantes para la ventaja competitiva se suponen existiendo desde un primer momento en el entorno doméstico de las empresas.

Gráficamente, el enfoque del doble diamante generalizado puede verse así:

\footnotetext{
${ }^{37}$ MOON, H.C, RUGMAN, A. y VERBEKE, A. The generalized double diamond approach to international competitiveness. en Alan m. Rugman, editor, research in global strategic management. A Research Annual; (1995). Vol. 5, pp. 97-114.
} 
Figura 6. El doble diamante de Moon, Rugman y Verbeke

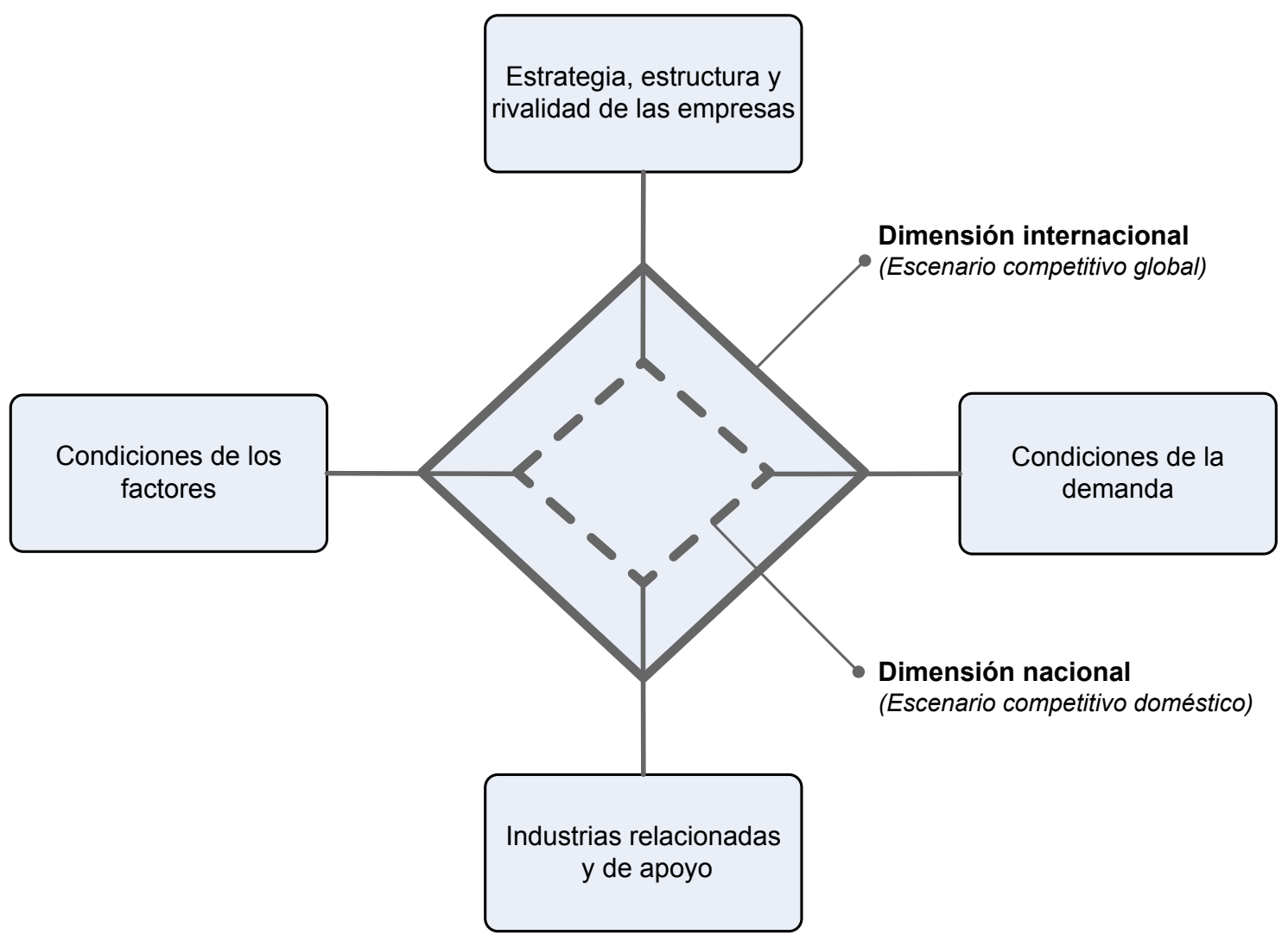

Fuente: Elaboración propia

En la figura puede apreciarse la presencia de los determinantes de la ventaja competitiva ya vistos en Porter, pero ahora interactuando, al mismo tiempo, en una dimensión nacional y en una internacional. En principio, el esquema plantea una dimensión internacional con condiciones "fijas", pero no porque estas realmente lo sean, sino porque se supone que un sector industrial que esté construyendo su ventaja competitiva desde la base de una economía doméstica pequeña no tiene gran capacidad de poder influir o moldear las condiciones del entorno internacional. Esta característica de "condiciones fijas" se representa en la figura por la línea continua de la dimensión internacional, la que sugiere "estabilidad", "no cambio".

Por el contrario, la dimensión nacional debe entenderse como más variable, más cambiante, lo que está visto en la figura por la línea discontinua del rombo interior que representa esta dimensión. La condición de "variable" de la dimensión nacional se explica por la mayor probabilidad de turbulencias de un escenario competitivo 
doméstico, en donde los distintos sectores que pueden estar analizándose tienen alta capacidad para diseñarlo y para influir en él de acuerdo a su necesidades. Esto último se magnifica al considerar economías pequeñas (objeto de análisis predominante en el enfoque de diamante ampliado), en las que las empresas y sectores que logran detentar ventaja competitiva suelen ser "actores de peso".

Si bien lo propuesto por Moon, Rugman y Verbeke resulta ser un aporte útil con aquello de considerar en forma simultánea la dimensión local y la global, el modelo de diamante ampliado, a pesar de la gran difusión y aceptación que ha tenido, no parece ser ni un nuevo cuerpo de conocimiento en si mismo ni ninguna importante innovación respecto de lo ya planteado por Porter en su tradicional modelo.

\section{Los NUeVe factores de CHO}

El enfoque de los nueve factores propuesto por $\mathrm{Cho}^{38}$ es básicamente una reformulación de los elementos ya propuestos por Porter como determinantes de la ventaja competitiva, pero presentados desde otra perspectiva en cuanto a la ponderación relativa otorgada a cada uno de ellos y a su posición dentro de una estructura funcional que no deja de ser un "diamante". Cho propone nueve factores determinando la capacidad de un país para crear ventaja competitiva, con dos aspectos salientes: la alta ponderación a todo factor relacionado con la disponibilidad y desarrollo de recursos humanos (cuatro de los nueve factores tienen que ver con eso y ocupan una posición central en el esquema), y la alta influencia que le otorga a lo que en Porter es el papel de la casualidad, que para el caso de Cho son los eventos oportunos.

Cho conserva la premisa de Porter en el sentido de que la ventaja competitiva real, la realmente válida y sustentable, es la ventaja "creada", en oposición a la ventaja "heredada", sin participación en su creación de un proceso "humano" de generación de valor. De allí que, independientemente del grado de desarrollo de un país, Cho

\footnotetext{
${ }^{38} \mathrm{CHO}$, D.S. y H.C.,MOON. From Adam Smith to Michael Porter, evolution of competitiveness theory. World Scientific Publishing Co. Pte. Ltd (2000).
} 
supone que todo lo referido a los recursos humanos tendrá siempre el papel estelar al momento de crear ventaja competitiva, porque son esos factores y ese tipo de recursos los que, desde el vamos, no pueden faltar en todo proceso de generación de determinado perfil competitivo.

Respecto de su otro gran foco, los eventos oportunos, bien se puede considerar que se trata de una reformulación del papel asignado al azar o a la casualidad en el esquema de Porter. Pero mientras en éste último tal papel no pasaba de ser accesorio, facilitador o inhibidor de los cuatro determinantes básicos, en el esquema de Cho ahora pasa a ser central. Y porqué: porque es el factor que permite analizar las oportunidades de un país para dar saltos de calidad en su proceso íntegro de creación y sostenimiento de ventaja competitiva. Sea cual sea el grado de desarrollo de un país, las oportunidades para crear ventaja competitiva pueden darse o bien por circunstancias previsibles, planificables, o bien por la ocurrencia de hechos imprevistos, disruptivos, no esperables, que determinan de un momento a otro un importante punto de inflexión en el escenario competitivo.

Gráficamente, el esquema de Cho puede presentarse así: 
Figura 7. Los nueve factores de Cho

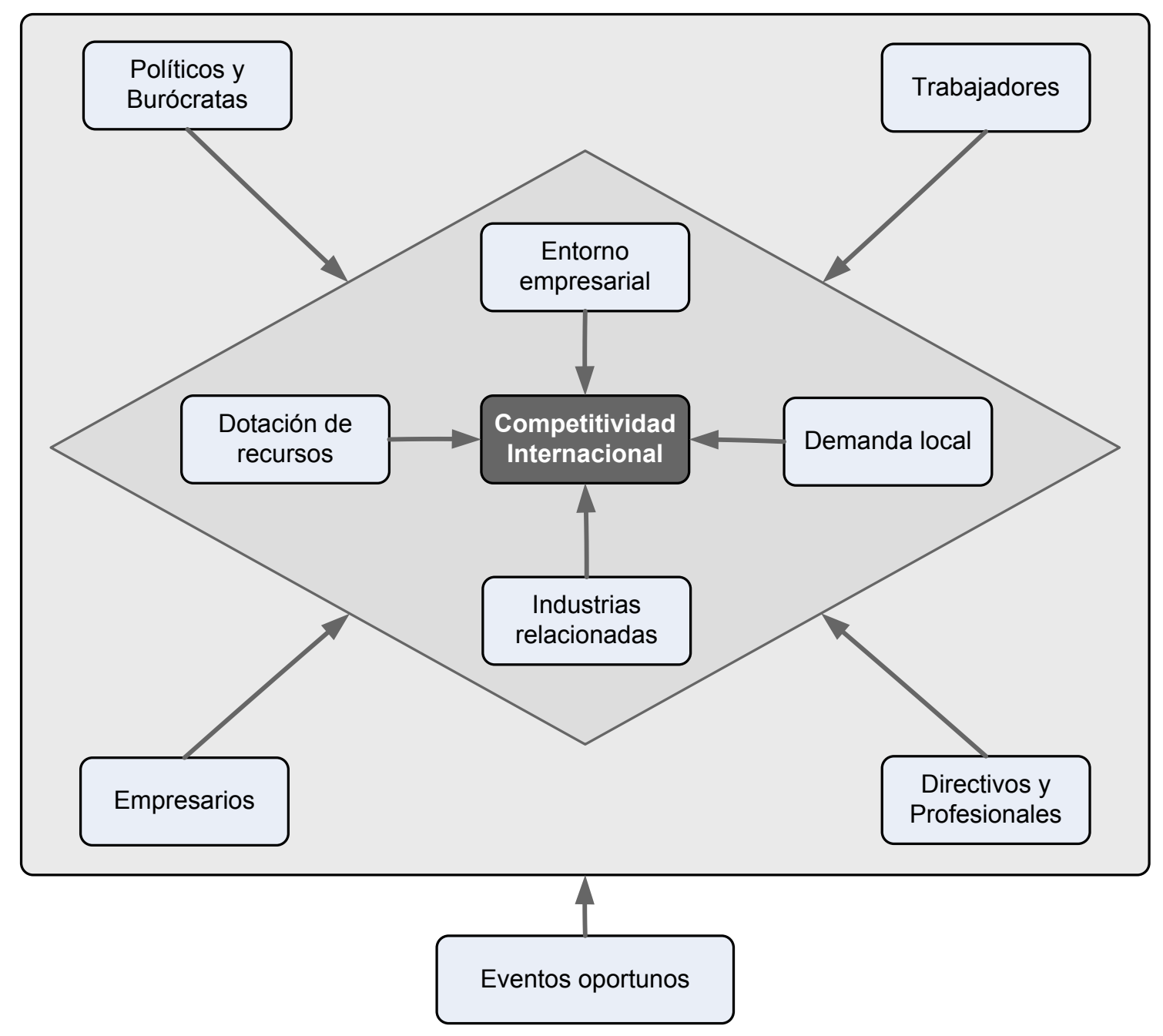

Fuente: Elaboración propia

En la figura vemos como punto central del esquema el gran objetivo: alcanzar un determinado grado de competitividad internacional por medio de la creación de ventajas competitivas sobre determinados sectores industriales de un país, encargados de impulsar el desarrollo de su economía. Luego, en un primer nivel de influencia se encuentran los factores recursos dotados, entorno empresarial, demanda local e industrias relacionadas y de apoyo; que, como puede recordarse, remiten todos ellos a la ya habitual disposición en Porter de los determinantes recursos, demanda, sectores relacionados y contexto para la estrategia y estructura de las empresas. Por lo tanto, hasta aquí no hay grandes aportes de Cho respecto a lo que ya propusiera Porter. 
Sí aparecen las contribuciones al considerar el segundo nivel de influencia sobre el objetivo central de obtener competitividad internacional, en la forma de la ya anticipada reformulación y revalorización de todo factor relacionado con los recursos humanos con que pueda contar un país. En este segundo nivel de influencia se destaca como determinantes de la ventaja competitiva el papel a desempeñar por los políticos y la burocracia gubernamental, por los trabajadores, los empresarios y los directivos y profesionales. Estos actores tendrán -y siempre siguiendo a Cho- distinto grado de injerencia en la formación de un perfil competitivo según sea el grado de desarrollo del país de que trate, pero en ninguna de las fases de desarrollo dejarán de estar presentes.

Por último, y casi sustentando todo el esquema, aparece el factor eventos oportunos, algo así como la "fuente" de oportunidades para que, aplicados los restantes ocho factores de determinada manera, se alcance la tan pretendida competitividad internacional. Los eventos oportunos son vistos entonces por Cho como los eventos puntuales que, apareciendo a raíz de determinada coyuntura, establecen las condiciones en las que luego pueden aplicarse los factores en pos del objetivo madre de crear competitividad.

Como para cerrar la mención al aporte de Cho, y al afirmar que el mismo se basa en una reformulación de los determinantes que considerara Porter, es oportuno presentar lo que sería un "cuadro de equivalencias" entre factores de Cho y determinantes de Porter, o en otros términos, entre modelo de diamante de la competitividad y modelo de los nueve factores. 
Figura 8. Los factores de Cho y los determinantes de Porter

\begin{tabular}{|c|c|c|c|c|}
\hline \multicolumn{4}{|c|}{$\mathrm{CHO}$} & \multirow{2}{*}{$\begin{array}{c}\text { PORTER } \\
\text { Elemento del diamante de Porter }\end{array}$} \\
\hline \multicolumn{2}{|c|}{ Tipo de factor de Cho } & \multicolumn{2}{|r|}{ Factor de Cho } & \\
\hline \multirow{8}{*}{ Internos } & \multirow{4}{*}{ Humanos } & 1 & Políticos y burócratas & Gobierno \\
\hline & & 2 & Trabajadores & Condición de los factores \\
\hline & & 3 & Empresarios & $\begin{array}{l}\text { Estrategia, estructura y rivalidad de las } \\
\text { empresas }\end{array}$ \\
\hline & & 4 & Directivos y profesionales & $\begin{array}{l}\text { Estrategia, estructura y rivalidad de las } \\
\text { empresas }\end{array}$ \\
\hline & \multirow{4}{*}{ Físicos } & 5 & Dotación de recursos & Condición de los factores \\
\hline & & 6 & Entorno empresarial & $\begin{array}{l}\text { Estrategia, estructura y rivalidad de las } \\
\text { empresas }\end{array}$ \\
\hline & & 7 & Demanda local & Condiciones de la demanda \\
\hline & & 8 & Industrias relacionadas & Industrias relacionadas y de apoyo \\
\hline \multicolumn{2}{|c|}{ Externos } & 9 & Eventos oportunos & Azar \\
\hline
\end{tabular}

Fuente: Elaboración propia

\section{La competitividad sistémica de Esser, Hillebrand, Mesner y Meyer-Stamer}

El de competitividad sistémica es un modelo originalmente formulado en el ámbito del Instituto Alemán del Desarrollo por cuatro de sus investigadores: Klaus Esser, Wolfgang Hillebrand, Dirk Mesner y Jürg Meyer-Stamer ${ }^{39}$. En principio, este nuevo enfoque supone un enriquecimiento del modelo de Porter, al considerar en forma adicional a los tradicionales cuatro determinantes de la ventaja competitiva una serie de factores ambientales y socioculturales que se van presentando en distintos niveles de agregación. Luego, la interrelación sistémica entre todos los elementos de los distintos niveles determina la capacidad de una nación para generar ventaja competitiva.

\footnotetext{
39 KLAUS ESSER, WOLFGANG HILLEBRAND, DIRK MESSNER y JÜRG MEYER-STAMER. Competitividad Sistémica.
} Revista CEPAL N 59 (1996). 
Lo innovador de este enfoque está entonces en la consideración tanto de los niveles en que se agrupan los factores como de la interrelación sistémica a través de ellos, y no tanto en los factores en sí mismos, todos los cuales ya eran considerados por Porter. Con el enfoque de competitividad sistémica se ensaya una propuesta similar a la que se viera para Cho y para Moon, Rugman y Verbeke: cambiar la consideración de factores ya considerados por Porter, otorgarles distintas prioridad y analizar su condición y comportamiento bajo distintos estadios de desarrollo de las naciones bajo estudio.

En concreto, el enfoque de la competitividad sistémica consiste en el planteamiento de que la competitividad de un país está determinada desde un punto inicial en un nivel micro, dado por la consideración estricta de sólo el desempeño de las empresas, hasta un nivel meta, el de máximo grado de abstracción y reservado para el trazado de los lineamientos fundamentales bajo los cuales se asignan los recursos y se encaminan los esfuerzos de toda la economía nacional.

Entonces, bajo este enfoque, existe un nivel micro económico que es punto de partida de la competitividad sistémica, y que tiene que ver con el entorno inmediato en el que las empresas deben poder desarrollar cuatro factores necesarios para alcanzar la competitividad: eficiencia en costos, calidad en el proceso productivo, diversidad de productos y capacidad de respuesta estratégica. Para esto, deben intervenir en forma permanente en una lógica de mejora continua de sus procesos organizacionales y de desarrollo de productos. Las empresas que mejor puedan manejar estos factores serán las más "preparadas" a nivel micro para constituir auténticos agrupamientos industriales, siendo estos la base de sustentación del siguiente nivel considerado por la competitividad sistémica, el nivel meso económico.

El nivel meso económico es aquél en el que toman forma y se fortalecen los agrupamientos industriales, siendo el corazón de estos las empresas de mejor desempeño que son el objeto del nivel micro. Y si las empresas son el "corazón" de los agrupamientos, las redes de relaciones que se tejen en torno a ellas son las "arterias" que le dan vida a la competitividad sistémica de una nación. En este nivel meso se cohesionan las empresas con todos sus sectores conexos y de apoyo, tejiendo la necesaria red de infraestructura física (puertos, redes ferroviarias y de carreteras, 
telecomunicaciones, sistemas de abastecimiento y eliminación de residuos) y de estructuras intangibles (sistemas educativos, políticas industriales activas, políticas selectivas de comercio exterior). El nivel meso toma características propias de un ámbito nacional o regional, que se van moldeando con el funcionamiento de la red de redes a lo largo del tiempo. Esto hace que la naturaleza del nivel meso en la competitividad sistémica no sea fácilmente transferible entre una y otra nación.

El nivel macro económico de la competitividad sistémica aborda los elementos necesarios para lograr un buen perfil competitivo por medio de una efectiva asignación de los recursos en la economía de una nación, para lo que resulta clave la existencia de eficientes mercados de bienes, de factores y de capital. El macro es el nivel en donde, en términos de Porter, es crítico el rol desempeñado por el Gobierno, ya que es el referido a todo el conjunto de políticas monetarias, fiscales, presupuestarias, de competencia, de tipo de cambio y el marco normativo que hace al funcionamiento del Estado y a la justicia.

Por último, el nivel meta económico se impone como los "cimientos" de los restantes niveles y de toda la competitividad sistémica, al suponer el gran lineamiento estratégico de un país, analizando la capacidad de los agentes a nivel local, regional y nacional para crear las condiciones favorables para el desarrollo económico y social. Implica la necesidad de alcanzar, por una lado, un consenso generalizado y con cierta permanencia en el tiempo respecto del tipo de modelo de desarrollo a seguir; y por otro, la necesidad de asegurar la debida separación institucional entre los roles del Estado, las empresas privadas y las organizaciones intermedias. En otros términos, el nivel meta de la competitividad sistémica supondría la generación y mantenimiento en el tiempo de las grandes creencias-guía de toda una nación, pilar fundamental de su posición competitiva.

Para concluir con su tratamiento, valga la presentación del siguiente esquema gráfico de los cuatro niveles de la competitividad sistémica: 
Figura 9. Los niveles de la competitividad sistémica

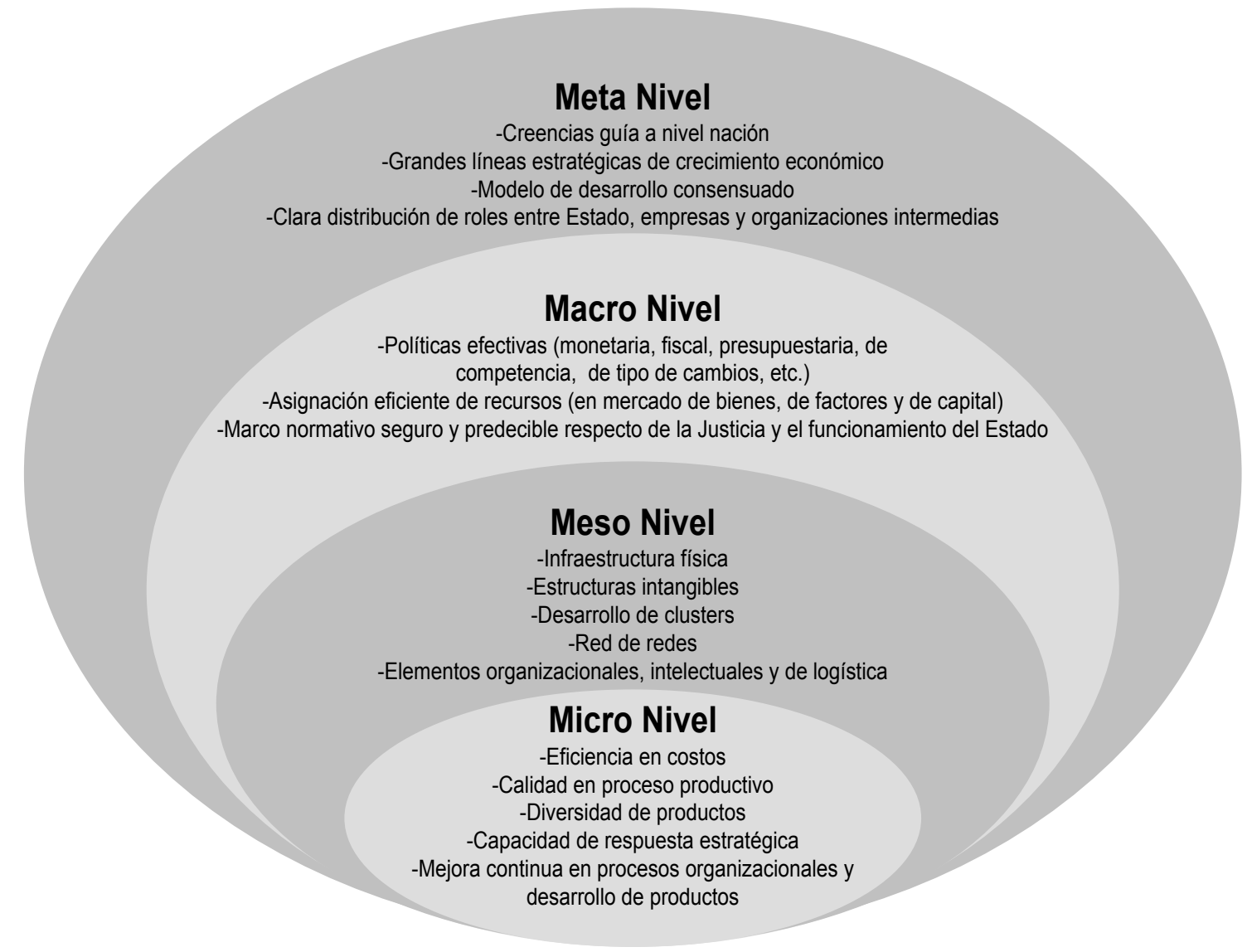

Fuente: Elaboración propia

\section{Metodología de LA INVESTIGACión}

\subsection{POBLACIÓN Y MUESTRA}

La población elegida para la fase de relevamiento de información primaria estuvo conformada por directivos de medianas y grandes empresas químicas de las ciudades de La Plata, Berisso y Ensenada. Se buscó de esta manera acceder al conocimiento que sobre el contexto económico, social y político de la región tienen aquellos que comandan los destinos de empresas de cierta envergadura, intentando obtener así una 
buena "radiografía" sobre el perfil competitivo del sector a partir de datos aportados por quienes en parte lo determinan.

Yendo a las cuestiones técnicas, puede decirse que el tamaño de la población (N) surgió de los padrones de contribuyentes de la Tasa de Seguridad e Higiene de las municipalidades de La Plata, Berisso y Ensenada. La Tasa de Seguridad e Higiene es el tributo -del ámbito municipal- que estratifica a las empresas contribuyentes en función del tamaño que tengan, considerando para ello sus niveles de facturación anuales. Esta estratificación es la que permitió para nuestro caso identificar a las medianas y grandes empresas mencionadas en el párrafo anterior.

Resulta oportuno aclarar que el relevamiento de información para el presente trabajo de tesis fue parte del relevamiento general para el proyecto global de investigación sobre La competitividad empresarial y su impacto regional, ya mencionado en el apartado 4. Alcances de la investigación; por lo que, como presentación en detalle de todo lo referido a metodología de la investigación, se presenta de aquí en más lo referido a todo el proyecto de investigación y no sólo a la parte del sector de empresas químicas.

Entonces, para el proyecto global se consideraron sectores industriales de acuerdo a la Clasificación Internacional Industrial Uniforme (CIUU). Resultando éstos los elegidos:

- Productos alimenticios, bebidas y tabaco

- Textiles y cueros

- Industria de la madera

- Imprentas y editoriales

- Sustancias químicas

- Productos minerales no metálicos

- Metálicas básicas

- Productos metálicos, maquinarias y equipos

Con el objetivo de lograr una mejor representatividad de las fuerzas productivas de cada uno de los sub-sectores en que se dividen las industrias según CIIU, la muestra 
fue estratificada proporcionalmente en dichos sub-sectores económicos, según la participación de cada uno, acorde con diversas variables. Finalmente, dentro de cada uno de esos sub-sectores, se realizó una selección al azar de empresas, utilizando una tabla de números aleatorios creada a través de Microsoft Excel (adicionalmente se seleccionaron de la misma manera empresas de reemplazo para cubrir errores y duplicaciones de los padrones).

El tamaño de la muestra se calculó a través de la fórmula de muestreo de proporciones con «N» conocido:

$$
n=\frac{Z_{\alpha}^{2} \cdot N \cdot p \cdot q}{e^{2} \cdot(N-1)+Z_{\alpha}^{2} \cdot p \cdot q}
$$

Donde:

$\mathrm{N}=318$ empresas (tamaño de la población)

$\mathrm{p}=$ prevalencia esperada del parámetro a evaluar, que en caso de desconocerse, se aplica la opción más desfavorable $(p=0,5)$, que hace mayor el tamaño muestral

$\mathrm{q}=$ complemento de la prevalencia esperada del parámetro a evaluar, es decir $1-p=0,5$

$\mathrm{Z}=1,96$ para $\alpha=5 \%$, o sea un nivel de confianza del $95 \%$

$\mathrm{e} \quad=8,95 \%$ error de muestreo

$\mathrm{n}=67$ empresas a encuestar (tamaño de la muestra)

Esta muestra se dividió entre todos los sub-sectores industriales, para lo cual, además de la cantidad de empresas, se consideraron otras variables tales como "cantidad de 
empleados por empleador" y "facturación anual promedio por empleado", en su calidad de indicadores de eficiencia ${ }^{40}$.

Tabla 1. Distribución de encuestas

\begin{tabular}{|c|c|c|c|c|c|c|}
\hline Sub.sector & $\begin{array}{c}\text { Cantidad } \\
\text { de } \\
\text { empresas }\end{array}$ & $\begin{array}{l}\text { Cantidad de } \\
\text { Empleados } \\
\quad \text { por } \\
\text { Empleador }\end{array}$ & $\begin{array}{l}\text { Facturación } \\
\text { Anual } \\
\text { promedio } \\
\text { por } \\
\text { empleado }\end{array}$ & $\begin{array}{l}\text { Encuestas } \\
\text { a realizar }\end{array}$ & $\begin{array}{c}\text { Encuestas } \\
\text { logradas }\end{array}$ & Diferencias \\
\hline $\begin{array}{l}\text { Productos Alimenticios, bebidas y } \\
\text { tabaco }\end{array}$ & 143 & 17,1 & $34.284,4$ & 23 & 22 & -1 \\
\hline Textiles y Cueros & 14 & 17,2 & $12.399,2$ & 4 & 6 & 2 \\
\hline Industria de la Madera & 9 & 7,6 & $8.792,7$ & 2 & 2 & 0 \\
\hline Imprentas y Editoriales & 27 & 15,9 & $21.693,2$ & 6 & 6 & 0 \\
\hline Sustancias Químicas & 29 & 23,4 & $40.796,6$ & 9 & 11 & 2 \\
\hline Productos Minerales No Metálicos & 25 & 24,0 & $38.193,1$ & 8 & 9 & 1 \\
\hline Metálicas Básicas & 3 & 10,8 & $19.600,0$ & 3 & 1 & -2 \\
\hline $\begin{array}{l}\text { Productos Metálicos, Maquinarias } \\
\text { y Equipos }\end{array}$ & 68 & 11,1 & $20.853,6$ & 12 & 10 & -2 \\
\hline Totales & 318 & & & 67 & 67 & 0 \\
\hline $\begin{array}{l}\text { Coeficientes de correlación con } \\
\text { "Empresas" }\end{array}$ & 1 & 0,10517542 & 0,40151238 & & & \\
\hline $\begin{array}{l}\text { Proporción por coeficiente de } \\
\text { correlación }\end{array}$ & $66,4 \%$ & $7,0 \%$ & $26,6 \%$ & & & \\
\hline
\end{tabular}

Fuente: elaboración propia

Cabe destacar que las diferencias entre "encuestas a realizar" y "encuestas logradas" en los casos "en menos"- ha obedecido a la persistente negación de algunas empresas en contestar al requerimiento de información, incluso agotando la instancia prevista antes de iniciar la fase de realización de encuestas de utilizar empresas "suplentes"

40 Lauría, Daniel y otros (2011) "Caracterización Productiva Regional La Plata - Berisso - Ensenada 2010", La Plata, MBA - FCE - UNLP en http://www.mba.econo.unlp.edu.ar 
extraídas también de las nóminas provistas por los tres municipios. Esto hizo que se procediera a una reasignación por sub-sectores durante el "operativo de campo".

\subsection{TIPO DE INVESTIGACIÓN}

La investigación realizada se trató de una de tipo explicativo, toda vez que los resultados generaron un sentido de entendimiento del fenómeno de la competitividad regional que estaba bajo estudio, y de los fundamentos y las causas de los determinantes que, a nivel regional, impulsan o degradan la capacidad de generar ventaja competitiva.

\subsection{TÉCNICAS DE RECOLECCIÓN DE DATOS}

Los datos fueron relevados en base a la encuesta original del Índice de competitividad de los negocios del Foro Económico Mundial (Executive Opinion Survey). Se trata de una encuesta con cincuenta y siete preguntas principales y cuatro adicionales referidas a las características propias de cada empresa relevada. Fue respondida en cada caso por los propietarios, gerentes o principales responsables de las firmas que formaron parte de la muestra, quienes debieron calificar cada una de las cincuenta y siete preguntas en una escala de uno a siete puntos (siendo uno la peor calificación para cada variable y siete la mejor).

\section{LA ENCUESTA SOBRE INDICE DE COMPETITIVIDAD DE LOS NEGOCIOS EN DETALLE}

La encuesta comprende dos grandes categorías: Operaciones y estrategias de las empresas y Ambiente de negocios. A su vez, cada categoría incluye numerosos indicadores -todos ellos con posibilidad de ser calificados de uno a siete- en base al siguiente detalle:

A) Operaciones y Estrategias de las Empresas 
Es la primera de las dos categorías que componen la encuesta. Es la que más relación tiene con el "puertas adentro" de las empresas, o en forma similar, con una visión "micro" de los sectores industriales. Cuenta con quince indicadores; a saber:

1. Sofisticación del proceso de producción (relacionado con el nivel de tecnología implicada en los procesos de producción).

2. Naturaleza de la ventaja competitiva (relacionado con la forma en que fundamentan su ventaja competitiva las empresa; esto es, si lo hacen por bajo costo o por productos y procesos únicos, innovadores).

3. Grado de capacitación del personal (atinente a los niveles de inversión y el foco que puedan poner las empresas en formación y desarrollo de sus recursos humanos).

4. Grado de enfoque hacia el mercado (indicador relacionado con el enfoque que tengan los sectores y las empresas hacia la función de comercialización de sus productos y servicios).

5. Disposición a delegar autoridad (tiene relación con las políticas de recursos humanos y el tema puntual de la capacidad de las empresas a delegar autoridad).

6. Capacidad de innovación (referido a cómo obtienen las empresas la tecnología que utilizan en sus procesos productivos; es decir, si incorporan tecnología de fuentes externas o tienen alguna capacidad de desarrollarla internamente)

7. Presencia de la cadena de valor (relacionado con el nivel de integración que tengan las empresas a lo largo de toda la cadena de agregación de valor entre insumos y producción y comercialización de productos y servicios).

8. Amplitud de los mercados internacionales (grado de alcance y penetración de las empresas en los mercados del exterior; en otras 
palabras, capacidad para acceder y diversificar sus mercados de exportación).

9. Originalidad en el diseño de productos (capacidad de las empresas para generar diseños y patentes propias o necesidad de recurrir siempre a la imitación o la obtención de permisos sobre diseños ajenos).

10. Grado de orientación al consumidor (referido a la capacidad de las empresas y al enfoque que muestren para detectar y satisfacer los deseos y necesidades de los consumidores).

11. Control de la distribución internacional (nivel de presencia de las empresas locales en las fases de distribución hacia los mercados de los distintos productos).

12. Extensión de la política de marcas (capacidad de las empresas para generar valor intangible en sus productos, generando marcas que puedan evitar comercializar sólo productos indiferenciados).

13. Soporte en la administración profesional (indicador relacionado con la profesionalización del management de las empresas, en oposición al copamiento de posiciones ejecutivas por parte de familiares, amistades, etc.).

14. Grado de compensación por incentivos (otro indicador relacionado con las políticas de recursos humanos, en este caso referido a si las empresas sólo compensan con salarios o bien hacen uso de incentivos monetarios que promuevan un elevado desempeño de su personal y equipo directivo).

15. Nivel de ventas a países de la región (relacionado con el comercio exterior a los países más cercanos, que habitualmente son socios comerciales o en donde se generan intentos de mercados comunes y demás). 


\section{B) Ambiente de Negocios.}

Es la segunda de las dos categorías que componen la encuesta. Agrupa a los indicadores mas relacionados con el "afuera" de las empresas, con el entorno en el que desempeñan su actividad, con los factores más "macro". A su vez cuenta con cuatro subdivisiones que en general respetan el tradicional diamante de Porter ya presentado en apartados anteriores (condiciones de los factores, condiciones de la demanda, industrias relacionadas y de apoyo y contexto para la estrategia y competencia de las empresas). En conjunto, toda la categoría de Ambiente de negocios cuenta -agrupados en las cuatro subdivisiones- con un total de cuarenta y dos indicadores (los que sumados a los quince de la primera categoría alcanzan el total de cincuenta y siete indicadores con que cuenta toda la encuesta). Son éstos:

B-1) Condiciones de factores de producción

1) Infraestructura física (con siete indicadores referidos al grado de desarrollo de la infraestructura general de la región y de las más particulares que hacen estado de las rutas, las vías férreas, los puertos, el transporte aéreo, la calidad de las líneas telefónicas y la penetración y velocidad de acceso a internet).

2) Infraestructura administrativa (con cuatro indicadores sobre si es débil o estricta la defensa de la propiedad intelectual, sobre si es realmente independiente la Justicia, sobre si son sencillos o muy engorrosos los trámites necesarios para iniciar un nuevo negocio, y cuánto tiempo en porcentajes estimados- debe dedicar la alta gerencia de las empresas a cumplir con las exigencias de los distintos niveles de la burocracia gubernamental).

3) Recursos humanos (con un par de indicadores que indagan sobre la calidad educativa en los niveles iniciales de la escuela pública y en los 
mucho más específicos relacionados con las escuelas de negocios donde se forman los cuerpos directivos).

4) Infraestructura tecnológica (tres indicadores referidos al grado de disponibilidad de científicos e ingenieros, a la calidad de los centros o institutos dedicados a la investigación científica y al grado de desarrollo de vínculos de colaboración entre empresas y universidades en pos de profundizar las tareas de investigación y desarrollo).

5) Mercado de capitales (cuatro indicadores sobre la facilidad de acceso a préstamos que puedan financiar nuevos proyectos, sobre el nivel de sofisticación del mercado financiero en cuanto a la proliferación de instrumentos de financiamiento, sobre el acceso al mercado de capitales y la factibilidad de emitir acciones o bonos, y sobre la disponibilidad de acceso a otros capitales de riesgo que puedan financiar proyectos).

B-2) Condiciones de la demanda

1) Sofisticación de los compradores (indicador referido al nivel de exigencia de la demanda que afrontan las empresas, dependiendo de si los consumidores son poco sofisticados y tienen comportamiento de consumo sólo basados en el precio o por el contrario analizan la oferta en función de criterios más elaborados como nivel de innovación, atributos ofrecidos, promesa simbólica de las marcas, etc.).

2) Presencia de normas regulatorias de la demanda (indicador que indaga sobre la presencia y el nivel de exigencia de normas y regulaciones referidas a, por ejemplo, el consumo de energía en los procesos productivos, los niveles de seguridad exigidos a los productos, etc.).

3) Rigurosidad de las regulaciones medioambientales (indicador similar al anterior pero enfocado a la consideración de todo el impacto ambiental de los procesos de producción y de los productos). 
4) Adquisición gubernamental de productos de tecnología de avanzada (considerando la trascendencia en la economía de una nación o de una región de las compras por parte de la administración gubernamental, indaga sobre el grado de sofisticación de este demandante puntual, en forma similar, pero para el gobierno, a lo expresado para el indicador Sofisticación de los compradores).

5) Leyes relacionadas al uso de las tecnologías de información y comunicación (último indicador del apartado sobre la demanda y que se relaciona con los sofisticado o no que sea el marco jurídico en todo lo atinente a comercio electrónico, firmas digitales, fraudes informáticos, etc.).

B-3) Industrias relacionadas y de apoyo

1) Calidad de los proveedores locales (indicador sobre lo eficiente, lo competitivos y lo confiables que puedan llegar a ser los proveedores de insumos de las empresas del sector industrial objeto de estudio).

2) Cantidad proveedores locales (en parte relacionado con el indicador anterior, pero que indaga sobre la cantidad de proveedores disponibles y la capacidad que tengan para proveer la mayor cantidad de insumos que requieren las empresas).

3) Estado de desarrollo de los agrupamientos industriales (indicador que indaga sobre la existencia y el grado de desarrollo que puedan tener lo que habitualmente se conoce como agrupamientos industriales o "clusters").

4) Grado de colaboración en los productos y procesos (en parte relacionado con el anterior, indaga sobre la lógica del desarrollo de productos y procesos, sobre que tan abierta o cerrada a nivel de empresas sea ésta). 
5) Disponibilidad local de componentes y partes (indicador concentrado en evaluar la dependencia a importaciones que pueda tener el sector industrial, sobre si depende enteramente de insumos importados con la alta sensibilidad en las condiciones de producción que esto puede generar o si por el contrario es independiente de todo esto y puede asegurar los procesos con insumos locales).

6) Disponibilidad local de servicios de tecnología de la información (referido exclusivamente a este tipo de insumos del proceso productivo, y destinado a evaluar si estos servicios están disponibles en la región y qué tipo de calificación pueden tener los proveedores).

7) Disponibilidad local de los procesos de producción (indaga sobre si tienen origen local los procesos y las rutinas de producción o por el contrario son tomados enteramente de experiencias del exterior).

8) Disponibilidad local de servicios especializados de búsqueda y capacitación (indicador relacionado con el grado de disponibilidad de recursos humanos, y en qué medida pueden disponer de servicios de calidad profesional aceptables para sus procesos de reclutamiento, selección, capacitación y desarrollo de personal).

B-4) Contexto para la estrategia y competencia de las empresas

1) Favoritismo en las decisiones de los funcionarios gubernamentales (indicador referido a la actitud de funcionarios públicos con poder de decisión ante la situación de adjudicar contratos, decidir compras del gobierno, resolver situaciones de conflicto, etc.; intenta indagar sobre la ecuanimidad y legitimidad con que en esos momentos proceden).

2) Grado de distorsión de los subsidios del gobierno (indicador que analiza si los subsidios a la actividad privada que tienen por origen fondos públicos son utilizados en programas integrales de incremento de la 
productividad de sectores industriales o si por el contrario se usan en el sostenimiento artificial de sectores inviables competitivamente).

3) Eficacia de la junta directiva (se refiere al grado de independencia con que pueden decidir y proceder los representantes de accionistas en empresas que tengan su capital abierto, para ellas intenta indagar sobre si la gerencia profesional de esas empresas puede o no "manejar" a la junta de accionistas).

4) Cooperación en las relaciones empleador-empleado (indicador que intenta evaluar si son cooperativas o confrontativas las relaciones laborales entre las empresas y sus trabajadores).

Por último, y dentro del mismo apartado sobre contexto para la estrategia y competencia de las empresas, la encuesta cierra con cinco indicadores finales que hablan sobre competencia:

1) Barreras de comercio encubiertas (indicador referido a al tipo y a la magnitud que pueden tener barreras de comercio encubiertas que dificulten el ingreso de insumos importados, como ser aranceles, cupos a la importación, restricción de divisas, etc.).

2) Intensidad de la competencia local (relacionado con la configuración del escenario competitivo, sobre cuál es el nivel de rivalidad entre las empresas que compiten en determinado sector y cuán estables o dinámicas se muestran las fuerzas competitivas).

3) Alcance de los competidores locales (relacionado con el anterior, esto otro indicador intenta evaluar algo así como el origen de las fuerzas competitivas que se despliegan en el sector, indagando sobre si pertenecen a empresas locales establecidas o subsidiarias de empresas extranjeras, o bien todo se explica por distintas ofertas competitivas todas ellas originadas en la importación de productos). 
4) Efectividad de las políticas antimonopólicas (indicador destinado a evaluar la existencia y efectividad de políticas antimonopolio que puedan implementar los gobiernos, preguntando si éstas, en caso de existir, son débiles o por el contrario fuertes, efectivas y promotoras de la competencia entre empresas).

5) Descentralización de la actividad empresarial (para terminar, la encuesta cierra con este indicador relacionado con el grado de concentración del poder y de las fuerzas competitivas en el sector industrial, indagando si la actividad comercial está dominada por unos pocos actores o en cambio son muchos y variados los que participan en ella con similar poder relativo).

\section{FUENTES DE INFORMACIÓN SECUNDARIA}

Como fuente de información complementaria a la relevada por la encuesta de opinión se recurrió al Reporte de Competitividad Global 2011-2012 elaborado por el Foro Económico Mundial. El objetivo de recurrir a esta fuente de información fue el de contar con datos comparativos para cotejar las diferencias entre los índices de competitividad -tanto los globales como los de cada uno de los indicadores que componen la encuesta- obtenidos para la región y los presentados por el reporte para los distintos países. Como se verá más adelante en el apartado que presenta los resultados de este trabajo de tesis, el recurrir al reporte permitió, por ejemplo, comparar el perfil competitivo del sector de empresas químicas y de los demás sectores industriales de la región de La Plata, Berisso y Ensenada con los correspondientes a los distintos países de todo el mundo.

El cotejo de distintos perfiles competitivos es lo que le otorga real valor a la información regional que se ha obtenido, ya que los índices de competitividad de una región o un país poco dicen por sí solos si no son cotejados con los índices de otras regiones o países que puedan servir como puntos de comparación relativa. 


\subsection{TÉCNICAS DE ANÁLISIS}

En el marco del proyecto de investigación La competitividad global y su impacto regional, el grado de competitividad de los distintos sectores industriales fue medido por medio del Indice de Competitividad de los Negocios $(\mathrm{BCl}$ o Business Competitiveness Index por su sigla en inglés). Obviamente, de idéntica forma se hizo para con las empresas químicas que conformaron la muestra y que fueron el objeto de estudio del presente trabajo de tesis.

En la práctica, el índice $\mathrm{BCl}$ fue obtenido a partir de la información relevada por la Encuesta de opinión ejecutiva, que en todo su detalle fuera descripta en el apartado anterior. Así fue como se obtuvo un índice global para toda la región e índices particulares para cada uno de los sectores industriales; y para ambas dimensiones, se obtuvieron también los índices parcializados de cada uno de los indicadores o variables que componen la encuesta, junto a los índices de los distintos agrupamientos de variables. Puede darse a entender mejor toda esta lógica diciendo que como resultado del estudio se ha podido conocer, por ejemplo:

- El índice de competitividad para la región de La Plata, Berisso y Ensenada, el que, incrementando su relevancia como herramienta de análisis, puede comprarse con el índice para todo el país e incluso con el correspondiente para otros países en el reporte del WEF;

- el índice para cada uno de los distintos sectores industriales;

- de importancia para el presente trabajo de tesis, el índice de competitividad específico del sector de las empresas químicas;

- a fin de desagregar el análisis, el índice general de las variables agrupadas en el apartado Operaciones y estrategias de las empresas (que permite cotejar, como ser, el grado de sofisticación de los procesos productivos o la naturaleza de la ventaja competitiva en los distintos sectores industriales, o entre la región y el país);

- o el índice de las variables referida al Ambiente de negocios (para comparar a distintos niveles, por ejemplo, la influencia sobre la 
competitividad que se esté midiendo de la infraestructura existente o el nivel de la educación y la calificación de los recursos humanos; la influencia de las condiciones de la demanda, de las industrias relacionadas y de los agrupamientos industriales, de las condiciones en que se desarrolla el escenario para la estrategia y la competencia de las empresas, etc.);

no agotando esta simple enunciación todos los índices que se pueden analizar y evaluar, ya que yendo al extremo de un análisis de todos ellos, se puede llegar al nivel de cada uno de los indicadores o variables que componen la encuesta.

En cuando a las cuestiones más prácticas referidas al cálculo del índice de competitividad puede decirse que:

1. Todas las variables incluidas en la encuesta contemplaron una graduación de siete niveles. Los entrevistados debían responder sobre cada variable calificándolas en algún punto entre el valor más bajo de "1" (el menor nivel de consideración que podía otorgarse a una variable) y el más alto de "7" (el mayor nivel de consideración que podía darse).

2. Recibidas las respuestas a las encuestas, se procedió a re-escalar las variables de 0 a 10, para lo cual se utilizó la siguiente ecuación de transformación ${ }^{41}: \mathrm{Y}=\frac{10}{6} \cdot(\mathrm{X}-1)$.

3. Seguidamente, se calculó el promedio de estas variables transformadas para construir cada uno de los sub-índices.

4. Por último, se calculó el promedio de todos los subíndices para obtener así el índice general.

\footnotetext{
${ }^{41}$ La fórmula es el resultado de la ecuación de la recta que une los pares $\left(x_{0}, y_{0}\right)=(1,0)$ y $\left(x_{1}, y_{1}\right)=(7,10)$
} 


\section{RESULTADOS DE LA INVESTIGACIÓN}

Se presentarán los resultados de la investigación en función de los distintos niveles de análisis que pueden hacerse para llegar a una interpretación precisa de la medición de competitividad empresarial para las empresas químicas en la región de La Plata, Berisso y Ensenada.

Un primer nivel de análisis tiene que ver con identificar el grado de competitividad de todo el país, para lo que se apelará a la medición que sobre ello hace el Foro Económico Mundial (WEF) en su Reporte anual de la competitividad mundial (recordar que el WEF y sus reportes han sido considerados antecedentes de la investigación, y son la referencia mundial por excelencia en cuanto a medición de competitividad de economías nacionales). Así es como se podrá observar la competitividad de Argentina y la posición que ocupa en relación a los casi ciento cincuenta países que componen el estudio del WEF. Para obtener estos datos, se ha tomado la edición del reporte correspondiente a 2011-2012 42 , por ser la que coincide temporalmente con el momento en que fueron relavados los datos para el presente trabajo sobre competitividad regional en empresas químicas. Este primer nivel de análisis, referido a todo el país, es necesario como para encontrar un marco, un parámetro de comparación a los resultados obtenidos para la región, con la siguiente lógica: la mejor manera de comenzar a comprender la competitividad regional es conocer primero en qué estado está la competitividad de todo el país.

Un segundo nivel de análisis ya tiene que ver con la competitividad regional. Y en este caso la idea es considerar a la región como si se tratara de un país, a fin de poder "incorporarla" al ranking de competitividad del WEF, el que, con este ensayo, pasaría a tener un registro adicional de un "país agregado". La idea implica un supuesto fuerte, porque son muchas las consideraciones a tomar en cuenta como para suponer que la región puede ser un país, pero al utilizar en la investigación regional exactamente la

\footnotetext{
${ }^{42}$ The Global Competitiveness Report 2011-2012 (reports.weforum.org/global-competitiveness-20112012/)
} 
misma metodología que la utilizada por el WEF para sus reportes, la suposición obtiene un basamento sólido, y el ensayo cobra plena validez.

Un tercer nivel ya se refiere exclusivamente a la región, haciendo foco sobre sus sectores industriales a fin de analizar comparativamente el nivel de competitividad de cada uno de ellos. Esto permitirá obtener un nuevo parámetro, un nuevo marco de referencia, ahora más enfocado y destinado a conocer cómo se ubica el sector de empresas químicas en cuanto a su competitividad respecto de los otros sectores industriales de La Plata, Berisso y Ensenada.

Por último, el cuarto nivel de análisis ya se concentra de lleno en la competitividad de las empresas químicas de la región, analizando tanto la medición de la competitividad del sector como, en detalle, la de las distintas variables que la determinan.

\section{1.- LA COMPETITIVIDAD DE ARGENTINA}

En su reporte 2011-2012 el Foro Económico Mundial midió la competitividad de 142 países, elaborando con ello su ya tradicional ranking anual de la competitividad. En el ranking puntual de ese año la Argentina ocupó la posición $n^{\circ} 85$, con un valor para su índice de competitividad de 3,99 (como referencia, el año previo la posición había sido la $n^{\circ} 87$, con un índice de 3,95).

Extractando parte del ranking de competitividad 2011-2012, puede verse la posición de Argentina respecto de los referentes mundiales de la competitividad, de algunos países latinoamericanos y de algunos con más débil posición competitiva. 
Tabla 2. Los niveles de competitividad de los países en el Reporte WEF

\begin{tabular}{lcc} 
País & Posición/142 & ICG (1-7) \\
\hline Suiza & 1 & 5,74 \\
\hline Singapur & 2 & 5,63 \\
\hline Suecia & 3 & 5,61 \\
\hline Finlandia & 4 & 5,47 \\
\hline Estados Unidos & 5 & 5,43 \\
\hline Reino Unido & 10 & 5,39 \\
\hline Australia & 20 & 5,11 \\
\hline Chile & 31 & 4,70 \\
\hline Brasil & 53 & 4,32 \\
México & 58 & 4,29 \\
\hline Argentina & 85 & 3,99 \\
Paraguay & 122 & 3,53 \\
Venezuela & 124 & 3,51 \\
\hline Chad & 142 & 2,87
\end{tabular}

Fuente: Elaboración propia (adaptado del Reporte de Competitividad Mundial 2011-2012, WEF, página 15)

El reporte WEF mide la situación competitiva de cada economía en base a la consideración de lo que llama los pilares de la competitividad de un país, y agrupa a estos en forma tal de considerar cuáles son los requerimientos básicos de la competitividad, cuáles los factores competitivos impulsados por la eficiencia de la economía y por último cuáles los que se sustentan en la innovación y la sofisticación de los procesos productivos. Bajo estos criterios, Argentina se muestra con mejor desempeño para todo lo relacionado a innovación y sofisticación, y apenas por debajo de esto aparecen los factores correspondientes a requerimientos básicos y a los impulsados por la eficiencia.

Según el WEF, los puntos fuertes de la competitividad de Argentina (y siempre para la medición puntual de 2011-2012) hay que buscarlos en el nivel de la educación tanto básica como avanzada de su población, en la disponibilidad tecnológica, en el tamaño de sus mercados doméstico y de exportación y en su entorno macroeconómico; 
mientras que sus puntos débiles se encuentran en la calidad de sus instituciones, en su infraestructura general y en los niveles de eficiencia de sus mercados de bienes, de trabajo y financiero.

Para medir la competitividad de los países, el WEF pondera las variables consideradas en función del grado de desarrollo económico alcanzado por cada uno de ellos. Esto permite ajustar la medición de la competitividad en base a cuáles son los factores que en cada país son más determinantes para la ventaja competitiva de toda su economía. El criterio para identificar las distintas etapas de desarrollo es el de ingreso per cápita medido en dólares, siendo tres las etapas posibles (en realidad cinco: etapa 1, 2 y 3, y las dos etapas intermedias entre ellas). Bajo este esquema, la economía argentina se encuentra en fase de transición desde la etapa 2 (la media) hacia la etapa 3 (la de mayor nivel de desarrollo). Las etapas se consideran para otorgar distintas ponderaciones según el grado de desarrollo a las variables relevadas para medir la competitividad de los países. Luego, para una mejor interpretación de la medición de competitividad el WEF coteja los valores obtenidos por cada país respecto de los valores medios de las economías con igual grado de desarrollo. Para Argentina, la comparación es entre su nivel de competitividad y el promedio de todas las economías ubicadas en la fase de transición entre las etapas de desarrollo 2 y 3 . Considerando esto último y lo dicho previamente sobre los puntos fuertes y débiles de la competitividad argentina, puede apreciarse claramente la situación competitiva en el siguiente gráfico: 


\section{Gráfico 1. La competitividad de Argentina y la de economías de similar grado de desarrollo}

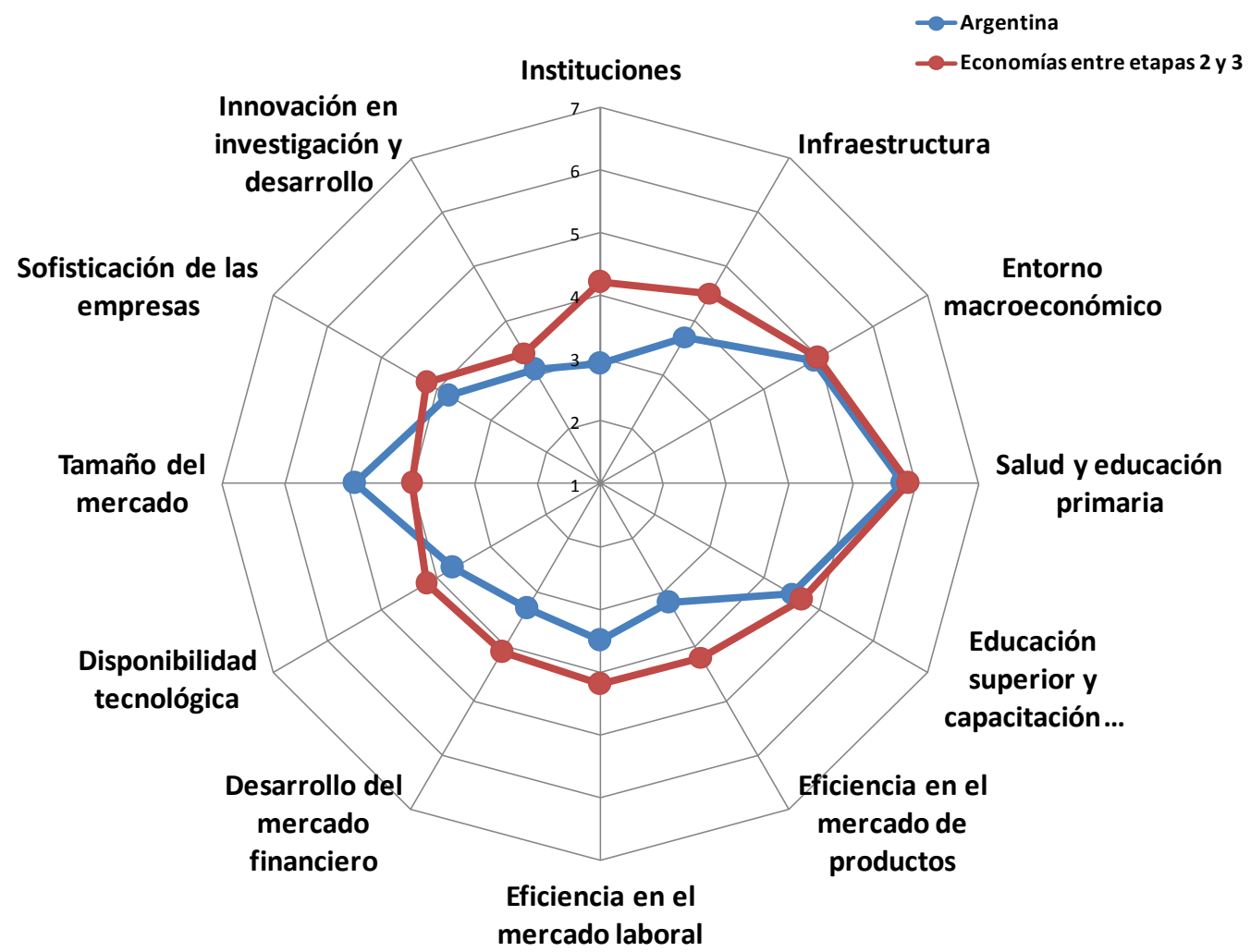

Fuente: Elaboración propia (adaptado de Reporte de Competitividad Mundial 2011-2012, WEF, página. 98)

En el gráfico se observa la posición relativa de Argentina en cada uno de los pilares de la competitividad en relación a la posición promedio de los países con igual grado de desarrollo. Los valores se interpretan así: cuanto más alejado del centro de la "red", mayor nivel de competitividad, y obviamente que cuanto más cerca, menor competitividad. En los valores se ve lo dicho: Argentina es fuerte en el entorno macroeconómico, salud, educación, disponibilidad tecnológica y tamaño de mercado; y débil en instituciones, infraestructura y en el funcionamiento de sus mercados de bienes, de trabajo y financiero.

Por último, para cerrar las consideraciones sobre Argentina, resulta atractivo presentar el relevamiento del WEF sobre las variables que, a opinión de la comunidad empresarial que han relevado para la elaboración del reporte, más problemas presentan al incremento de la competitividad del país. Esto puede apreciarse en el siguiente gráfico, que expone los porcentajes de aparición en las respuestas de todos los encuestados de estos factores "más problemáticos" para la competitividad. 


\title{
Gráfico 2. La competitividad de Argentina y la de economías de similar grado de desarrollo
}

\author{
Inflación \\ Inestabilidad política \\ Corrupción \\ Regulación del mercado de cambios \\ Acceso a financiamiento \\ Burocracia gubernamental deficiente \\ Restrictivas regulaciones laborales \\ Regulación tributaria \\ Presión tributaria \\ Infraestructura inadecuada \\ Baja ética del trabajo en fuerza laboral \\ Inadecuada educación de trabajadores \\ Inestabilidad/golpes de gobierno \\ Insuficiente capacidad para innovar \\ Crimen y robo \\ Deficiente salud pública
}

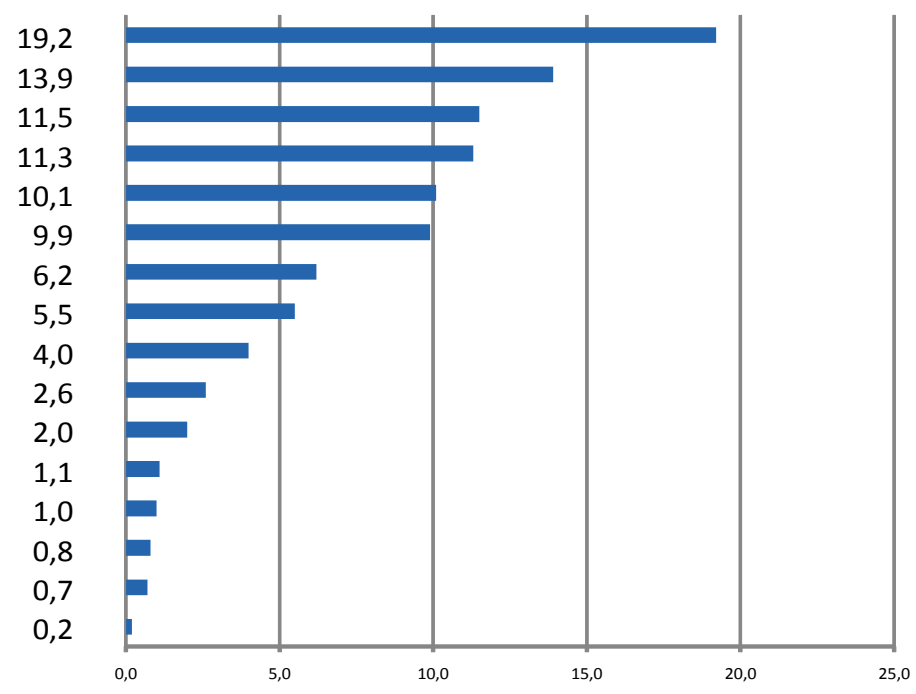

Fuente: Reporte de Competitividad Mundial 2011-2012, WEF, página. 98

\section{2.- La COMPetitividad de La Plata, Berisso y EnSEnada bajo el supuesto de LA REGIÓN CONSIDERADA COMO UN PAÍS}

Ya se adelantó que es un supuesto fuerte el considerar a la región como si de un país se tratara, no tanto por cuestiones referidas a superficie de su territorio, cantidad de habitantes o complejidad y diversidad de su economía, puntos fuertes de la región, sino porque el análisis no agota la cantidad de variables que deberían ser consideradas para tomar a la economía regional como si de una economía nacional se trátese (instituciones, moneda, marco legal, etc.). No obstante, también se adelantó que el supuesto cobra validez al tomar en cuenta que la metodología utilizada para el estudio regional es exactamente la misma que la del WEF, en cuyo caso resultan absolutamente comparables los valores obtenidos a nivel regional con los relevados para el conjunto de países por parte de la institución suiza. Por lo tanto, y sólo como ensayo en pos de enriquecer el análisis sobre la competitividad regional, se considera 
relevante y enteramente viable la consideración de la región como si fuera un país más en el reporte de competitividad global del WEF.

Entonces, incorporando a la región de La Plata, Berisso y Ensenada a la edición 20112012 del reporte ésta se ubicaría en la posición $n^{\circ}$ 87, con un índice de 3,97, tal como puede verse en este nuevo extracto del reporte, ahora más acotado y ya considerando a la región.

Tabla 3. La región incorporada al reporte WEF

\begin{tabular}{lcc|} 
País & Posición/143 & ICG (1-7) \\
\hline Suiza & 1 & 5,74 \\
\hline Singapur & 2 & 5,63 \\
\hline Suecia & 3 & 5,61 \\
\hline Reino Unido & 10 & 5,39 \\
\hline Australia & 20 & 5,11 \\
\hline Brasil & 53 & 4,32 \\
\hline Argentina & 85 & 3,99 \\
\hline Región LP-B-E & 87 & 3,97 \\
Venezuela & 125 & 3,51 \\
Chad & 143 & 2,87
\end{tabular}

Fuente: Elaboración propia (adaptado del Reporte de Competitividad Mundial 2011-2012, WEF, página. 15)

Aquí puede verse por primera vez el resultado de la investigación regional: el índice de competitividad obtenido, e incorporado al reporte del WEF, ubica a la región de La Plata, Berisso y Ensenada prácticamente en el mismo nivel que el país en su conjunto, con sólo 0,02 puntos y dos posiciones en el ranking como diferencia.

La medición permite suponer que la región mantiene características similares a las del país en su conjunto en cuanto a cuáles son los determinantes de su competitividad. Como se verá con detalle más adelante, presenta sus fortalezas en los niveles de educación, en el tamaño de su mercado y en la disponibilidad tecnológica, mientras que su flanco débil -al igual que para toda Argentina- hay que buscarlo en la calidad de las instituciones, la infraestructura y la eficiencia de sus mercados de bienes, laboral y financiero. 


\section{3.- LA COMPETITIVIDAD RELATIVA DE LOS SECTORES INDUSTRIALES DE LA PLATA, BERISSO Y ENSENADA}

Enfocando el análisis ya definitivamente en la región, es tiempo de cotejar la competitividad relativa de los distintos sectores industriales que la componen. En este caso, la investigación arrojó los índices de competitividad sectoriales que pueden verse en el siguiente gráfico, que incluye el índice obtenido para la región en general y el de todos los sectores en particular:

Gráfico 3. La competitividad de los sectores industriales en la región

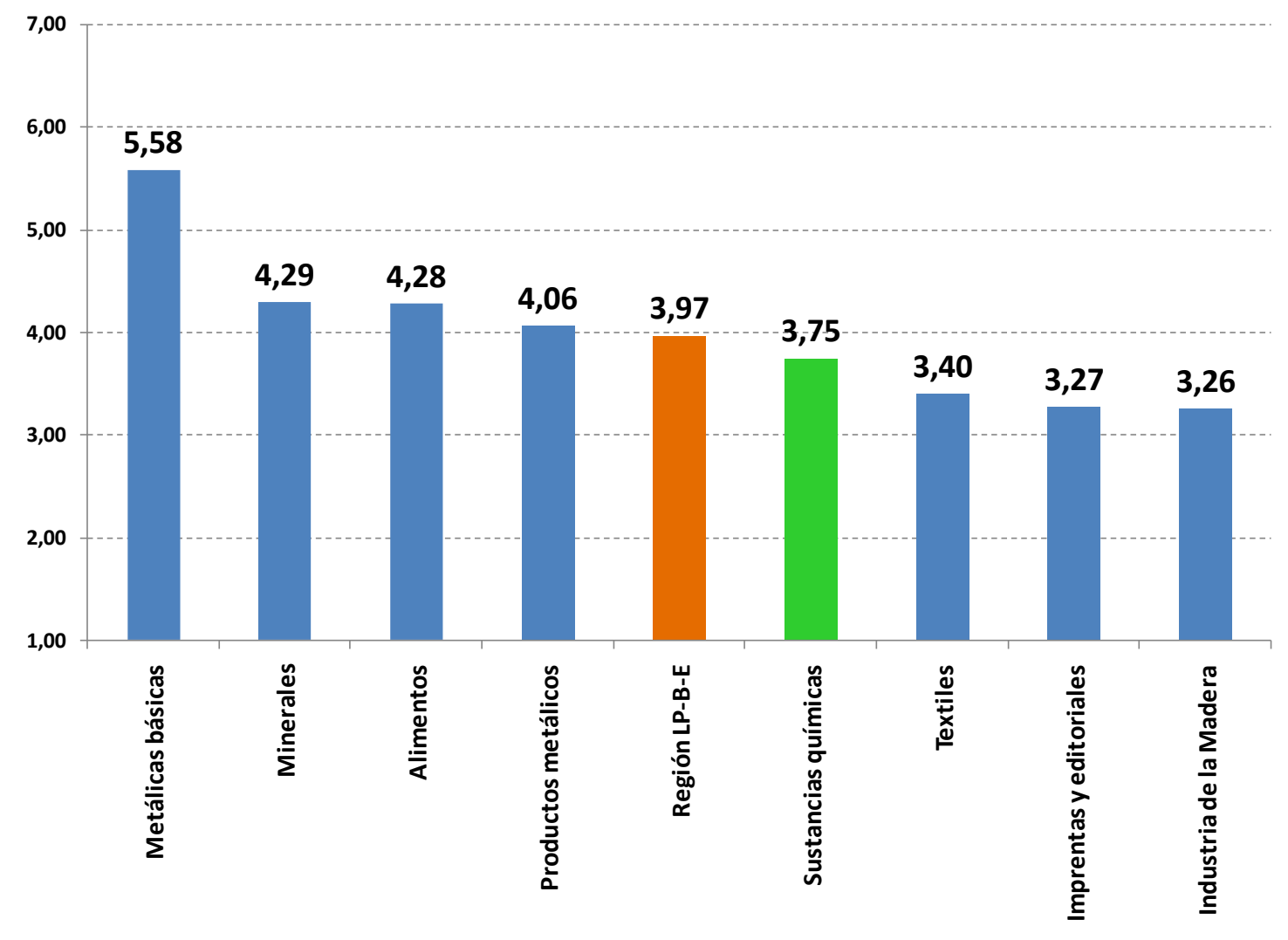

Fuente: Elaboración propia

Como puede verse, el sector de metálicas básicas se desprende claramente del resto, con un nivel de competitividad muy elevado, casi de acuerdo con los registros de los países que son referentes mundiales en cuanto a competitividad. El resto de los sectores se agrupan en un rango de un punto de medición entre el 4,29 de minerales y el 3,26 de madera. El sector de químicas se ubica en un punto medio dentro de este último rango, con un índice de competitividad de 3,75. 
El sector de las metálicas básicas comparte obviamente con el resto de los sectores las condiciones del escenario competitivo regional, del que no extrae los fundamentos para su diferencia en ventajas competitivas relativas. Por el contrario, su muy buen nivel de competitividad debe buscarse en las condiciones propias del sector, destacándose en esto, según las mediciones, la capacidad de innovación que presenta, la naturaleza de su ventaja competitiva y la alta predisposición de sus empresas a enfocarse en el mercado y en las necesidades muy específicas de sus tipos de demanda.

También con buenos niveles de competitividad se muestran los sectores de minerales, de gran fortaleza en todos los factores que son típicos del sector, como su tipo de ventaja competitiva y su alto enfoque en el mercado; de alimentos, con gran enfoque en el mercado y elevada capacidad de innovación; y productos metálicos, también con muy alta capacidad de innovación y una fuerte orientación hacia las necesidades del mercado y las características específicas de la demanda.

En el otro extremo, el sector maderas no tiene particularmente muy malos registros en las condiciones típicas del sector, pero, por su tipo de productos y su estructura productiva, sufre mucho las condiciones del escenario económico relacionadas con la infraestructura de transporte, cierta debilidad en la capacitación elemental de su fuerza de trabajo y el muy restringido acceso al mercado financiero o a fuentes de financiación alternativas. Imprenta se encuentra casi al nivel de maderas, sufriendo en este caso por una muy baja capacidad de innovación y los efectos prejudiciales sobre la industria de una débil protección de los derechos de propiedad intelectual. Por parte el sector textil, integrante también del grupo de sectores de menor competitividad, registra sus debilidades en factores de competencia como la carencia de un buen marco legal que castigue prácticas de concentración de oferta o que proteja respecto de derechos de propiedad intelectual, además de las dificultades para acceder en condiciones convenientes a los mercados de capital y a las fuentes de financiamiento.

El sector de empresas químicas, objeto de estudio del presente trabajo y cuyo análisis se reserva para la sección posterior, es junto al de productos metálicos los que más cerca están en su nivel de competitividad respecto de la competitividad de toda la región considerada en conjunto. 
En general, todos los sectores parecen verse afectados en forma similar respecto de determinadas condiciones del escenario económico. Así es como en las mediciones se nota como afecta a sus niveles de competitividad la débil infraestructura física de la región, que afecta todo el sistema logístico de provisión de insumos y distribución de bienes, la ineficiencia del mercado financiero con sus restricciones para el acceso a fuentes de financiación regulares y en línea con las tasas de rentabilidad de los distintos sectores, y también determinados factores relacionados con el nivel de competencia, como la existencia de prácticas monopólicas u oligopólicas o de barreras encubiertas al comercio de mercaderías.

Por el contrario, la mayor parte de los sectores parecen disfrutar de una alta disponibilidad en cuanto a desarrollos de tecnología para sus procesos productivos y un buen nivel de capacitación y formación permanente de la fuerza laboral, principalmente en todo lo relacionado a educación superior.

Mirando puertas adentro de las empresas en cada uno de los sectores, es en los factores propios del desempeño de las mismas donde se aprecia las mayores diferencias en el nivel de competitividad, siendo lo que explica los distintos valores en los índices sectoriales. En la sofisticación de los distintos procesos productivos y en las variadas formas de responder a las necesidades respecto de las condiciones de la demanda es donde los sectores industriales muestran la disímil condición de los determinantes de sus ventajas competitivas.

Por último, la información relativa a la medición de competitividad de todos los sectores puede observarse planteando los grados de competitividad y la brecha de competitividad por cubrir respecto del nivel de competitividad óptimo. Como se sabe, la medición de competitividad utilizando la metodología del Foro Económico Mundial supone la obtención de un índice con valores posibles entre 1 y 7 . Entonces, el grado de competitividad representará el nivel de competitividad medido respecto del valor óptimo de 7, y expresado en porcentajes. Del mismo modo, la brecha de competitividad será la diferencia, también en porcentajes, entre el nivel de competitividad óptima y el nivel realmente obtenido. Así planteada la cuestión, la información puede apreciarse en la siguiente figura: 


\section{Gráfico 4. Grados de competitividad y brechas por cubrir}

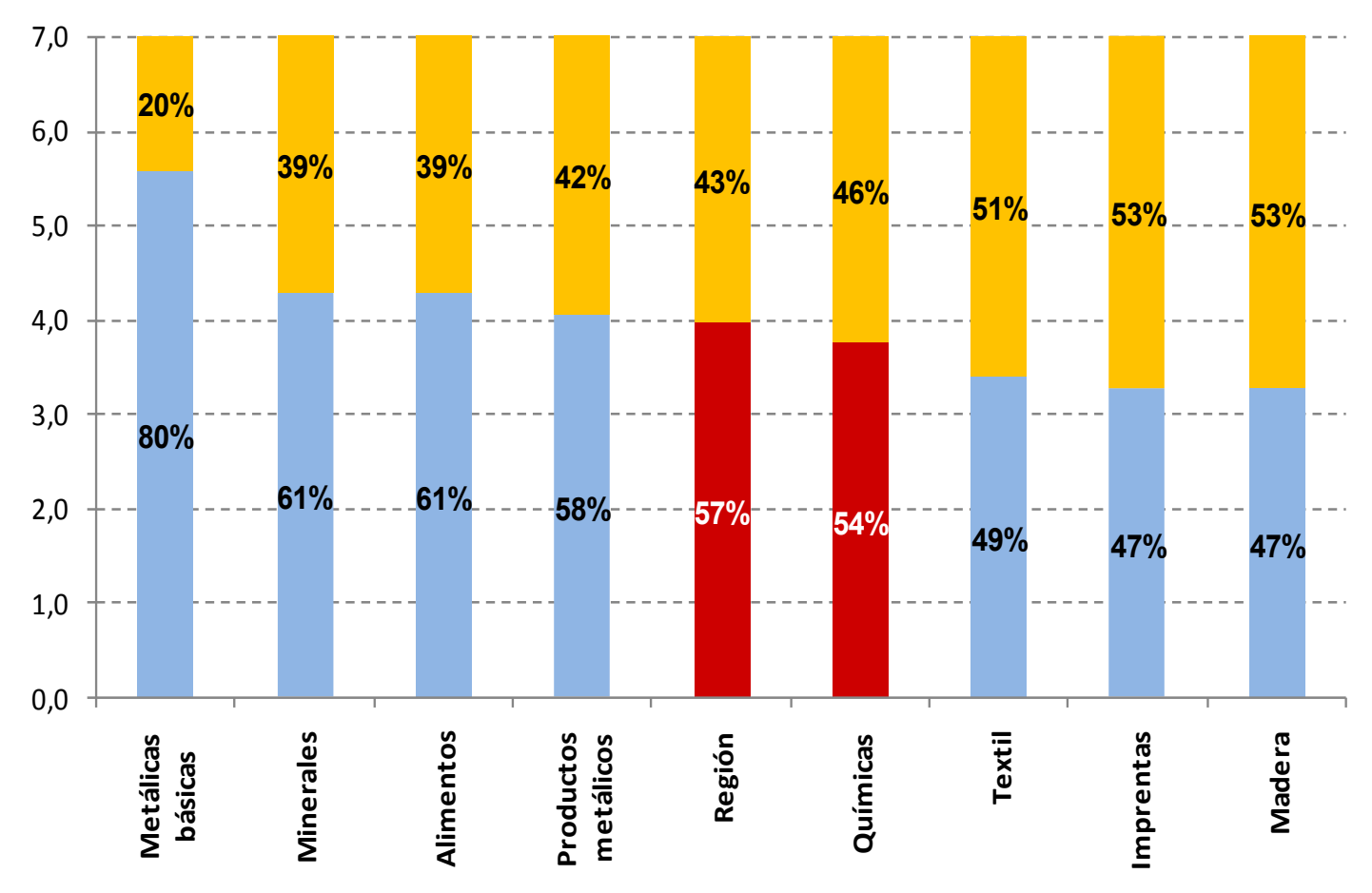

Fuente: elaboración propia

Esto no es más que otro formato de la información ya presentada, pero en todo caso es muy gráfica en cuanto a la situación competitiva de cada sector. Por ejemplo, al de metálicas básicas no le queda más que un camino por recorrer de $20 \%$ respecto del nivel de competitividad óptima. En un punto de una competitividad más habitual para la región y para nuestro país se ubican todos los demás sectores y la región. La región, con un grado de competitividad de $57 \%$ y una brecha por cubrir hacia lo óptimo de $43 \%$. En forma similar el sector de químicas con valores de $54 \%$ y $46 \%$, y así para todos los demás.

El plantear la información en términos de brechas por cubrir puede ayudar a enfocar el análisis y los esfuerzos respecto de "cuánta competitividad" queda aún por ganar en la región. 
7.4.- LA COMPETITIVIDAd DEL SECTOR DE EMPRESAS químicAS EN LA Plata, Berisso Y ENSENADA

EL ÍNDICE DE COMPETITIVIDAD DE EMPRESAS QUÍMICAS

Enfocando ahora sí el análisis en las empresas químicas, se presenta en primer término el índice de competitividad obtenido por el sector y los subíndices parciales referidos a los dos grandes agrupamientos de variables relevadas: Operaciones y estrategia de las empresas y Ambiente de negocios. Luego, se da a conocer también el valor puntual medido para cada variable.

Se expone entonces en la tabla siguiente el índice de competitividad de los negocios ( $\mathrm{BCl}$ por sus siglas en inglés, tal la denominación que utiliza el Foro Económico Mundial) de todo el sector, los subíndices de cada uno de los dos agrupamientos de variables y el valor de cada una de las treinta y una variables relevadas. Los datos se presentan con su cotejo respecto de los valores correspondientes a toda la región de La Plata, Berisso y Ensenada, marcando las diferencias positivas o negativas de cada par de valores. 
Tabla 4. Medición de índices, subíndices y variables relevadas

\begin{tabular}{|c|c|c|c|}
\hline Variables medidas & $\begin{array}{l}\text { (1) } \mathrm{BCl} \\
\text { Sector } \\
\text { empresas } \\
\text { químicas }\end{array}$ & $\begin{array}{c}(2) \mathrm{BCl} \\
\text { Global de } \\
\text { región LP-B- } \\
E\end{array}$ & $\begin{array}{c}\text { Diferencia de } \\
\text { (1) respecto } \\
\text { de (2) }\end{array}$ \\
\hline INDICE GENERAL & 3,75 & 3,97 & $-0,22$ \\
\hline A. Operaciones y estrategias de las empresas & 4,18 & 4,36 & $-0,18$ \\
\hline Sofisticación del proceso de producción & 3,82 & 3,93 & $-0,11$ \\
\hline Naturaleza de la ventaja competitiva & 4,50 & 4,11 & 0,39 \\
\hline Disposición a delegar autoridad & 4,00 & 3,60 & 0,40 \\
\hline Capacidad de innovación & 3,20 & 4,15 & $-0,95$ \\
\hline Grado de orientación del consumidor & 5,00 & 5,69 & $-0,69$ \\
\hline Extensión de la marca & 4,56 & 4,69 & $-0,13$ \\
\hline B. Ambiente de Negocios & 3,31 & 3,58 & $-0,27$ \\
\hline B.1. Condiciones de los factores & 2,97 & 3,00 & $-0,03$ \\
\hline B.1.1. Infraestructura física & 2,58 & 2,61 & $-0,03$ \\
\hline Calidad de la infraestructura en general & 3,18 & 3,18 & 0,00 \\
\hline Calidad de la infraestructura de las rutas & 3,64 & 3,75 & $-0,11$ \\
\hline Desarrollo de la infraestructura férrea & 1,27 & 1,33 & $-0,06$ \\
\hline Calidad de la infraestructura de los puertos & 2,36 & 2,28 & 0,08 \\
\hline Calidad de la infraestructura del transporte aéreo & 2,45 & 2,50 & $-0,05$ \\
\hline B.1.2. Infraestructura administrativa & 2,81 & 3,00 & $-0,18$ \\
\hline Protección de la propiedad intelectual & 2,90 & 2,82 & 0,08 \\
\hline Independencia Judicial & 2,73 & 3,18 & $-0,45$ \\
\hline B.1.3. Recursos Humanos & 3,47 & 3,16 & 0,31 \\
\hline Calidad de las escuelas públicas & 2,55 & 2,74 & $-0,20$ \\
\hline Calidad de las escuelas de negocios & 4,40 & 3,58 & 0,82 \\
\hline B.1.4. Infraestructura Tecnológica & 3,64 & 3,53 & 0,11 \\
\hline Disponibilidad de científicos e ingenieros & 4,73 & 4,42 & 0,31 \\
\hline Calidad de los institutos de investigación científica & 4,09 & 3,89 & 0,20 \\
\hline Colaboración en la investigación Universidad / Empresas & 2,10 & 2,27 & $-0,17$ \\
\hline B.1.5. Mercado de Capitales & 2,32 & 2,70 & $-0,38$ \\
\hline Facilidad en el acceso a préstamos & 1,64 & 2,35 & $-0,71$ \\
\hline Sofisticación del mercado financiero & 3,00 & 3,04 & $-0,04$ \\
\hline B.2. Condiciones de la Demanda & 3,27 & 3,69 & $-0,42$ \\
\hline Sofisticación de los compradores & 4,18 & 3,98 & 0,20 \\
\hline Adquisición gub.de productos de tecnología de avanzada & 2,36 & 3,40 & $-1,04$ \\
\hline B.3. Industrias relacionadas y de apoyo & 3,97 & 4,08 & $-0,11$ \\
\hline Calidad de los proveedores locales & 4,09 & 4,45 & $-0,36$ \\
\hline Cantidad de proveedores locales & 4,09 & 4,52 & $-0,43$ \\
\hline Estado de desarrollo de agrupamientos & 3,73 & 3,26 & 0,46 \\
\hline B.4. Contexto para la Estrategia y Comp. de las Empresas & 3,04 & 3,55 & $-0,51$ \\
\hline B.4.1. Incentivos & 2,96 & 3,48 & $-0,52$ \\
\hline Favoritismo en las decisiones de los funcionarios gub. & 2,45 & 3,03 & $-0,58$ \\
\hline Eficacia de la junta directiva & 3,43 & 2,56 & 0,87 \\
\hline Cooperación en las relaciones empleador-empleado & 3,00 & 4,85 & $-1,85$ \\
\hline B.4.2. Competencia & 3,12 & 3,62 & $-0,50$ \\
\hline Barreras de comercio encubiertas & 2,18 & 3,98 & $-1,80$ \\
\hline Intensidad de la competencia local & 4,27 & 4,54 & $-0,27$ \\
\hline Efectividad de las políticas antimonopólicas & 2,91 & 2,35 & 0,56 \\
\hline
\end{tabular}


Como los de todos los demás sectores, el $\mathrm{BCl}$ de las empresas químicas se construye desde los valores obtenidos por los dos grandes apartados de variables, lo que da un primer elemento de análisis como para poder afirmar que, respecto de su índice general, las químicas de la región tienen mejor posición competitiva en lo relacionado con las Operaciones y estrategia de las empresas que con el Ambiente de negocios. Esto puede observarse en el siguiente gráfico con el $\mathrm{BCl}$ general del sector y los subíndices de ambos apartados.

Gráfico 5. Medición del índice general y de los dos subíndices

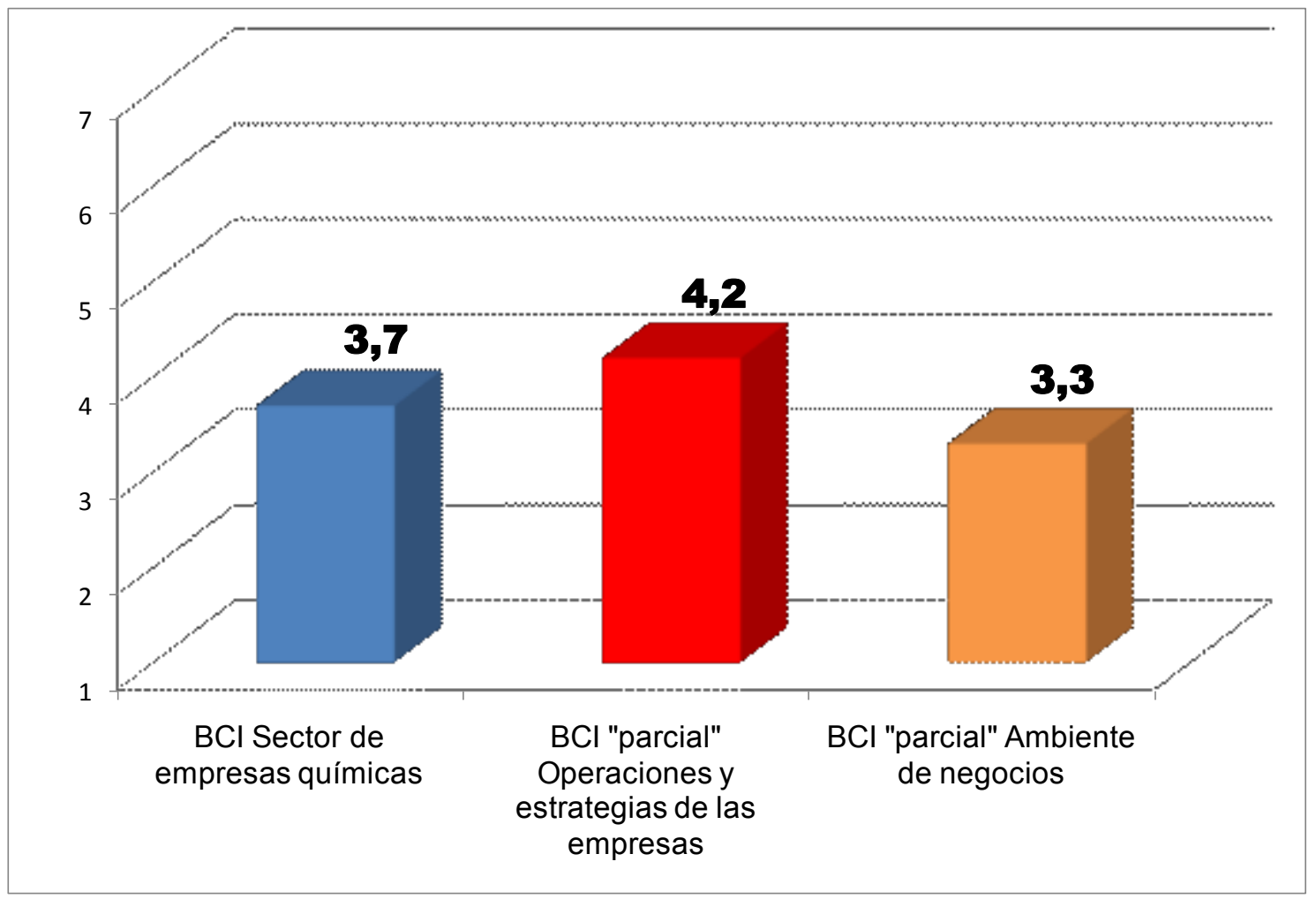

Fuente: Elaboración propia

Desagregando estos datos y comparándolos, puede analizarse la situación de las empresas químicas respecto de la región y del país, en cada uno de los factores que hacen a las Operaciones y estrategias de las empresas y el Ambiente de negocios. En el siguiente gráfico de red se vuelcan el primer nivel de valores de la tabla presentada más arriba y esto permite apreciar la posición relativa de cada factor relacionado con 
la competitividad del sector (los seis de Operaciones y estrategia de las empresas y los cuatro de Ambiente de negocios)

\section{Gráfico 6. Los factores de competitividad para Argentina, para la región y para las empresas químicas}

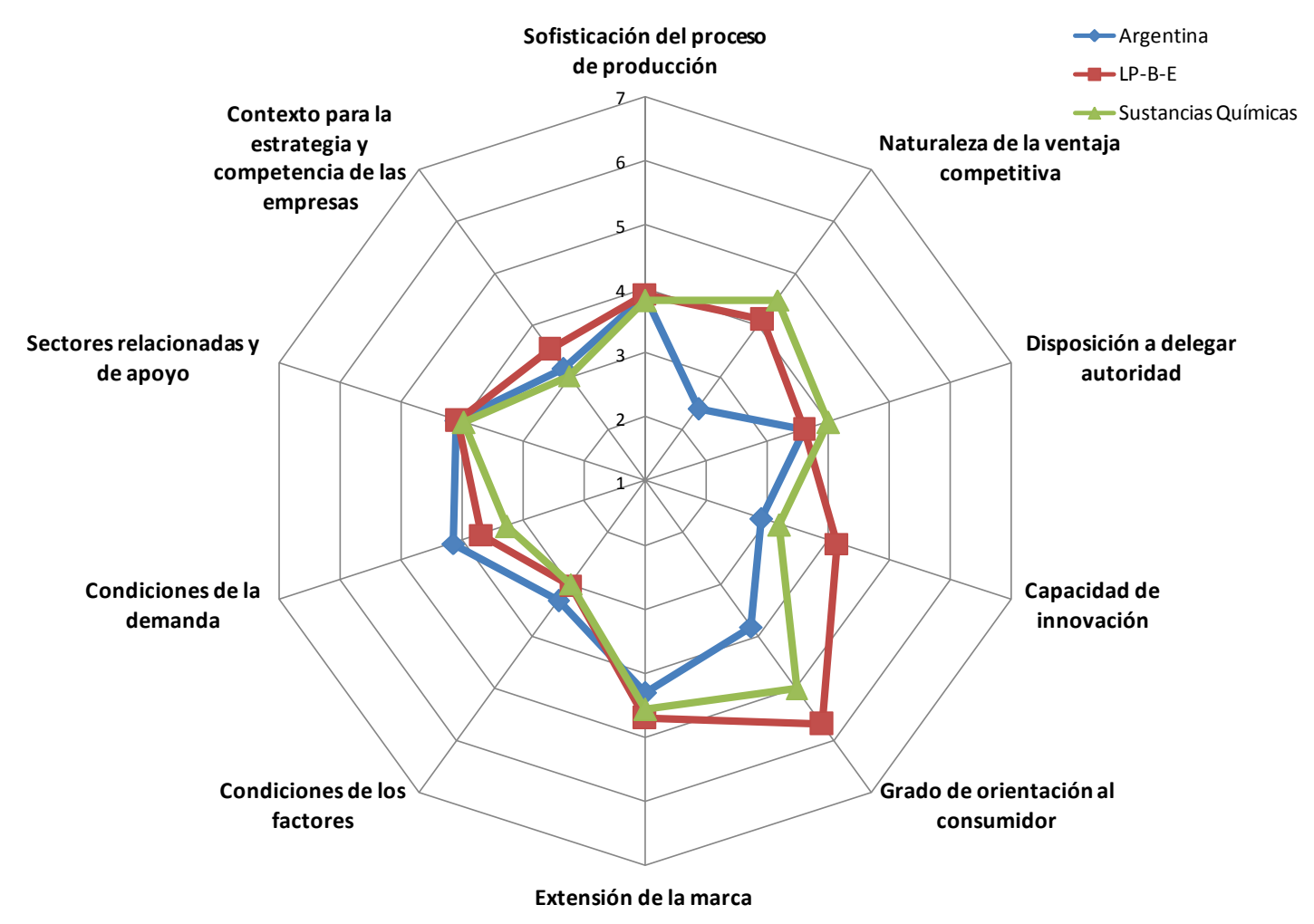

Fuente: Elaboración propia

La lectura del gráfico supone que cuánto más alejado un valor del centro de la red mayor competitividad representa para el factor que mide. La observación de estos valores permite afirmar algo ya sugerido cuando se analizaron todos los sectores: las diferencias en los niveles de competitividad deben buscarse más en lo relacionado con las Operaciones y estrategias de las empresas (sofisticación del proceso de producción, naturaleza de la ventaja competitiva, disposición a delegar autoridad, capacidad de innovación, grado de orientación al consumidor y extensión de marca), que en lo referido a Ambiente de negocios (condiciones de los factores, condiciones de la demanda, sectores relacionados y de apoyo y contexto para la estrategia y la competencia de las empresas). 
Como puede verse en el gráfico, el subíndice de 4,18 en Operaciones y estrategias de las empresas lo explica sobre todo la naturaleza de su ventaja competitiva (los fundamentos sobre los que compiten las empresas), la disposición a delegar autoridad (referido a prácticas de gestión participativas, abiertas a la información) y el fuerte grado de orientación al consumidor y la extensión de marca (cuestiones ambas relacionadas con un profundo enfoque hacia las necesidades del mercado). Por el contrario, algo se castiga este subíndice por la capacidad de innovación de las empresas, aunque esto ocurre respecto de la situación regional y no si se consideran los valores a nivel país.

Sobre el subíndice de valor 3,31 de Ambiente de negocios, lo referido a sectores relacionados y de apoyo logra traccionar fuertemente sobre el mismo, mientras que suponen algún freno las condiciones de los factores y el contexto para la estrategia de las empresas.

\section{EL COMPORTAMIENTO DE TODAS LA VARIABLES RELEVADAS}

Utilizando otro gráfico de red puede evaluarse el comportamiento de cada una de las treinta y una variables relevadas, profundizando el análisis respecto de los determinantes de la competitividad de las empresas químicas y cotejándolos ahora sólo con los valores de la región. En otras palabras, se analiza ahora el comportamiento de todas las variables relevadas para el sector de empresas químicas y se lo compara con idéntico tipo de valores obtenidos para toda la región (abandonando ahora sí el análisis más general respecto de los valores para el país). 


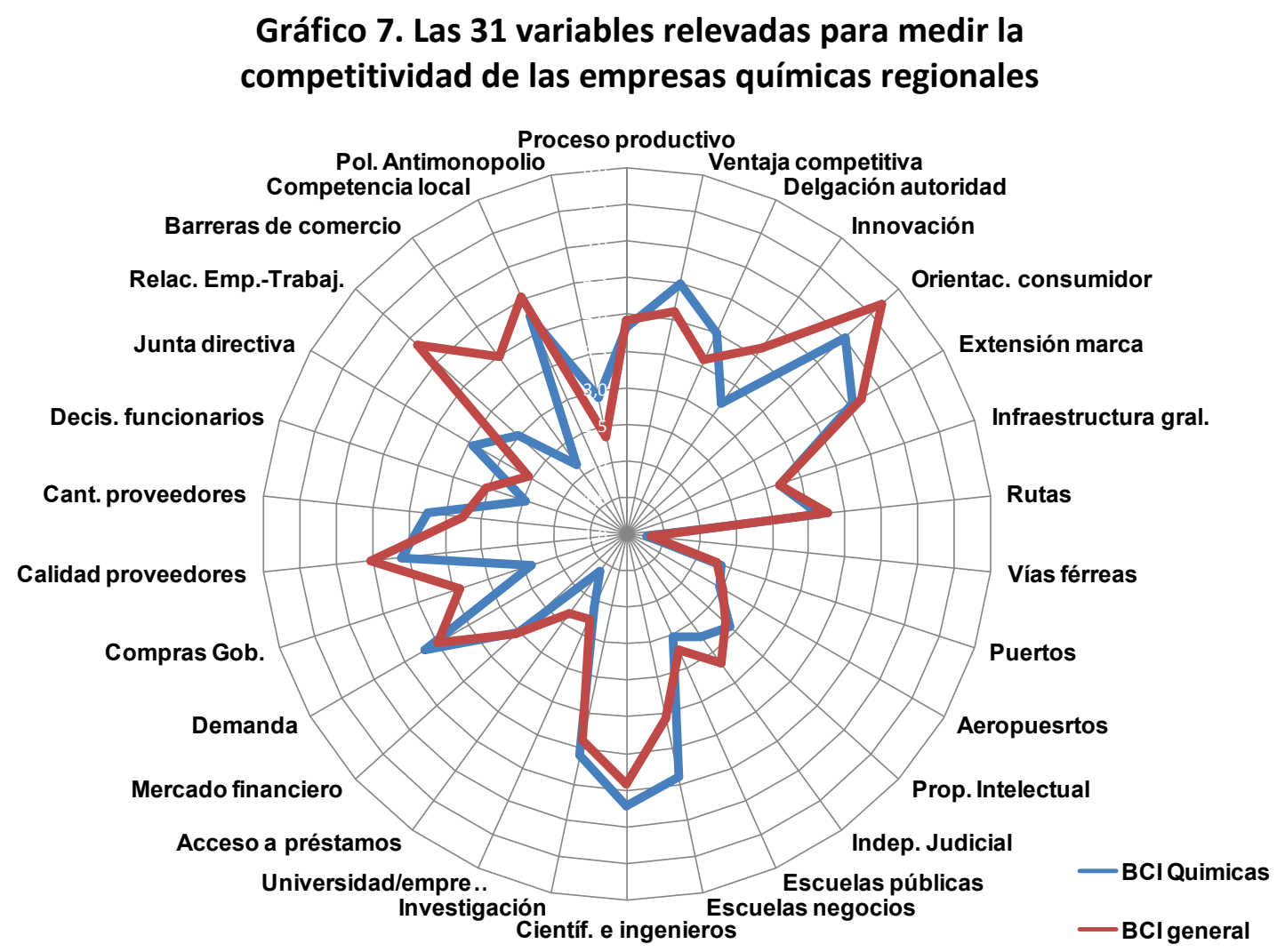

Fuente: Elaboración propia

Esta es obviamente la misma información ya presentada previamente en la tabla de variables medidas, y sin llegar a ahondar en la diferencia de valor entre cada uno de los pares de variables (valor sectorial y regional), puede resumirse que la competitividad del sector de empresas químicas en la región tiene ciertas variables que traccionan claramente en pos de una mejora de la competitividad, mientras que otras resultan ser un freno a la capacidad competitiva. Para priorizar el análisis sobre lo realmente determinante de lo bueno y lo malo para la competitividad sectorial, se identifican, de las treinta y una relavadas, las cinco mejores y las cinco perores variables, en valor absoluto y en relación a los valores de la región. El resultado es este:

Las cinco variables de mejor desempeño:

1. Orientación al consumidor: Marca el claro énfasis de las empresas del sector por responder a las necesidades de la demanda, una virtud saliente de todas ellas. 
2. Disponibilidad de científicos e ingenieros: Dada la complejidad del proceso productivo de las empresas químicas, muy técnico y muy exigente respecto de la permanente necesidad de incorporar nueva tecnología, el sector se beneficia claramente de esta característica del escenario competitivo regional de disponer de suficientes científicos, ingenieros y personal técnico que de una u otra forma pueda colaborar con el proceso productivo de las empresas.

3. Extensión de la marca: Una variable similar a la de orientación al consumidor, que muestra la fortaleza de las marcas de las distintas empresas como un producto adicional del fuerte impulso que muestran en toda su función comercial.

4. Naturaleza de la ventaja competitiva: Otra variable, como la 1 y la 3 , también relacionada con las operaciones y estrategia de las empresas. En este caso, el impulsor de la competitividad resulta ser la capacidad de las empresas para crear ventajas competitivas necesarias para mantener y/o incrementar sus posiciones de mercado.

5. Calidad de las escuelas de negocios: Variable como la 2 referida al ambiente de negocios, y similar en cuanto a la oportunidad que para la competitividad del sector representa contar con un escenario con oferta suficiente de recursos humanos muy calificados; en este caso, para las funciones de gestión general de las empresas.

Las cinco variables de peor desempeño:

1. Infraestructura férrea: La peor de todas. Muestra el claro deterioro que en la región presenta el estado de los trenes y de las vías férreas, no pudiendo constituirse este tipo de transporte en un eslabón válido de toda la cadena de logística de insumos y productos. 
2. Acceso a préstamos: Muestra el "freno" o la "amenaza" que para la competitividad del sector supone un mercado financiero muy poco desarrollado, con pocas opciones en cuanto a instrumentos financieros disponibles y fuentes de financiación muy restringidas tanto en oferentes como en montos de los créditos.

3. Colaboración entre universidad y empresas: Algo contradictorio dada la alta disponibilidad regional de profesionales con formación universitaria, pero esta variable indica en todo caso un sub-aprovechamiento de estos recursos humanos altamente calificados, ya que su potencial sería mucho mayor con la existencia de fuertes vínculos de colaboración entre los ámbitos académico y empresario.

4. Barreras de comercio encubiertas: Variable relacionada con la baja eficiencia en los mercados de bienes y la debilidad del marco jurídico y legal que hace a la comercialización de productos. En ese contexto, aparecen barreras al comercio encubiertas que hacen mella en la capacidad competitiva de las empresas del sector.

5. Adquisición gubernamental de productos de tecnología: Variable que supone, más en general, prácticas ineficientes y hasta no transparentes en cuanto a la forma que el Estado se comporta como agente económico del escenario competitivo, en este caso, en su rol de adquirir productos de tecnología.

De la mención y análisis hecho respecto de las mejores y las peores variables, es bueno destacar que tres de las mejores están relacionadas con las operaciones y estrategias de las empresas, mientras que las cinco peores, todas ellas, forman parte del ambiente de negocios.

Como elemento adicional de análisis, se presenta la misma información en forma gráfica, con "las cinco mejores y las cinco peores" variables y el valor puntual para cada una obtenido en la medición. 
Gráfico 8. Las cinco variables de mejor y peor desempeño

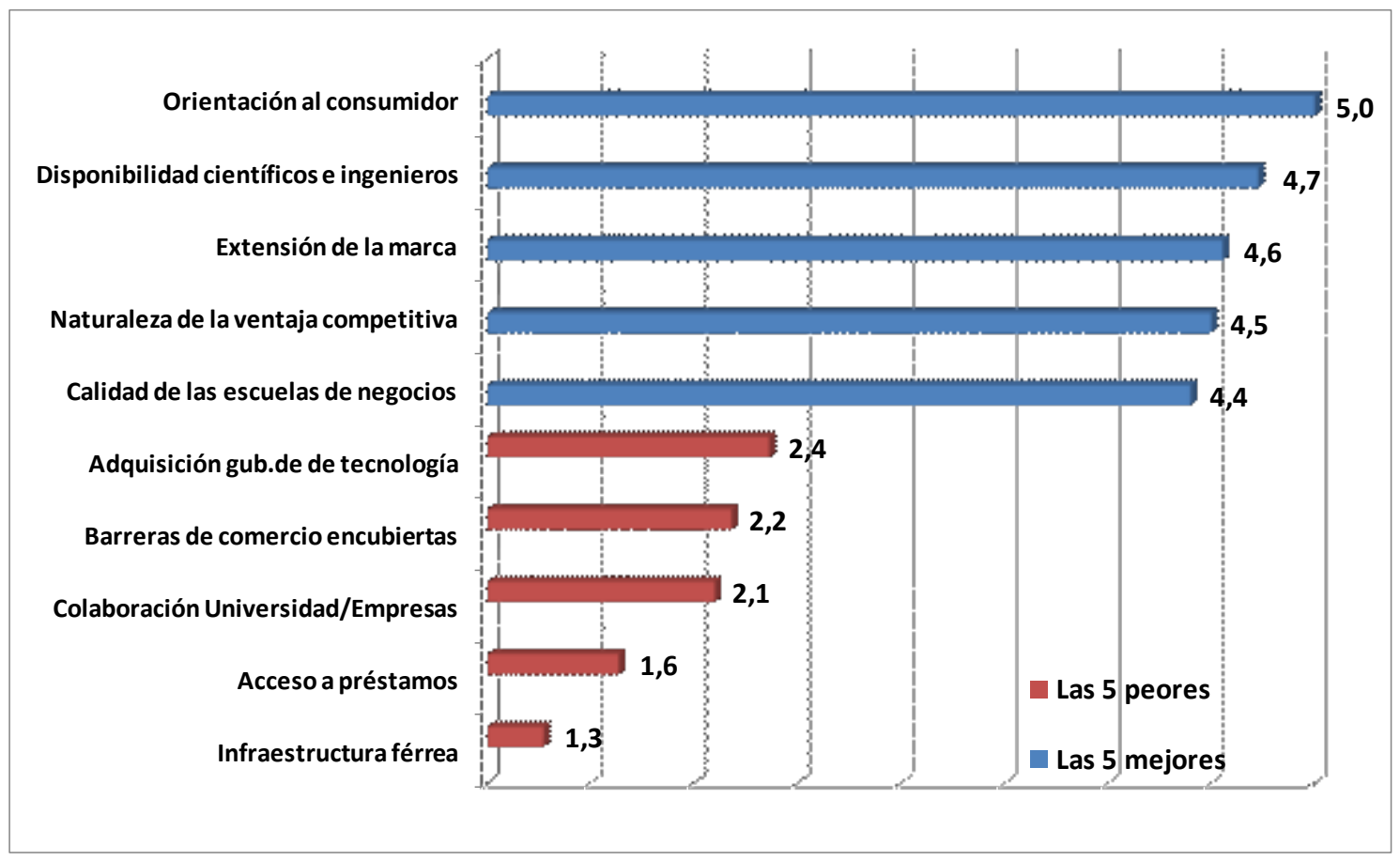

Fuente: Elaboración propia

Para completar el análisis de todas las variables relevadas es útil el cuadro de la página siguiente, en el que se presenta el $\mathrm{BCl}$ de empresas químicas junto a las treinta y una variables ordenadas por orden decreciente al valor medido, el detalle de las diferencias respecto del índice $\mathrm{BCl}$, los rangos de valores a lo largo de la escala de 1 a 7 y los porcentajes de cada rango y el acumulado. 
Tabla 5. Ordenamiento de variables de competitividad para el sector de empresas químicas de La Plata, Berisso y Ensenada

\begin{tabular}{|c|c|c|c|c|c|c|c|c|c|c|}
\hline 1 & 2 & 3 & 4 & 5 & 6 & 7 & 8 & 9 & 10 & 11 \\
\hline Rank & Variable & & Determinante & Valor $\mathrm{BCl}$ & $\begin{array}{c}\text { Dif. en valor } \\
\text { respecto BCl } \\
\text { Químicas }\end{array}$ & $\begin{array}{c}\text { Dif. en porc. } \\
\text { respecto BCl } \\
\text { Químicas }\end{array}$ & Rangos $\mathrm{BCl}$ & \begin{tabular}{|c|} 
Cant. de \\
variables por \\
rangos $\mathrm{BCl}$
\end{tabular} & $\%$ acum. & $\%$ acum \\
\hline & $\mathrm{BCl}$ sector de empresas químicas & & & 3,7 & & & & & & \\
\hline 1 & Grado de orientación del consumidor & $\bar{E}$ & Estrategia y operaciones de las empresas & 5,0 & 1,30 & $35 \%$ & Mas de 5 & $\overline{1}$ & $3 \%$ & $3 \%$ \\
\hline 2 & Disponibilidad de científicos e ingenieros & $\mathrm{F}$ & Condiciones de los factores & 4,7 & 1,03 & $28 \%$ & \multirow{10}{*}{4 a 5} & \multirow{10}{*}{10} & \multirow{10}{*}{$32 \%$} & \multirow{10}{*}{$35 \%$} \\
\hline 3 & Extensión de la marca & $\mathbf{E}$ & Estrategia y operaciones de las empresas & 4,6 & 0,86 & $23 \%$ & & & & \\
\hline 4 & Naturaleza de la ventaja competitiva & $\mathbf{E}$ & Estrategia y operaciones de las empresas & 4,5 & 0,80 & $22 \%$ & & & & \\
\hline 5 & Calidad de las escuelas de negocios & $\mathbf{F}$ & Condiciones de los factores & 4,4 & 0,70 & $19 \%$ & & & & \\
\hline 6 & Intensidad de la competencia local & E & Contexto para la estrategia y rivalidad empr. & 4,3 & 0,57 & $15 \%$ & & & & \\
\hline 7 & Sofisticación de los compradores & D & Condiciones de la demanda & 4,2 & 0,48 & $13 \%$ & & & & \\
\hline 8 & Calidad de los institutos de invest. científica & $\mathbf{F}$ & Condiciones de los factores & 4,1 & 0,39 & $11 \%$ & & & & \\
\hline 9 & Calidad de los proveedores locales & I & Industrias relacionadas y de apoyo & 4,1 & 0,39 & $11 \%$ & & & & \\
\hline 10 & Cantidad de proveedores locales & I & Industrias relacionadas y de apoyo & 4,1 & 0,39 & $11 \%$ & & & & \\
\hline 11 & Disposición a delegar autoridad & $\mathbf{E}$ & Estrategia y operaciones de las empresas & 4,0 & 0,30 & $8 \%$ & & & & \\
\hline 12 & Sofisticación del proceso de producción & $E$ & Estrategia y operaciones de las empresas & 3,8 & 0,12 & $3 \%$ & \multirow{8}{*}{3 a 4} & \multirow{8}{*}{8} & \multirow{8}{*}{$26 \%$} & \multirow{8}{*}{$61 \%$} \\
\hline 13 & Estado de desarrollo de agrupamientos & I & Industrias relacionadas y de apoyo & 3,7 & 0,03 & $1 \%$ & & & & \\
\hline 14 & Calidad de la infraestructura de las rutas & $\mathbf{F}$ & Condiciones de los factores & 3,6 & $-0,06$ & $-2 \%$ & & & & \\
\hline 15 & Eficacia de la junta directiva & $\mathbf{E}$ & Contexto para la estrategia y rivalidad empr. & 3,4 & $-0,27$ & $-7 \%$ & & & & \\
\hline 16 & Capacidad de innovación & $\mathbf{E}$ & Estrategia y operaciones de las empresas & 3,2 & $-0,50$ & $-14 \%$ & & & & \\
\hline 17 & Calidad de la infraestructura en general & $\mathbf{F}$ & Condiciones de los factores & 3,2 & $-0,52$ & $-14 \%$ & & & & \\
\hline 18 & Sofisticación del mercado financiero & $\mathbf{F}$ & Condiciones de los factores & 3,0 & $-0,70$ & $-19 \%$ & & & & \\
\hline 19 & Cooperación en las relaciones empr-trabaj. & E & Contexto para la estrategia y rivalidad empr. & 3,0 & $-0,70$ & $-19 \%$ & & & & \\
\hline 20 & Efectividad de las políticas antimonopólicas & $\mathrm{E}$ & Contexto para la estrategia y rivalidad empr. & 2,9 & $-0,79$ & $-21 \%$ & \multirow{10}{*}{2 a 3} & \multirow{10}{*}{10} & \multirow{10}{*}{$32 \%$} & \multirow{10}{*}{$94 \%$} \\
\hline 21 & Protección de la propiedad intelectual & $\mathbf{F}$ & Condiciones de los factores & 2,9 & $-0,80$ & $-22 \%$ & & & & \\
\hline 22 & Independencia Judicial & $\mathbf{F}$ & Condiciones de los factores & 2,7 & $-0,97$ & $-26 \%$ & & & & \\
\hline 23 & Calidad de las escuelas públicas & $\mathbf{F}$ & Condiciones de los factores & 2,5 & $-1,15$ & $-31 \%$ & & & & \\
\hline 24 & Calidad de la infraestructura del transporte aéreo & $\mathbf{F}$ & Condiciones de los factores & 2,5 & $-1,25$ & $-34 \%$ & & & & \\
\hline 25 & Favoritismo en las decis. de los funcionarios gub. & $\mathbf{E}$ & Contexto para la estrategia y rivalidad empr. & 2,5 & $-1,25$ & $-34 \%$ & & & & \\
\hline 26 & Calidad de la infraestructura de los puertos & $\mathbf{F}$ & Condiciones de los factores & 2,4 & $-1,34$ & $-36 \%$ & & & & \\
\hline 27 & Adquis. gub.de productos de tecnología & $\mathbf{D}$ & Condiciones de la demanda & 2,4 & $-1,34$ & $-36 \%$ & & & & \\
\hline 28 & Barreras de comercio encubiertas & E & Contexto para la estrategia y rivalidad empr. & 2,2 & $-1,52$ & $-41 \%$ & & & & \\
\hline 29 & Colaboración en la investigación Univ. / Empr. & $\mathrm{F}$ & Condiciones de los factores & 2,1 & $-1,60$ & $-43 \%$ & & & & \\
\hline 30 & Facilidad en el acceso a préstamos & $\mathrm{F}$ & Condiciones de los factores & 1,6 & $-2,06$ & $-56 \%$ & 1 a ? & 2 & $6 \%$ & $100 \%$ \\
\hline 31 & Desarrollo de la infraestructura férrea & $\mathbf{F}$ & Condiciones de los factores & 1,3 & $-2,43$ & $-66 \%$ & & & & \\
\hline
\end{tabular}


Del análisis del cuadro puede resaltarse que:

- El $90 \%$ de las variables se ubica en valores del rango entre más de 2 y menos de 5.

- De hecho, sólo una variable obtiene un valor mayor a 5. Como contrapartida, son sólo dos las que se ubican por debajo de un valor de 2 .

- Sólo un 35\% de las variables tiene un valor mayor a 4. Y ya al considerar el rango de valores mayores a 3 aparecen acumuladas el $61 \%$ del total de variables.

- Los determinantes del perfil competitivo son bastante heterogéneos, pues en general todos ellos "distribuyen" sus variables en los distintos rangos de valores.

\section{LOS VALORES DE COMPETITIVIDAD MEDIDOS DENTRO DEL ESQUEMA DE PORTER}

El apartado ambiente de negocios de la encuesta de opinión responde en forma exacta al planteamiento de Porter respecto de los determinantes de la ventaja competitiva, ya que contiene conjuntos de variables referidas a condiciones de los factores, condiciones de la demanda, industrias relacionadas y de apoyo y contexto para la estrategia, estructura y rivalidad de las empresas. Ahora, pudiendo forzar para incluirlas dentro de ambiente de negocios a las variables relevadas para el apartado operaciones y estrategias de las empresas, se puede ensayar la plena consideración de todas las variables de la encuesta dentro de un encuadramiento exacto al esquema de Porter; esto es, todas las variables relevadas asignadas dentro de alguno de los cuatro determinantes. Un ensayo así habilita un análisis adicional: la consideración de qué porción aporta cada determinante a la ventaja competitiva total del sector de empresas químicas en La Plata, Berisso y Ensenada.

Se procedió entonces a "reasignar" las variables de operaciones y estrategias de las empresas según los siguientes criterios:

- Capacidad de innovación, Grado de orientación al consumidor y Extensión de la marca: reasignadas al determinante Condiciones de la demanda. 
- Sofisticación del proceso de producción, Naturaleza de la ventaja competitiva y Disposición a delegar autoridad: reasignadas al determinante Contexto para la estrategia, estructura y rivalidad de las empresas.

Medido el valor de cada una de las variables se puede analizar qué porcentaje aporta cada determinante (siempre bajo la consideración estricta del esquema de Porter) respecto del total de ventaja competitiva del sector. Así:

- $21 \%$ corresponde a Condiciones de los factores.

- $24 \%$ a Estrategia, estructura y rivalidad de las empresas

- $27 \%$ a Condiciones de la demanda

- $28 \%$ a Sectores relacionados y de apoyo

En esquema gráfico, estos resultados pueden presentarse así:

Figura 10. Las mediciones de competitividad dentro del esquema de Porter

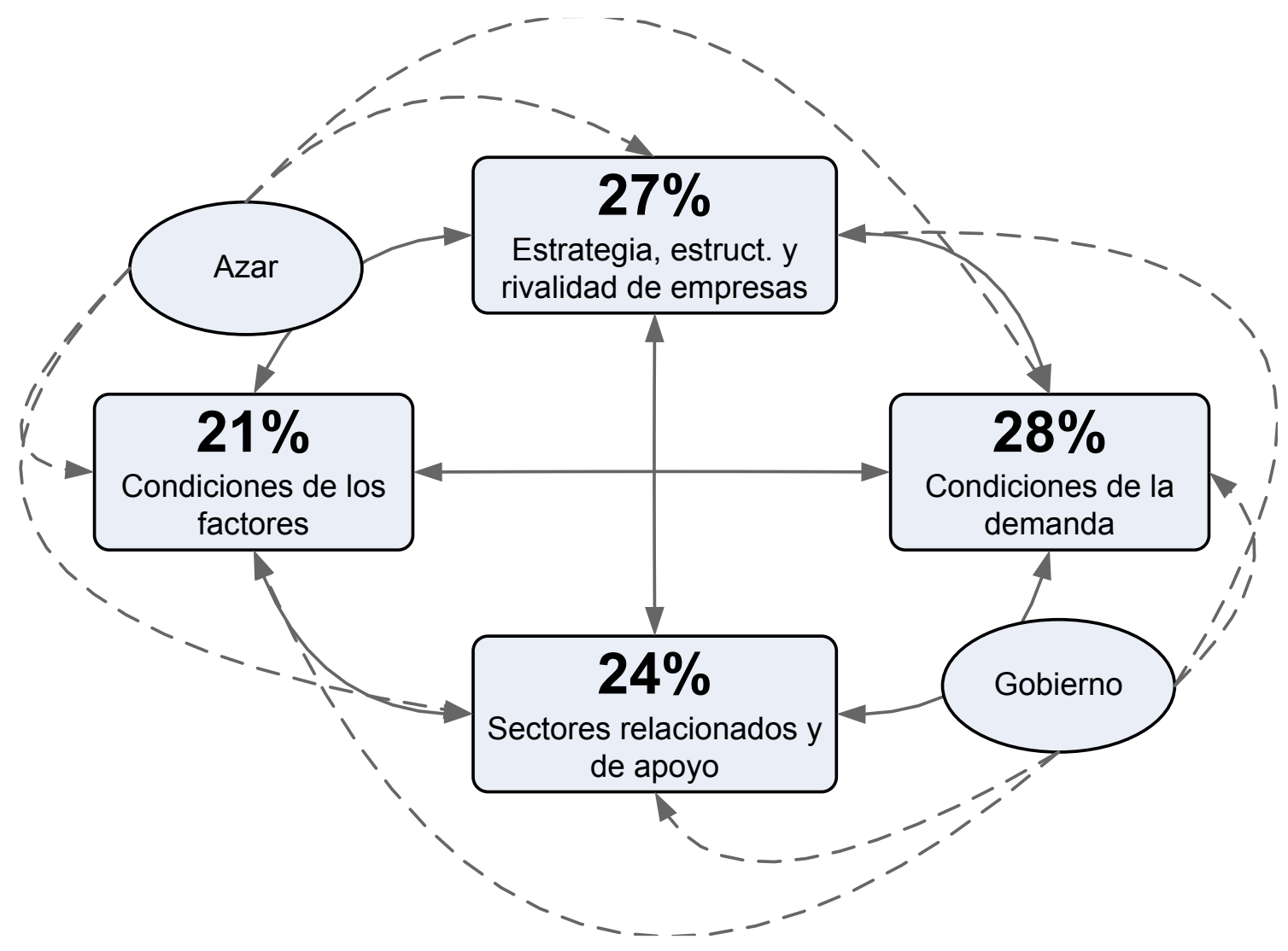

Fuente: Elaboración propia 
Los resultados obtenidos con la "reasignación" de variables al esquema de Porter coinciden con los análisis que se vienen haciendo: los puntos fuertes del escenario competitivo de las empresas químicas de la región se encuentran en las condiciones de demanda (28\%), exigente y sofisticada, a las que las empresas responden con estrategias acordes para aprovechar esa fuente de ventaja competitiva (27\%), caracterizadas por un profundo enfoque a las necesidades del consumidor y acertadas políticas de marca. Y mientras los sectores relacionados y de apoyo colaboran (24\%) con cuestiones puntuales como la disponibilidad de recursos humanos útiles al sector y de alta preparación, el peor desempeño se lo lleva el determinante relacionado con las condiciones de los factores (21\%), que erosiona la ventaja competitiva con sus cuestiones puntuales de infraestructura general, de transporte, el bajo desarrollo del mercado financiero y la falta de fuentes alternativas de financiación.

\section{CUMPLIMIENTO DEL PRIMER OBJETIVO DE LA INVESTIGACIÓN}

Los resultados presentados en los puntos anteriores han permitido cumplir con uno de los objetivos de la investigación: medir la competitividad del sector industrial de empresas químicas en la zona de La Plata, Berisso y Ensenada. Como toda medición de competitividad, los resultados cobran sentido cuando se los compara con resultados similares, sean de otro sector, de una región, del propio país o de otros países. Todo eso se hizo, en la medida en que se cotejaron los resultados del índice global y de los distintos sub-índices de las empresas químicas con los de los otros sectores relevantes de la región, y los de la región considerada como un todo, con los de Argentina y con los de países que por distintas circunstancias resultaron relevantes en la comparación.

Resta ahora presentar, en el siguiente apartado destinado a las Conclusiones, conceptos referidos al segundo de los objetivos de la investigación: evaluar el potencial de desarrollo competitivo del sector bajo estudio, identificando las fuerzas y debilidades que presenta y las oportunidades y amenazas a las que se enfrenta. 


\section{CONCLUSIONES}

En vista de los resultados obtenidos, y no perdiendo el foco respecto de lo que fueron los objetivos de la investigación, pueden plantearse dos tipos de conclusiones. Las primeras más inclinadas a destacar algunas particularidades que ha permitido mostrar la medición de la competitividad del sector de empresas químicas en la región (en el marco, claro está, de la medición más global de toda la competitividad empresaria regional). Las segundas, intentando indagar en la existencia y perspectiva de refuerzo de los factores clave que marcan determinado potencial de desarrollo de la ventaja competitiva del sector industrial bajo estudio.

\subsection{CONSIDERACIONES SOBRE LA MEDICIÓN DE LA COMPETITIVIDAD}

- El sector de las empresas químicas es un buen referente del perfil competitivo que presenta toda la región de La Plata, Berisso y Ensenada. Resultan similares las mediciones hechas sobre la competitividad global de la región y la del sector, por lo que puede afirmarse que, en general, los determinantes de una y otra son prácticamente los mismos. Aunque la competitividad del sector se ubica un escalón por debajo respecto de la regional, ambas comparten el mayor aporte al nivel de competitividad en todo aquello relacionado con las operaciones y estrategias de las empresas por sobre las cuestiones referidas al ambiente de negocios. En términos más llanos, esto significa que tanto la región como el sector sustentan su competitividad más en lo que ocurre "puertas adentro" de las empresas y no tanto en lo que son las condiciones del escenario en general.

- Para reforzar la imagen del sector como buen referente de lo que ocurre en la región, basta hacer notar que de las treinta y una variables relevadas en el estudio sólo tres de ellas presentan una diferencia de más de un punto -en la escala de uno a siete- entre ambas mediciones (medición de la competitividad regional vs. medición de la competitividad en el sector). 
- Y para remarcar que la competitividad del sector se fundamenta más en los factores internos a las empresas que en los referidos al escenario, es válido notar que tres de las cinco variables más poderosas para la competitividad de las empresas químicas tienen que ver con el desempeño empresario (la orientación al consumidor, la extensión de marca y la naturaleza de la ventaja competitiva), mientras que las dos restantes referidas al escenario (disponibilidad de científicos e ingenieros y calidad de las escuelas de negocios) pertenecen a una condición puntual que se nota en la región: la buena calidad de la oferta educativa de nivel superior y su consecuente abundante oferta de profesionales muy capacitados.

- En el otro extremo, es fácil percibir como la competitividad del sector paga un costo muy alto por las condiciones del entorno inmediato y general de sus empresas, que determinan un escenario competitivo nada favorable para la formación de ventaja competitiva. Muestra de esto es que las cinco variables de peor desempeño entre las treinta y una medidas son todas referidas al escenario: compras de tecnología por parte del Gobierno, barreras de comercio encubiertas, colaboración entre universidad y empresas -la única de las "peores variables" atribuible a estas últimas-, acceso a préstamos e infraestructura férrea. El entorno competitivo inmediato de las empresas se convierte así en el gran freno al desarrollo de la competitividad sectorial.

- En el ensayo de forzar todas las variables medidas para incluirlas en el esquema del diamante de Porter, y ver así cuánto aporta porcentualmente cada conjunto de ellas, quedaron mejor posicionadas las que tienen que ver con las condiciones de la demanda y con el contexto para la estrategia y la estructura de las empresas, y algo relegadas las dos restantes. Sobre cada una de estas cuestiones algo se puede agregar a modo de conclusión.

- El aporte de las condiciones de la demanda sirve para resaltar la alta exigencia de muchos segmentos de consumidores de las empresas del sector, fundamentalmente de aquellos que utilizan los productos de la química y la petroquímica como insumos intermedios de sus propios procesos productivos. El elevado contenido técnico incluido en las condiciones de la demanda es el 
que mantiene la alta orientación al consumidor como una de las fortalezas de las empresas del sector, las que en las mediciones han mostrado su alta propensión a priorizar las funciones empresarias relacionadas con la comercialización de productos.

- Sobre las cuestiones referidas al determinante estrategia, estructura y rivalidad de las empresas, es destacable la intensidad del escenario competitivo en el sector, seguramente explicado por los actores económicos de menor dimensión, ya que las grandes empresas participantes (ej.: YPF, Petroken) han sabido alcanzar posiciones de dominancia en las que casi ni deben preocuparse por competidores de origen local. Así, es fuerte el grado de rivalidad que se percibe cuando el foco recae sobre las porciones del escenario ocupadas por las empresas más chicas (laboratorios químicos, procesadores de sustancias con destino al mercado local, etc.), donde hay un gran conjunto de ellas que, por sus dimensiones y su equilibrado poder relativo, están sometidas a una intensa competencia sin poder ninguna imponer sobre las otras un marcado grado de dominancia sobre el mercado.

- Luego, el resto de las variables sobre estrategia, estructura y rivalidad ya no aportan tanto a un buen perfil competitivo. Algunas de ellas, por causas atribuibles enteramente a las empresas, como la eficacia de las juntas directivas (seguramente por la inexistencia o no funcionamiento efectivo de este tipo de órgano institucional en la mayoría de las empresas del sector en esta región) y el grado de cooperación en las relaciones entre empresas y trabajadores (aquí afecta la nula presencia de trabajadores en instancias de decisión y la habitualmente conflictiva relación entre empresas y sindicatos), mientras que otras ya caen en la esfera de responsabilidad del Estado, pocas veces efectivo al momento de paliar los efectos perjudiciales de las prácticas monopólicas, del favoritismo que suele estar presente en las decisiones gubernamentales y de las barreras encubiertas a un libre ejercicio del comercio.

- En tercer término, también es importante la posición de las variables sobre sectores industriales relacionados y de apoyo, lo que sirve para resaltar la 
presencia en la región de ciertas conformaciones de agrupamientos industriales en forma de clusters. El ejemplo saliente es el del Polo Petroquímico ubicado en Ensenada, altamente integrado en sentido vertical para poder incluir todas las fases del proceso productivo en la industria petroquímica. El Polo Petroquímico ha sido siempre muy cuestionado por su difícil relación con la región, a causa de las dificultades que en toda su historia ha tenido para poder cumplir con exigencias ambientales de mínima que aseguran un desarrollo sustentable. Pero esto no debe impedir reconocer lo que implica para la región en cuanto a movimiento productivo y comercial, fuente de trabajo y sustento de los Estados del ámbito municipal, amén de considerar que el corazón del mismo es la empresa más grande de toda la región (la destilería de YPF ubicada en Ensenada).

- Por último, resta concluir sobre el desempeño de las variables de lo que en el diamante competitivo es la condición de los factores. A riesgo de caer en reiteraciones, se puede destacar el buen posicionamiento del sector en todo lo referente a disponibilidad y desarrollo de recursos humanos calificados (calidad y cantidad de científicos e ingenieros, calidad de institutos de investigación científica y de instituciones para formación superior), fundamento elemental de toda construcción de ventaja competitiva. En cambio, y aquí sí ya seguramente reiterando, el gran "talón de Aquiles" de la ventaja competitiva del sector es una nada feliz combinación de pobre infraestructura física (vías férreas, puertos, aeropuertos, estado de las rutas) e institucional (justicia, educación, mercados de capitales), sobre factores que se han venido degradando desde haca décadas y sobre los que no será nada fácil recomponerlos en un horizonte de planeamiento de corto o mediano plazo.

\section{CONSIDERACIONES SOBRE EL POTENCIAL DE DESARROLLO COMPETITIVO}

- Dando continuidad a lo recientemente considerado sobre la medición de la competitividad, y al momento de pensar en cómo remover los grandes limitantes de una mejor competitividad de las empresas químicas, se puede 
concluir que, en general, gran parte de las limitaciones tienen que ver con el plano institucional del escenario competitivo o con el stock o el ritmo de inversión pública en infraestructura. La mala noticia aquí es que este tipo de limitantes no suelen ser de fácil remoción. Grandes períodos de tiempo con gestiones erráticas sobre todo el entramado institucional, plagadas de impulsos pendulares que poco han colaborado para un desarrollo armónico de las distintas instituciones (fundamento esto de toda buena sociedad) han derivado en un estado de cosas en el que, con razón, todo se cuestiona. La seguridad jurídica, el desempeño de la justicia, la efectividad de las políticas públicas, el sistema educativo, todo parece estar reñido con las condiciones necesarias para fomentar un escenario de prosperidad y desarrollo económico sustentable, sin la permanente sensación de cómo actuar ante las ineludibles y periódicas crisis económicas. En consecuencia, un escenario así mal puede ser tierra fértil para la creación y sostenimiento de ventaja competitiva, sea del sector de empresas químicas o de cualquier otro en la región. La necesaria calidad institucional para generar, como ser, una adecuada normativa referida al comercio, buenas escuelas públicas, equitativas decisiones de los funcionarios del gobierno o una justicia plenamente independiente no es algo que se consiga de un día para el otro. Los países con buena calidad en sus instituciones son los que han trabajo por ello durante generaciones, por lo que no es prudente esperar grandes avances en lo institucional en un horizonte de corto o mediano plazo.

- Del mismo modo, no es racional plantearse una rápida remoción de los limitantes que tienen que ver con el stock de bienes y servicios relacionados con la infraestructura general. Estás, si bien son cuestiones más propicias para abordar desde una perspectiva de región (lo "institucional" siempre exigirá un abordaje más a nivel provincia o nación), son algo que dependen no sólo del elevado ritmo de inversiones públicas que todo incremento del stock de infraestructura requiere sino también del planteamiento de un nuevo esquema de desarrollo regional, permutando, por ejemplo, parte del transporte terrestre por el de vías férreas, o impulsando una profunda descentralización del esquema de puertos, o habilitando un aeropuerto al menos de alcance nacional 
para la comercialización más rápida y directa de determinados productos de alto valor agregado hacia otras regiones del país o el exterior. Las empresas químicas de la región -y también las de otros sectores- pueden colaborar con esto detectando necesidades, elaborando diagnósticos, participando en las fases de planeamiento y ejecución y hasta tomando el cargo de su financiación vía nuevos tributos de fines específicos. Pero, no obstante, el rol fundamental de impulsor que dote a la región de una adecuada infraestructura recaerá siempre en el Estado, y en sus tres niveles, dependiendo del volumen y del ritmo en que deban realizarse las inversiones necesarias.

- Por el contrario, gran potencial para el desarrollo competitivo del sector tiene la alta disponibilidad en la región de recursos humanos con conocimientos muy técnicos y de alta calificación. La ciudad de La Plata mantiene con el tiempo el gran prestigio de su Universidad, polo de atracción para estudiantes de las más diversas regiones del país y fuente permanente de nuevos profesionales. Particular capacidad de formar buenos profesionales con alta probabilidad de una fácil inserción en el mercado laboral tienen las facultades relacionadas con la ingeniería, la química y todo el conocimiento muy técnico y especializado que requieren las empresas del sector de la industria química y petroquímica. Estos profesionales tienen a las empresas de la región como una alternativa válida para desarrollar sus carreras sin necesidad de apartarse de lugar donde se formaron como tales. Si a esto le agregamos la buena calidad que la medición de competitividad ha registrado sobre la educación de posgrado, rápidamente es fácil percibir la formación de un círculo virtuoso de gran disponibilidad de buenos profesionales / formados en universidades prestigiosas / en ramas del conocimiento técnico de fácil aplicación sobre la industria / y con buena oferta educativa para un proceso de formación continua.

- Más aún, reforzando este circuito virtuoso sobre los recursos humanos se encuentra todo el entramado de las áreas de investigación de las propias facultades y algunos ámbitos puntuales de investigación científica a cargo del Estado (la Comisión de Investigaciones Científicas a cargo del Gobierno 
provincial es buen ejemplo de esto). Por su naturaleza, la investigación científica es el gran motor de los distintos procesos de innovación industrial, determinantes éstos, en gran medida, de la creación y sostenimiento de ventaja competitiva. La disponibilidad de ámbitos para la investigación y el desarrollo científico y tecnológico es entonces una característica de la región, e importante punto de apoyo para incrementar su perfil competitivo. No obstante, dentro del mismo marco de análisis, está pendiente en la región el trabajar más estrechamente en la relación entre universidades y empresas, variable puntualmente medida en el estudio, de no muy buen desempeño, y crítica para traducir en resultados concretos la alta potencialidad ya descripta del "stock" de recursos humanos.

- Otro pilar que puede considerarse como de alto potencial para el desarrollo competitivo del sector es el del marcado foco que han arrojado las mediciones de competitividad en todo aquello relacionado con la satisfacción del consumidor por parte de las empresas. Como ya se expresó, esto va de la mano de la elevada sofisticación que muestran los consumidores del sector, algo a lo que, según la investigación, las empresas han sabido responder. El mantener y hasta mejorar en forma continua esta capacidad de dar respuesta a las condiciones de la demanda resulta un valioso fundamento para la creación de ventaja competitiva. Sobre este aspecto, dos parecen ser los perfiles empresarios que colaboran, cada cuál a su manera, en el desarrollo de un buen potencial competitivo. Por un lado, están las grandes empresas del sector, YPF sobre todo y en menor medida Petroken. En ellas se ven deliberadas estrategias de comercialización que son implementadas por medio de ingentes volúmenes de recursos invertidos. Estos son actores que, por su dimensión, siempre intentan maximizar las fortalezas que sus escalas les permiten en cuanto al uso de sus recursos físicos y sus bienes intangibles. En una dimensión menor aparecen las PyMES del sector, igualmente muy enfocadas a las necesidades del mercado pero mas vulnerables a las condiciones del escenario en su intento por mantener capacidad competitiva. Es este último tipo de empresa la que más sufre las "patologías" del perfil competitivo del sector originadas en las ya mencionadas debilidades institucionales y de 
infraestructura presentes en la región, pero, no obstante, logran mantener un buen desempeño en su función comercial. Gran potencial en incrementar su desarrollo competitivo tendrán estas PyMES si se logran remover las debilidades del escenario.

- La conformación de un auténtico agrupamiento industrial de las empresas químicas es una cuestión adicional por considerar en el análisis del potencial competitivo del sector. Existe una buena base para pensar en la creación de un agrupamiento industrial de este tipo, y es el Polo Petroquímico de Ensenada. Lamentablemente, desde su constitución, el polo no ha sido mucho más que la expresión de deseo de las distintas administraciones locales por que la zona explotara todo su potencial de desarrollo de la mano de dos o tres grandes actores del sector petroquímico, a quienes acompañarían todo un conjunto de PyMES con quienes tejer un entramado empresario a lo largo de toda la cadena de valor de la industria. Al contrario de esto, el polo se convirtió más pronto que tarde en un vecino hostil de la comunidad, si bien proveedor de numerosas fuentes de trabajo, a un precio muy elevado en cuanto al impacto ambiental de sus actividades. Poco aportaron también, con el tiempo, las gestiones de los tres niveles del Estado, las que más bien por omisión no pudieron nunca percibir y gatillar todo el potencial económico que el polo prometía. No obstante, el agrupamiento de empresas existe, y funciona. En torno a la presencia de un gigante de la industria como YPF se despliegan a su alrededor todo un conjunto de PyMES proveedoras de productos y servicios que suponen la mejor base para plantear la constitución de un auténtico agrupamiento petroquímico de la región de La Plata, Berisso y Ensenada. Falta para ello una deliberada política industrial que cree los incentivos necesarios para poder encauzar los objetivos empresarios bajo el gran lineamiento estratégico de la constitución de un agrupamiento industrial. Es fácil estimar también que la constitución de un gran agrupamiento incrementaría el poder relativo del sector industrial para exigir mejoras en los determinantes de la ventaja competitiva regional relacionados con lo institucional y el stock de recursos físicos. 
- Vaya una última conclusión al rol del Gobierno como impulsor o facilitador de ventajas competitivas en la región. De la medición de competitividad regional que se ha hecho, surge que el rol del Gobierno está íntimamente relacionado con la existencia de los principales limitantes al potencial competitivo. Deberá ser entonces el propio Gobierno quien impulse un incremento en la calidad de las instituciones y en la inversión necesaria en infraestructura. Estas dos cuestiones son los grandes limitantes para la creación de ventaja competitiva y sobre ambas la responsabilidad atribuible a los tres niveles del Estado es ineludible. Pero además, es imprescindible pensar en políticas industriales deliberadas para impulsar el potencial competitivo que pueda tener la región, por ejemplo, creando las condiciones para el desarrollo del ya mencionado agrupamiento petroquímico, o ayudando a las PyMES con programas específicos para un mejor acceso a los recursos necesarios para sus procesos productivos, o impulsando medidas tendientes a favorecer una mayor inserción de todo el sector en mercados extra-región o internacionales, o, en definitiva, logrando un trabajo codo a codo entre empresas y Estado bajo un alineamiento general de los intereses particulares y los de la sociedad en su conjunto. 


\section{BIBLIOGRAFÍA}

ACEMOGLU, DARON y ROBINSON, JAMES. Por qué fracasan los países. Los orígenes del poder, la prosperidad y la pobreza. Editorial Ariel (2013).

AGHÓN, GABRIEL; ALBURQUEQUE, FRANCISCO Y CORTÉS PATRICIA. Desarrollo económico local y descentralización en América Latina: un análisis comparativo. CEPAL / GTZ, Santiago de Chile (2001).

BARBERO, MARÍA INÉS Y OTROS. Historia económica mundial. Del paleolótico a internet. Emecé (2007).

BUITELAAR, RUDOLF M. ¿Cómo crear competitividad colectiva? Unidad de Industria. División de Desarrollo Productivo y Empresarial (2000).

CHO, D.S. y H.C., MOON. From Adam Smith to Michael Porter, evolution of competitiveness theory. World Scientific Publishing Co. Pte. Ltd (2000).

CORIAT, BENJAMIN. Los desafíos de la competitividad. Asociación Trabajo y Sociedad, Oficina de Publicaciones del CBC, Universidad de Buenos Aires (1997).

GALBRAITH, JOHN KENNETH. Historia de la economía. Editorial Ariel (1994).

GERCHUNOFF, PABLO Y LLACH, LUCAS. El ciclo de la ilusión y el desencanto: un siglo de políticas económicas argentinas. Ariel (2003).

KEYNES, JOHN MAYNARD. Teoría general de la ocupación, el interés y el dinero. Fondo de Cultura Economómica (1992).

KLAUS ESSER, WOLFGANG HILLEBRAND, DIRK MESSNER y JÜRG MEYER-STAMER. Competitividad Sistémica. Revista CEPAL N 59 (1996).

KRUGMAN, PAUL. El internacionalismo moderno. La economía internacional y las mentiras de la competitividad. Editorial Crítica (2004).

LEVY, ALBERTO. Desarrollo competitivo y dinámica de los sectores industriales. Granica (2009).

MOON, H.C, RUGMAN, A. y VERBEKE, A. The generalized double diamond approach to international competitiveness. en Alan m. Rugman, editor, research in global strategic management. A Research Annual; (1995). Vol. 5, pp. 97-114.

NEFFA. JULIO CESAR. ¿Qué hacer para mejorar la competitividad de las PyMEs ARGENTINAS? Asociación Trabajo y Sociedad. PIETTE CONICET (2000). 
PORTER, MICHAEL E. Estrategia competitiva. Técnicas para el análisis de los sectores industriales y de la competencia. CECSA (1981).

PORTER, MICHAEL E. Ventaja competitiva. Creación y sostenimiento de un desempeño superior. CECSA (1986).

PORTER, MICHAEL E. La ventaja competitiva de las naciones. Javier Vergara Editor (1991).

PORTER, M. Cambiar el modo de competir internacionalmente. Publicado en Estrategia y Ventaja Competitiva. Ediciones Deusto (2002).

RAPOPORT, MARIO. Las políticas económicas de la Argentina. Una breve historia. Planeta Booket (2010).

RICARDO, DAVID. Principios de economía política y tributación. Fondo de Cultura Económica (2010).

ROCCATAGLIATA, JUAN ALBERTO (Coordinador). Argentina. Una visión actual y prospectiva desde la dimensión territorial. Editorial Emecé (2008).

SCHUMPETER, JOSEPH A. Capitalismo, socialismo y democracia. Ediciones Folio (1996).

SMITH, ADAM. Una investigación sobre la naturaleza y causas de la riqueza de las naciones. Alianza Editorial (1994).

STIGLITZ, JOSEPH E. Y CHARLTON, ANDREW. Comercio justo para todos: cómo el comercio puede promover el desarrollo. Pensamiento/Taurus (2007).

THUROW, LESTER. La guerra del siglo XXI: La batalla económica que se avecina entre Japón, Europa y Estados Unidos. Javier Vergara Editor (1994).

WEBER, MAX. La ética protestante y el espíritu del capitalismo. Editorial Reus (2009). 


\section{ANEXO}

Modelo de Encuesta sobre la visión sectorial de aspectos de competitividad empresarial regional

\section{A. Operaciones y estrategias de las empresas}

\begin{tabular}{|c|c|c|c|c|c|c|c|}
\hline 1. Sofisticación del proceso de producción & 1 & 2 & 3 & 4 & 5 & 6 & 7 \\
\hline $\begin{array}{l}\text { Los procesos de producción en general (1=usan tecnología obsoleta, } 7 \\
=\text { utilizan la mejor y más eficiente tecnología mundial) }\end{array}$ & & & & & & & \\
\hline 2. Naturaleza de la ventaja competitiva & 1 & 2 & 3 & 4 & 5 & 6 & 7 \\
\hline $\begin{array}{l}\text { La ventaja competitiva de las empresas de su región en el mercado } \\
\text { internacional se debe a ( } 1 \text { =bajo costo laboral, } 7=\text { productos y procesos } \\
\text { únicos) }\end{array}$ & & & & & & & \\
\hline 3. Grado de capacitación del personal & 1 & 2 & 3 & 4 & 5 & 6 & 7 \\
\hline $\begin{array}{l}\text { En su región, en general el enfoque de las empresas en los recursos } \\
\text { humanos es invertir ( } 1=\text { Poco en capacitación y desarrollo, } 7=\text { Fuertemente } \\
\text { para atraer, capacitar y retener al personal) }\end{array}$ & & & & & & & \\
\hline 4. Grado de enfoque hacia el mercado & 1 & 2 & 3 & 4 & 5 & 6 & 7 \\
\hline $\begin{array}{l}\text { El nivel de marketing en su región es (1=limitado o primitivo, } 7=\text { alto o más } \\
\text { sofisticado del mundo) }\end{array}$ & & & & & & & \\
\hline 5. Disposición a delegar autoridad & 1 & 2 & 3 & 4 & 5 & 6 & 7 \\
\hline $\begin{array}{l}\text { La disposición a delegar autoridad en los subordinados es } \\
\text { (1=generalmente baja, 7=generalmente alta) }\end{array}$ & & & & & & & \\
\hline 6. Capacidad de innovación & 1 & 2 & 3 & 4 & 5 & 6 & 7 \\
\hline $\begin{array}{l}\text { Las empresas obtienen tecnología ( } 1=\text { exclusivamente de empresas } \\
\text { extranjeras, } 7=\text { =siendo pioneros con sus propios nuevos productos o } \\
\text { procesos) }\end{array}$ & & & & & & & \\
\hline 7. Presencia de la cadena de valor & 1 & 2 & 3 & 4 & 5 & 6 & 7 \\
\hline $\begin{array}{l}\text { Las empresas exportadores en su región (1=están involucradas } \\
\text { primariamente en la producción, } 7=\text { además de la producción, también } \\
\text { hacen desarrollo de productos, distribución y comercialización) }\end{array}$ & & & & & & & \\
\hline 8. Amplitud de los mercados internacionales & 1 & 2 & 3 & 4 & 5 & 6 & 7 \\
\hline $\begin{array}{l}\text { Las empresas exportadoras de su región venden ( } 1=\text { primariamente en } \\
\text { unos pocos mercados extranjeros, } 7=\text { en virtualmente todos los mercados } \\
\text { internacionales) }\end{array}$ & & & & & & & \\
\hline
\end{tabular}




\begin{tabular}{|c|c|c|c|c|c|c|c|}
\hline 9. Originalidad en el diseño de productos & 1 & 2 & 3 & 4 & 5 & 6 & 7 \\
\hline $\begin{array}{l}\text { El diseño de los productos es ( } 1=\text { copiado o con licencias del extranjero, } \\
7=\text { desarrollado localmente) }\end{array}$ & & & & & & & \\
\hline $\begin{array}{l}\text { 10. Grado de orientación del consumidor } \\
\text { Las empresas en su región (1=generalmente tratan mal al consumidor, } \\
7=\text { prestan mucha atención a la satisfacción del consumidor) }\end{array}$ & 1 & 2 & 3 & 4 & 5 & 6 & 7 \\
\hline $\begin{array}{l}\text { 11. Control de la distribución internacional } \\
\text { La distribución y comercialización internacional en su región ( } 1=e s \\
\text { realizada por empresas extranjeras, } 7=e s \text { propiedad y controlada por } \\
\text { empresas locales) }\end{array}$ & 1 & 2 & 3 & 4 & 5 & 6 & 7 \\
\hline $\begin{array}{l}\text { 12. Extensión de la marca } \\
\text { Las empresas que venden internacionalmente ( } 1=\text { venden commodities } \\
\text { (productos sin marca) o en un mercado de marcas extranjeras, } 7=\text { han } \\
\text { desarrollado sus propias marcas internacionales) }\end{array}$ & 1 & 2 & 3 & 4 & 5 & 6 & 7 \\
\hline $\begin{array}{l}\text { 13. Soporte en la administración profesional } \\
\text { Las posiciones gerenciales de mayor jerarquía en su región ( } 1=\text { son } \\
\text { generalmente ocupadas por familiares, } 7=\text { son solamente ocupadas por } \\
\text { profesionales capacitados) }\end{array}$ & 1 & 2 & 3 & 4 & 5 & 6 & 7 \\
\hline $\begin{array}{l}\text { 14. Grado de compensación por incentivos } \\
\text { La compensación de la administración en su región ( } 1=\text { está basada } \\
\text { exclusivamente en el salario, } 7=\text { incluye incentivos sustanciales en la forma } \\
\text { de bonos y opciones de acciones) }\end{array}$ & 1 & 2 & 3 & 4 & 5 & 6 & 7 \\
\hline $\begin{array}{l}\text { 15. Nivel de ventas a países de la región } \\
\text { Las exportaciones a los países cercanos son (1=limitadas, } 7=\text { considerables } \\
\text { y crecientes) }\end{array}$ & 1 & 2 & 3 & 4 & 5 & 6 & 7 \\
\hline
\end{tabular}

\section{B. Ambiente de Negocios}

\section{B.1. Condiciones de los factores}

\section{B.1.1. Infraestructura física}

\begin{tabular}{|c|c|c|c|c|c|c|c|}
\hline 1. Calidad de la infraestructura en general & 1 & 2 & 3 & 4 & 5 & 6 & 7 \\
\hline \multicolumn{8}{|l|}{$\begin{array}{l}\text { La infraestructura general en su región es ( } 1=\text { poco desarrollada e } \\
\text { ineficiente, } 7=\text { =ntre las mejores del mundo) }\end{array}$} \\
\hline 2. Calidad de la infraestructura de las rutas & 1 & 2 & 3 & 4 & 5 & 6 & 7 \\
\hline \multicolumn{8}{|l|}{$\begin{array}{l}\text { De acuerdo con la calidad de las rutas en su región (excepto autopistas), la } \\
\text { velocidad típica de manejo entre ciudades es (1=10 Km/hr, 7=150 Km/h) }\end{array}$} \\
\hline 3. Desarrollo de la infraestructura férrea & 1 & 2 & 3 & 4 & 5 & 6 & 7 \\
\hline $\begin{array}{l}\text { El ferrocarril en su región es (1=poco desarrollado, 7=extenso y eficiente } \\
\text { como los mejores del mundo) }\end{array}$ & & & & & & & \\
\hline
\end{tabular}




\begin{tabular}{|c|c|c|c|c|c|c|c|}
\hline 4. Calidad de la infraestructura de los puertos & 1 & 2 & 3 & 4 & 5 & 6 & 7 \\
\hline $\begin{array}{l}\text { Los servicios portuarios y las vías navegables interiores en su región son } \\
\text { ( } 1=\text { poco desarrollados, } 7=\text { =xtensos y eficientes como los mejores del } \\
\text { mundo) }\end{array}$ & & & & & & & \\
\hline $\begin{array}{l}\text { 5. Calidad de la infraestructura del transporte aéreo } \\
\text { El transporte aéreo en su región es (1=infrecuente e ineficiente, } \\
7=\text { extenso y eficiente como los mejores del mundo) }\end{array}$ & 1 & 2 & 3 & 4 & 5 & 6 & 7 \\
\hline 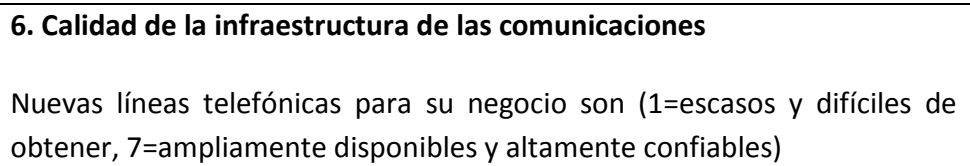 & 1 & 2 & 3 & 4 & 5 & 6 & 7 \\
\hline $\begin{array}{l}\text { 7. Velocidad y costo de acceso a Internet } \\
\text { El acceso a Internet en su región es (1=lento y caro, 2=tan rápido y barato } \\
\text { como en el resto del mundo) }\end{array}$ & 1 & 2 & 3 & 4 & 5 & 6 & 7 \\
\hline
\end{tabular}

\section{B.1.2. Infraestructura administrativa}

\begin{tabular}{|l|l|l|l|l|l|l|l|}
\hline $\begin{array}{l}\text { 1. Protección de la propiedad intelectual } \\
\text { La protección de la propiedad intelectual en su región es (1=débil o no } \\
\text { existe, 7=igual a la de los países más estrictos) }\end{array}$ & $\mathbf{1}$ & $\mathbf{2}$ & $\mathbf{3}$ & $\mathbf{4}$ & $\mathbf{5}$ & $\mathbf{6}$ & $\mathbf{7}$ \\
\hline $\begin{array}{l}\text { 2. Independencia Judicial } \\
\text { El Poder Judicial en su región es independiente y no está sujeto a } \\
\text { interferencias del gobierno y/o partidos políticos en los juicios (1=no } \\
\text { es verdad, 7=verdad) }\end{array}$ & & & & & \\
\hline
\end{tabular}

\section{B.1.3. Recursos Humanos}

\begin{tabular}{|c|c|c|c|c|c|c|c|}
\hline 1. Calidad de las escuelas públicas & 1 & 2 & 3 & 4 & 5 & 6 & 7 \\
\hline $\begin{array}{l}\text { Las escuelas públicas (gratuitas) en su } \\
7=\text { igual a las mejores del mundo) }\end{array}$ & & & & & & & \\
\hline 2. Calidad de las escuelas de negocios & 1 & 2 & 3 & 4 & 5 & 6 & 7 \\
\hline
\end{tabular}


Las escuelas de negocios en su región son (1=limitadas y de baja calidad, 7=entre las mejores del mundo)

\section{B.1.4. Infraestructura Tecnológica}

1. Disponibilidad de científicos e ingenieros

Los científicos e ingenieros en su región son (1=no existen o raros, 7=ampliamente disponibles)

\begin{tabular}{|l|l|l|l|l|l|l|}
\hline 1 & 2 & 3 & 4 & 5 & 6 & 7 \\
\hline & & & & & & \\
\hline
\end{tabular}




\begin{tabular}{|c|c|c|c|c|c|c|c|}
\hline 2. Calidad de los institutos de investigación científica & 1 & 2 & 3 & 4 & 5 & 6 & 7 \\
\hline $\begin{array}{l}\text { Las instituciones de investigación científica en su región, tales como } \\
\text { universidades o laboratorios del gobierno son ( } 1=\text { no existen, } 7=\text { los } \\
\text { mejores en su disciplina) }\end{array}$ & & & & & & & \\
\hline 3. Colaboración en la investigación Universidad / Empresas & 1 & 2 & 3 & 4 & 5 & 6 & 7 \\
\hline $\begin{array}{l}\text { En sus actividades de investigación y desarrollo, la colaboración de las } \\
\text { empresas con las universidades locales es (1=mínima o no existe, } \\
7=\text { intensiva y progresiva) }\end{array}$ & & & & & & & \\
\hline
\end{tabular}

\section{B.1.5. Mercado de Capitales}

\begin{tabular}{|c|c|c|c|c|c|c|c|}
\hline 1. Facilidad en el acceso a préstamos & 1 & 2 & 3 & 4 & 5 & 6 & 7 \\
\hline $\begin{array}{l}\text { ¿Cuán fácil es obtener un préstamo en tu región con solamente un } \\
\text { buen plan de negocios y sin garantías? ( } 1=\text { =imposible, } 7=\text { fácil) }\end{array}$ & & & & & & & \\
\hline 2. Sofisticación del mercado financiero & 1 & 2 & 3 & 4 & 5 & 6 & 7 \\
\hline $\begin{array}{l}\text { El nivel de sofisticación del mercado financiero en su región es } \\
\text { (1=menor que el promedio internacional, } 7=\text { mayor que el promedio } \\
\text { internacional) }\end{array}$ & & & & & & & \\
\hline 3. Acceso al mercado accionario interno & 1 & 2 & 3 & 4 & 5 & 6 & 7 \\
\hline $\begin{array}{l}\text { Obtener capital a través de la emisión de acciones en el mercado } \\
\text { accionario interno es ( } 1=\text { prácticamente imposible, } 7=\text { bastante posible } \\
\text { para una buena empresa) }\end{array}$ & & & & & & & \\
\hline 4. Disponibilidad de capitales de riesgo & 1 & 2 & 3 & 4 & 5 & 6 & 7 \\
\hline $\begin{array}{l}\text { Los emprendedores con proyectos innovadores pero riesgosos en su } \\
\text { región, generalmente pueden encontrar capital de riesgo disponible } \\
\text { para invertir ( } 1=\text { no es verdad, } 7=\text { es verdad) }\end{array}$ & & & & & & & \\
\hline
\end{tabular}

\section{B.2. Condiciones de la Demanda}

\begin{tabular}{|c|c|c|c|c|c|c|c|}
\hline 1. Sofisticación de los compradores & 1 & 2 & 3 & 4 & 5 & 6 & 7 \\
\hline $\begin{array}{l}\text { Los compradores en su región son ( } 1=\text { poco sofisticados y eligen en } \\
\text { función del precio más bajo, } 7=\text { inteligente, bien informado, } \\
\text { demandante y comprador de productos innovadores) }\end{array}$ & & & & & & & \\
\hline 2. Presencia de Normas regulatorias de la demanda & 1 & 2 & 3 & 4 & 5 & 6 & 7 \\
\hline $\begin{array}{l}\text { Las normas regulatorias -por ejemplo para productos, energía, } \\
\text { seguridad, medioambiente- en su región son (1=laxas o no existentes, } \\
7=\text { entre las más estrictas del mundo) }\end{array}$ & & & & & & & \\
\hline 3. Rigurosidad de las regulaciones medioambientales & 1 & 2 & 3 & 4 & 5 & 6 & 7 \\
\hline
\end{tabular}


La rigurosidad de las regulaciones medioambientales globales en su región es (1=laxa comparada con la mayoría de los otros países, $7=e n t r e$ las más estrictas del mundo)

4. Adquisición gubernamental de productos de tecnología de avanzada

Las decisiones gubernamentales de adquisición de productos de tecnología avanzada están basadas en (1=solamente precios, 7=tecnología y fomento de la innovación)

5. Leyes relacionadas al uso de las TIC's (tecnologías de la información y comunicación)

Las leyes relacionadas al comercio electrónico, firma digital y protección al consumidor son (1=no existen, 7=bien desarrolladas $y$ puestas en vigor)

\section{B.3. Industrias relacionadas y de apoyo}

\section{Calidad de los proveedores locales}

Los proveedores del país en su región son (1=ineficientes y tienen poca capacidad tecnológica, 7=internacionalmente competitivos $y$ brindan asistencia en el desarrollo de nuevos productos y procesos)

\section{Cantidad de proveedores locales}

Los proveedores del país en su región son (1=prácticamente inexistentes, $7=$ numerosos y proveen los materiales, componentes, equipos y servicios más importantes)

\section{Estado de desarrollo de agrupamientos}

¿Las agrupaciones empresarias son comunes en su región? (1=las agrupaciones son limitadas y superficiales, 7=las agrupaciones son comunes e intensas)

\section{Grado de colaboración en los productos y procesos}

El desarrollo de productos y procesos en su región es llevado a cabo ( $1=$ dentro de las empresas o con proveedores extranjeros, $7=e n$ colaboración con proveedores locales, organizaciones de investigación de mercado)

\section{Disponibilidad local de componentes y partes}

En su sector, los componentes y partes son (1=casi todos importados, $7=$ casi siempre producidos localmente)

\section{Disponibilidad local de servicios de tecnología de la información}

En su sector, los servicios especializados en tecnología de la información son (1=no disponibles en la región, 7=disponibles por parte de instituciones locales de clase mundial)
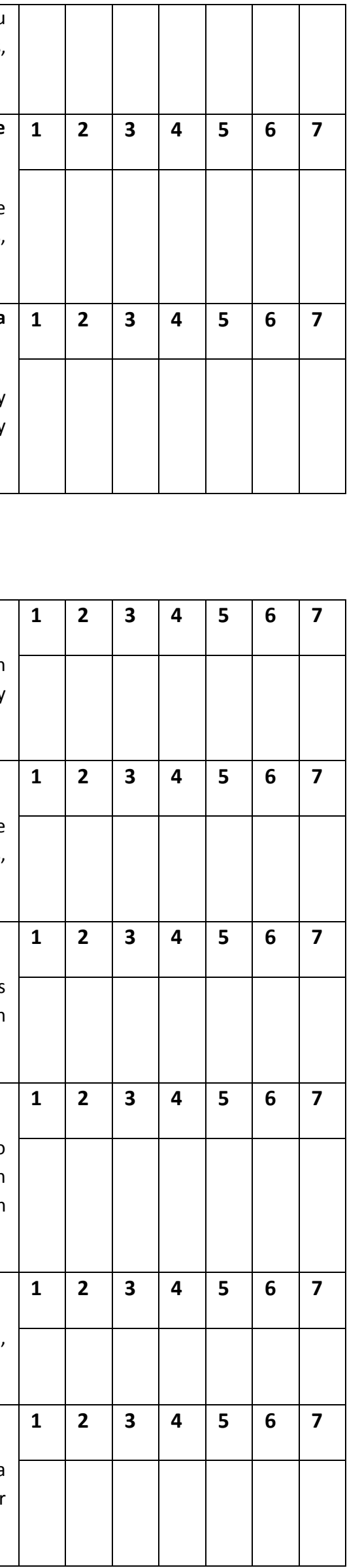


\begin{tabular}{|c|c|c|c|c|c|c|c|}
\hline 7. Disponibilidad local de los procesos de producción & 1 & 2 & 3 & 4 & 5 & 6 & 7 \\
\hline $\begin{array}{l}\text { En su sector, los procesos de producción son (1=casi siempre } \\
\text { importados, } 7=\text { casi siempre de origen del propio país) }\end{array}$ & & & & & & & \\
\hline $\begin{array}{l}\text { 8. Disponibilidad local de servicios especializados de búsqueda y } \\
\text { capacitación }\end{array}$ & 1 & 2 & 3 & 4 & 5 & 6 & 7 \\
\hline $\begin{array}{l}\text { En su sector, los servicios especializados de búsqueda y capacitación } \\
\text { son ( } 1=\text { no disponibles en su región, } 7=\text { disponibles por parte de } \\
\text { instituciones locales de clase mundial) }\end{array}$ & & & & & & & \\
\hline
\end{tabular}

\section{B.4. Contexto para la Estrategia y Competencia de las Empresas}

\section{B.4.1. Incentivos}

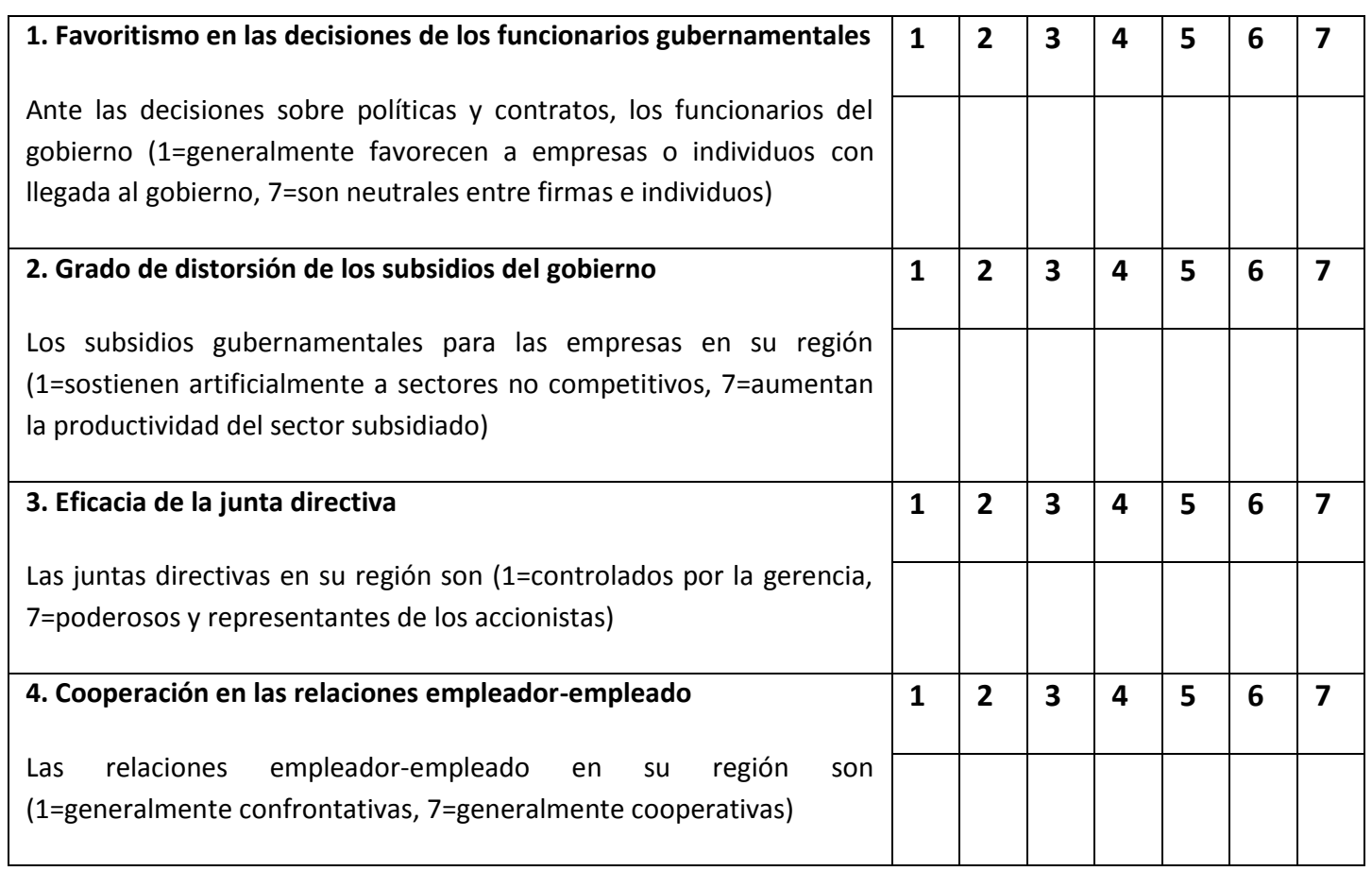

\section{B.4.2. Competencia}

\begin{tabular}{|c|c|c|c|c|c|c|c|}
\hline 1. Barreras de comercio encubiertas & 1 & 2 & 3 & 4 & 5 & 6 & 7 \\
\hline $\begin{array}{l}\text { En su región, las barreras de importación encubiertas (otras que no } \\
\text { sean aranceles y cupos) son ( } 1=\text { un problema importante, } 7=\text { no son un } \\
\text { problema importante) }\end{array}$ & & & & & & & \\
\hline 2. Intensidad de la competencia local & 1 & 2 & 3 & 4 & 5 & 6 & 7 \\
\hline $\begin{array}{l}\text { Mayormente la competencia en el mercado local es ( } 1=\text { limitada y la } \\
\text { competencia por precios es rara, } 7=\text { intensa y el liderazgo en el } \\
\text { mercado cambia cada tanto) }\end{array}$ & & & & & & & \\
\hline
\end{tabular}




\begin{tabular}{|l|l|l|l|l|l|l|l|}
\hline 3. Alcance de los competidores locales & $\mathbf{1}$ & $\mathbf{2}$ & $\mathbf{3}$ & $\mathbf{4}$ & $\mathbf{5}$ & $\mathbf{6}$ & $\mathbf{7}$ \\
\cline { 2 - 6 } $\begin{array}{l}\text { La competencia en el mercado local proviene primariamente de }(1=\text { las } \\
\text { importaciones, } 7=\text { empresas locales o subsidiarias locales de empresas } \\
\text { multinacionales) }\end{array}$ & & & & & & & \\
\end{tabular}




\begin{tabular}{|c|c|c|c|c|c|c|c|}
\hline 4. Efectividad de las políticas antimonopólicas & 1 & 2 & 3 & 4 & 5 & 6 & 7 \\
\hline $\begin{array}{l}\text { Las políticas antimonopólicas en su región ( } 1=\text { son laxas y no son } \\
\text { efectivas para promover la competencia, } 7=\text { promueven efectivamente } \\
\text { la competencia) }\end{array}$ & & & & & & & \\
\hline 5. Descentralización de la actividad empresarial & 1 & 2 & 3 & 4 & 5 & 6 & 7 \\
\hline $\begin{array}{l}\text { La actividad empresarial en su región es ( } 1=\text { dominada por unos pocos } \\
\text { grupos de negocios, } 7=\text { diseminada entre muchas empresas }\end{array}$ & & & & & & & \\
\hline
\end{tabular}

